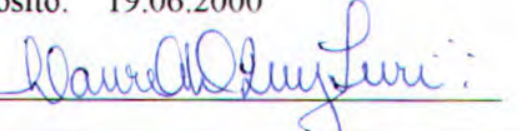

\title{
Projeto de um Sistema de Monitoramento de Ambientes de Intranet usando Data Werehousing
}

\author{
Claudio Haruyoshi Hirose
}

Orientador: Prof. Dr. Edson dos Santos Moreira

Dissertação apresentada ao Instituto de Ciências Matemáticas e de Computação - ICMC-USP, como parte dos requisitos para obtenção do título de Mestre em Ciências - Área: Ciências de Computação e Matemática Computacional.

USP - São Carlos

Junho de 2000 
Aos meus pais, pelo carinho e compreensão.

Aos meus imãos Regina, Lúcia e Roberto, pelo apoio constante. 


\section{AGRADECIMENTOS}

Ao Prof. Edson do Santos Moreira, meu orientador, pelo apoio e constante incentivo para que este trabalho pudesse ser realizado.

Ao "irmãozinho" Mauro pelo apoio, confiança e companheirismo.

Ao amigo Enzo pelo incentivo, pelas discussões oferecidas, além do companheirismo nas experiências do dia-a-dia.

Aos amigos Dani, Walter e Will pela confiança, pelo companheirismo e pelo apolo nos momentos dificeis.

Aos amigos Cláudia, Débora, Gedson, Igor, Renato e Zé pelo otimismo, incentivo e companheirismo.

Aos amigos de trabalho Anjinho, Jô, Edson, Salete, Mário e Val pelo apoio e a confiança depositada em mim.

A todos os amigos do Intermídia e do GBDI, pelo apoio e pelas discussões oferecidas.

Aos demais amigos do ICMC-SP, que de uma maneira ou outra, contribuiram com o estímulo para o prosseguimento deste trabalho.

Aos amigos da Prefeitura de Londrina, pelo apoio e atenção que me foi dedicado. 


\section{SUMÁRIO}

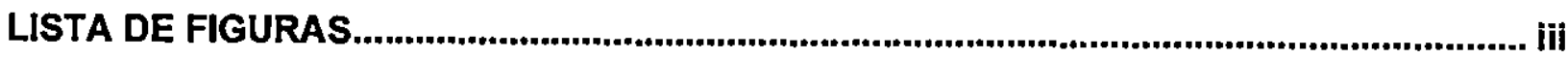

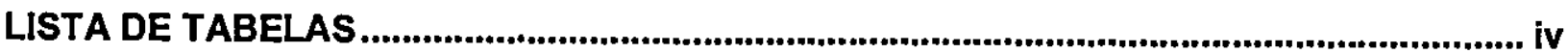

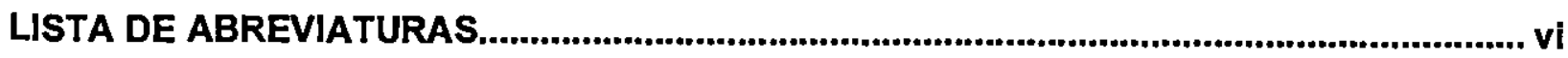

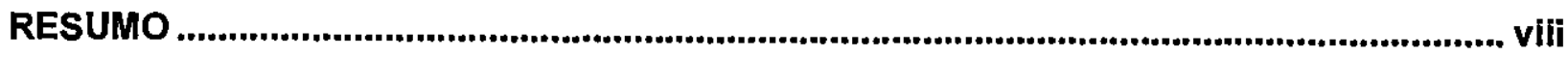

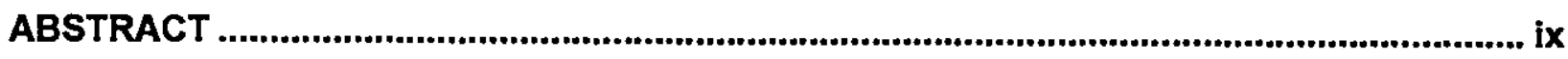

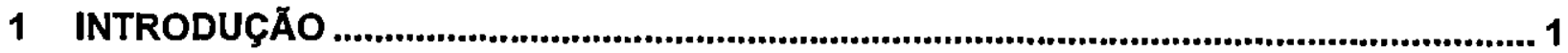

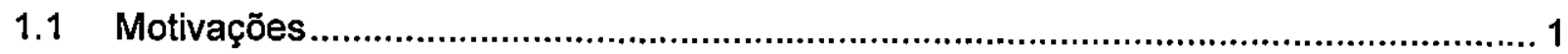

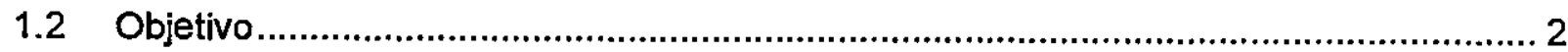

1.3 Organização do Trabalho ................................................................................. 3

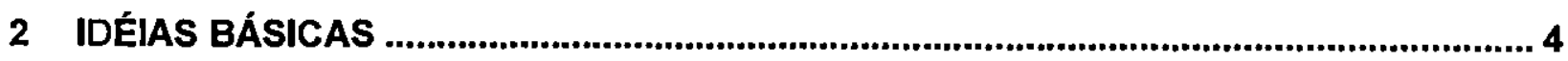

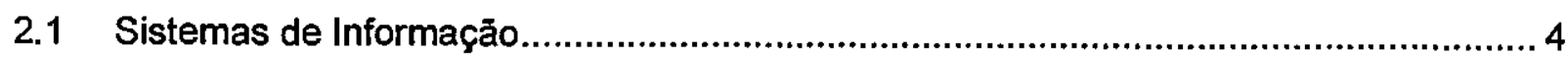

2.2 Breve Histórico sobre Internet .......................................................................... 5

2.2.1 A Internet no Brasil ................................................................................. 7

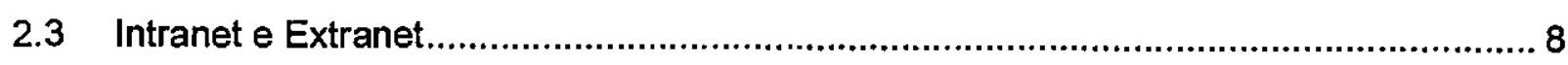

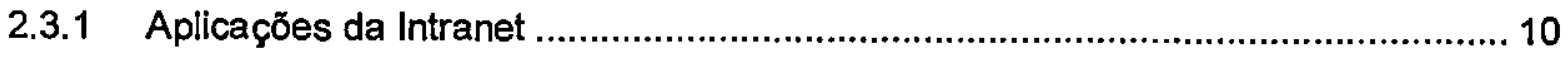

2.3.2 Como as Empresas estão usando as Intranets e Extranets ............................... 13

2.4 Breve Histórico de SGBD .................................................................................. 14

2.4.1 O Ambiente de Aplicações e de Dados.............................................................. 15

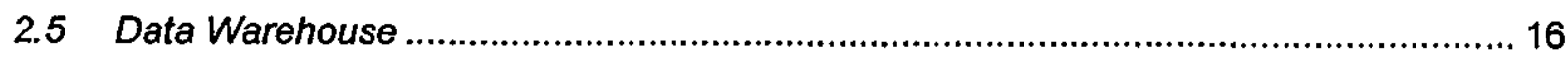

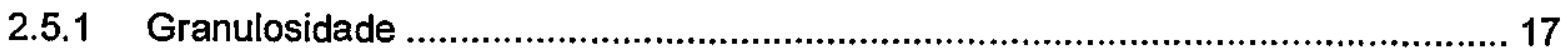

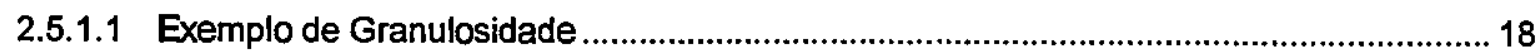

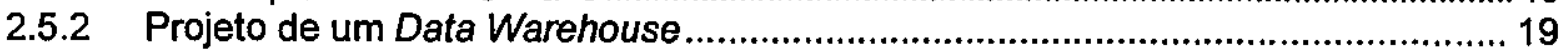

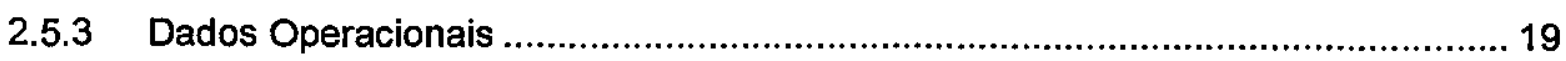

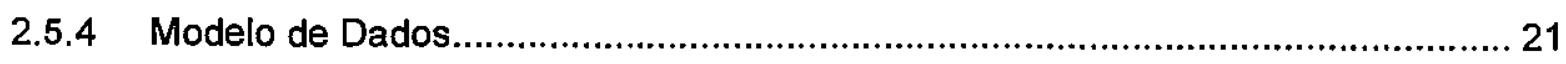

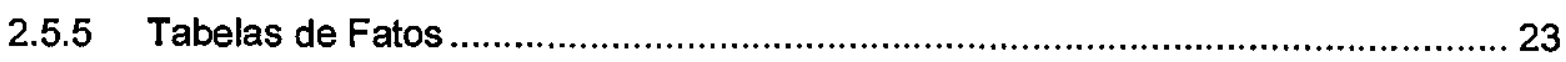

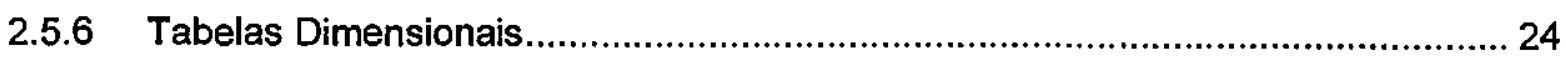

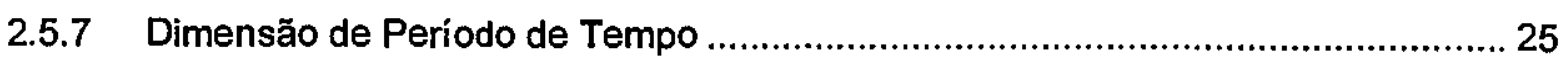

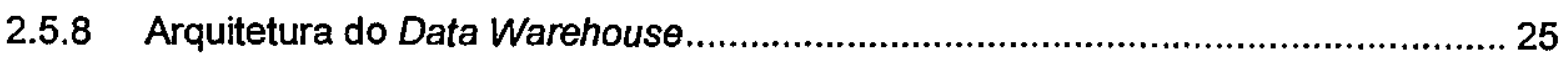

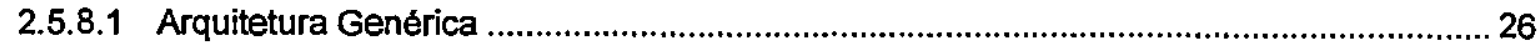

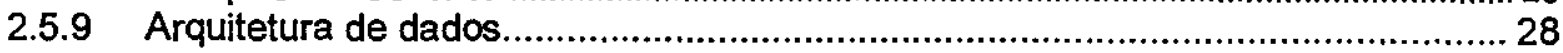

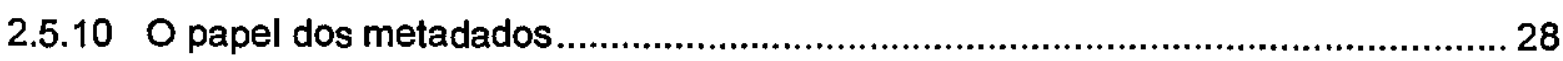


2.5.11 Ferramentas Utilizadas em Data Warehouse .................................................. 30

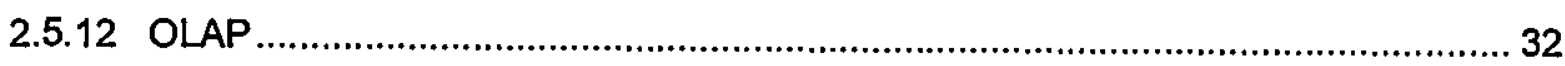

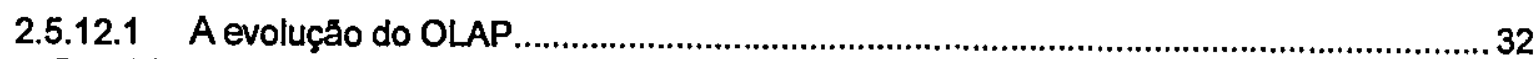

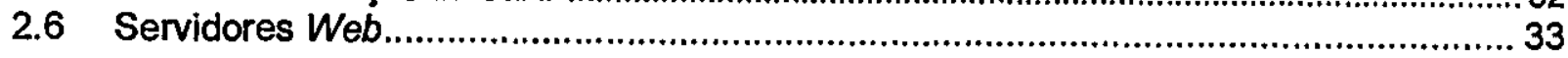

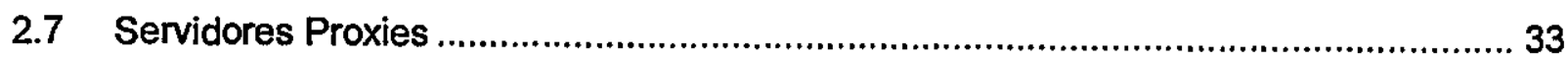

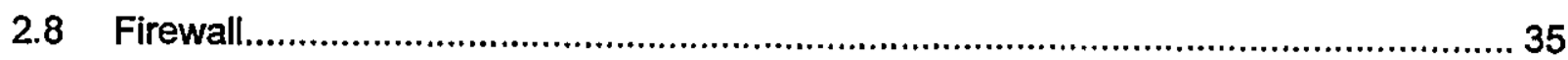

3 AMBIENTE DE MONITORAMENTO ........................................................................ 36

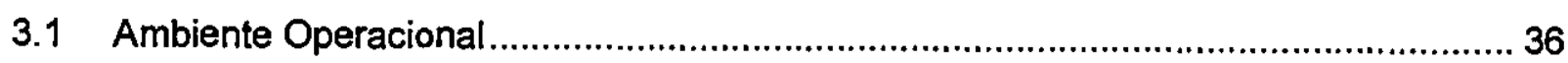

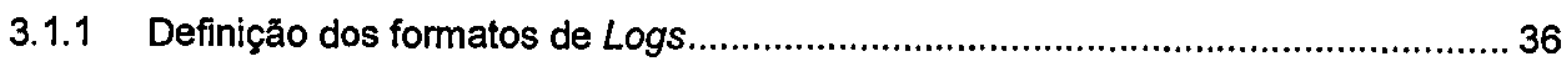

3.1.2 Caracteristicas das Entidades ................................................................ 41

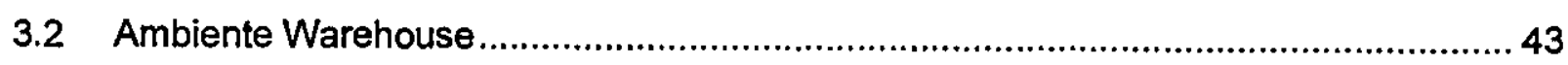

4 PROJETO DO DATA WAREHOUSE COM ORACLE 8.i................................................ 46

4.1 Criação do Projeto de Data Warehouse ............................................................ 47

4.1.1 Fase de Definiçăo .................................................................................... 48

4.1.2 Fase de Geraçăo ..................................................................................... 50

4.1.3 Fase de Gerenciamento ....................................................................... 50

4.2 Como alimentar o Data Warehouse .................................................................. 50

4.2.1 Método de alimentação direta do Log para um banco de dados ......................... 51

4.2.2 Método de alimentação indireta do Log para um banco de dados ....................... 51

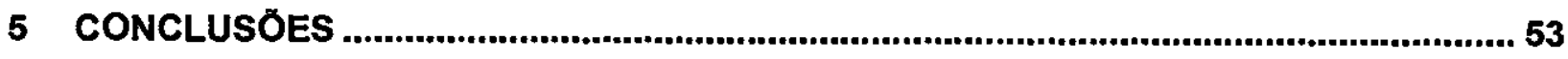

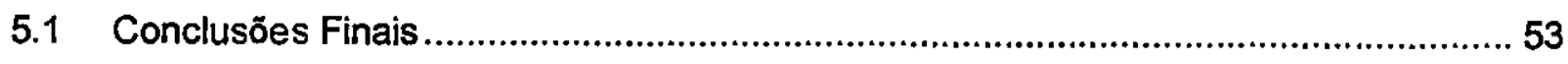

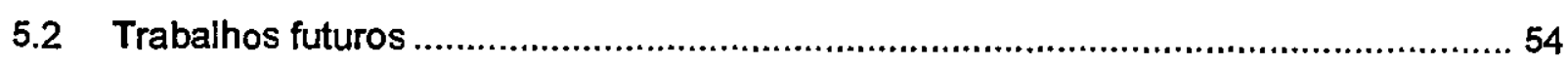

ANEXO I - DEFINIÇÃO DE LOGS PARA SERVIDORES WEB E PROXIES ........................ 55

ANEXO II - CÓDIGOS DE STATUS HTTP ..................................................................... 58

ANEXO III - ESQUEMA DE DATA WAREHOUSE PARA CONTROLE E AVALIAÇÃO ......... 59

REFERÊNCIAS BIBLIOGRÁFICAS............................................................................... 74 


\section{LISTA DE FIGURAS}

Figura 1 - Esquema de um Data Warehouse para um sistema de monitoramento de Intranet ... 2

Figura 2 - A Intemet e serviços................................................................................ 7

Figura 3 - Exemplo de uma rede Intranet com conexão à Internet ......................................... 9

Figura 4 - Exemplo de uma rede Extranet ...................................................................... 10

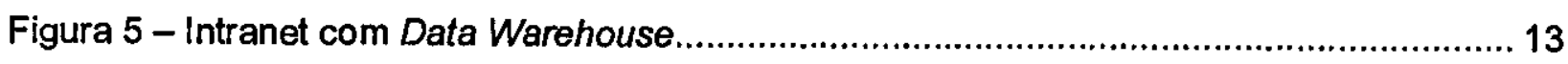

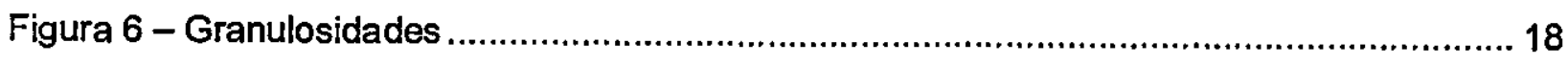

Figura 7 - Exemplo de um projeto lógico de um modelo de dados ER................................... 21

Figura 8 - Exemplo de uma Tabela de Fatos................................................................... 23

Figura 9 - Exemplo de uma Tabela Dimensional .............................................................. 25

Figura 10 - Arquitetura de Data Warehouse genérica proposta por Orr (Orr, 1996)................ 27

Figura 11 - Ferramentas utilizadas em Data Warehouse.................................................... 31

Figura 12 - Exemplo de uma requisição ao Servidor Web ................................................ 33

Figura 13 - Exemplo um servidor Proxy em uma rede Intranet............................................. 34

Figura 14 - Exemplo de uma rede privada com acesso à Internet com Firewall ...................... 35

Figura 15 - Ambiente Operacional........................................................................... 36

Figura 16 - Entidades envolvidas no acesso ao Servidor Web ......................................... 41

Figura 17 - Entidades envolvidas no acesso ao Servidor Proxy ....................................... 42

Figura 18 - Entidades envolvidas no acesso ao Firewall .................................................. 43

Figura 19 - Modelo Estrela do Sistema de Monitoramento ................................................. 44

Figura 21 - Esquema Warehouse do Sistema de Monitoramento projetado com OWB .......... 48

Figura 22 - Fluxo de transferência dos dados operacionais para o esquema Warehouse ....... 49

Figura 23 - Projeto físico do ambiente operacional (OLTP) para monitoramento.................... 71

Figura 24 - Projeto físico do ambiente Warehouse (granulosidade grossa) ........................... 72

Figura 25 - Projeto fisico do ambiente Warehouse (granulosidade fina).............................. 73 


\section{LISTA DE TABELAS}

Tabela 1 - Diferenças entre os dados primitivos e dados derivados 16

Tabela 2 - Principais Campos de Formato Estendido de Log utilizados para Servidores Web. 38 Tabela 3 - Principais Campos de Formato Estendido de Log utilizados para Servidores Proxies 39

Tabela 4 - Principais campos utilizados no Log de Firewall.............................................. 40

Tabela 5 - Descriçăo dos Códigos de Status de HTTP .................................................... 58

Tabela 6 - Tabela Operacional com os Acessos ao Servidor Web (Log) ............................... 59

Tabela 7 - Tabela Operacional com os Acessos ao Servidor Proxy (Log) ............................. 59

Tabela 8 - Tabela Operacional com os Acessos ao Firewall (Log) ........................................60 60

Tabela 9 - Tabela Operacional com as caracteristicas do Servidor Web..............................60 60

Tabela 10 - Tabela Operacional com as caracterlsticas do Servidor Proxy........................... 60

Tabela 11 - Tabela Operacional com as características do Visitarite que acessa o Servidor Web

Tabela 12 - Tabela Operacional com as descriçōes do Status do HTTP.............................. 61

Tabela 13 - Tabela Operacional com os possiveis Códigos Resultantes do Acesso do Proxy. 61

Tabela 14 - Tabela Operacional do com as descrições do Usuário da Intranet ....................... 61

Tabela 15 - Tabela Operacional com as descriçōes do Departamento.....................................62 62

Tabela 16 - Tabela Operacional com as características do Host Cliente................................62 62

Tabela 17 - Tabela Operacional com os Horários de Trabalho do Usuário ............................62 62

Tabela 18 - Tabela Operacional com as Permissōes de Uso dos Hosts Clientes.................... 62

Tabela 19 - Tabela Operacional com as características do Firewall.....................................63 63

Tabela 20 - Tabela Operacional com as características da Interface do Firewall ................... 63

Tabela 21 - Tabela Operacional com as possíveis tipos de açöes do Firewall ........................ 63

Tabela 22 - Tabela Operacional com as possíveis ações realizadas pelo Firewall...................63

Tabela 23 - Tabela Operacional com os protocolos suportados pelo Firewall .........................63

Tabela 24 - Tabela Operacional com os serviços suportados pelo Firewall............................ 64

Tabela 25 - Tabela Operacional com os horários de acesso permitido ao Firewall .................64 64

Tabela 26 - Tabela Operacional com as possiveis causas de ações do Firewall ..................... 64

Tabela 27 - Tabela Operacional com Grupos de Subredes com acesso ao Firewall ............... 64

Tabela 28 - Tabela Operacional com as Datas de Acessos ..............................................6 65

Tabeia 29 - Tabela de Fatos sobre os acessos realizados ao Servidor Web........................... 65

Tabela 30 - Tabela de Fatos sobre os acessos realizados ao Servidor Proxy........................66

Tabeia 31 - Tabela de Fatos sobre os acessos realizados ao Firewall................................. 66 
Tabela 32 - Tabela de Fatos sobre os acessos realizados ao Servidor Web.. 67

Tabela 33 - Tabela de Fatos sobre os acessos realizados ao Servidor Proxy .........................67

Tabela 34 - Tabela de Fatos sobre os acessos realizados ao Firewall...................................68

Tabela 35 - Tabela Dimensional com os horários de acesso ...............................................68

Tabela 36 - Tabela Dimensional com as caracteristicas dos Hosts .........................................6 68

Tabela 37 - Tabela Dimensional com as caracteristicas dos Firewall....................................... 69

Tabela 38 - Tabela Dimensional com os serviços suportados pelo Firewall ............................. 69

Tabela 39 - Tabela Dimensional com as caracteristicas do Servidor Web .............................. 69

Tabela 40 - Tabela Dimensional com as características dos arquivos armazenados no Servidor

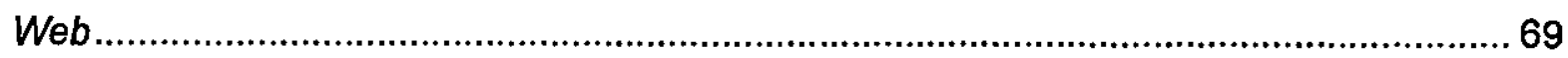

Tabela 41 - Tabela Dimensional com as caracteristicas dos Usuário.....................................70 


\section{LISTA DE ABREVIATURAS}

ANS Academic Network at São Paulo ARPA Advanced Research Projects Agency

BD Banco de Dados COBOL Common Business Oriented Language CSNET Computer Science Network

DASD. Direct Acess Storage Device DRI Defense Research Internet

EE. Enterprise Edition

E-mail Eletronic Mail

E-R Entidade-Relacionamento ESP. Eletronic Sales Partner

FAPESP Fundação de Amparo à Pesquisa do Estado de São Paulo

FTP File Transfer Protocol

HP. Hewilett-Packard

HTML Hipertext Make Language HTTP Hipertext Transfer Protocol

HTTPd Hipertext Transfer Protocol Daemon LNCC Laboratório Nacional de Computação Científica - RJ MIS Management Information System

NCSA National Center for Supercomputing Applications NSF. National Science Foundation

OAS Oracle Aplication Server OEM Oracle Enterprise Manager

OLAP OnLine Analytical Processing OLTP OnLine Transaction Processing OWB Oracle Warehouse Builder PLSQL Procedural Language/Structured Query Language POP Point of Presence RNP .Rede Nacional de Pesquisa

SAD Sistemas de Apoio à Decisão SGBD Sistema Gerenciador de Banco de Dados SMTP Simple Mail Transfer Protocol SNMP Simple Network Management Protocol 
SQL Structured Query Language

TCL Tool Command Language TCPIIP Transfer Common Protocol - Internet Protocol URI Uniform Resource Identifier

URL Uniform Resource Locator WWW World Wide Web 


\section{RESUMO}

Este trabalho foi projetado com o objetivo de auxiliar o Administrador de Web no monitoramento do acesso da rede, através da análise do histórico de acesso (Logs) dos servidores Web, Proxy e Firewall, das características dos hosts e servidores, e detalhes sobre os usuários que realizaram os acessos. Para suportar a gama de dados a serem armazenados e analisados é proposta a utilização da tecnologia de Data Warehouse para fornecer informações atualizadas e que possam servir como base em relatórios estatísticos e gráficos. Para a construção do Data Warehouse, foram escolhidos 0 banco de dados relacional Oracle 8 Enterprise e o pacote Business Intelligence Tools, desenvolvidos pela empresa Oracle Corporation. 


\section{ABSTRACT}

This work was designed with the objective of assisting the Web Administrator in the monitoring WWW site access, through the analysis of the description of those accesses (Logs) of the Web Servers, Proxy Servers and Firewall, of the features of hosts and servers, and details about the users who carried out the accesses. To support the gamma of data to be stored and analyzed is proposed the use of the technology of Data Warehousing to supply update information and that can serve as base in statistical and graphical reports. For the construction of the Data Warehouse, the relational data base Oracle 8 Enterprise and the Business Intelligence Tools package, developed by the Oracle Corporation, was been chosen. 


\section{INTRODUÇÃO}

Existe atualmente uma grande preocupação no que se refere ao uso da informática dentro das corporações, e há vários estudos no sentido de oferecer mecanismos que auxiliem os administradores a terem uma maior visão corporativa e que os auxiliem no processo de tomada de decisões, incluindo as áreas de segurança e desempenho de comunicação. Vários esforços têm sido realizados por pesquisadores que abrangem diversas áreas da Ciência da Computação, incluindo Sistemas de Informação, Redes de Computadores, Banco de Dados, Inteligência Artificial, entre outros. Dentre os avanços conseguidos podem-se citar a utilização de Data Warehousing, Data Mining, Ferramentas OLAP, mecanismos de catalogação e procura de dados como Search Engines (Tanler, 1996) (Harrison, 1998).

Com a implantação da tecnologia de Intranet na década de 90, muitas corporações conseguiram melhorar e agilizar o trabalho corporativo com a utilização da interface amigável do Web Browser. (Tanler, 1996) (Hills,1997) (Bremmer,1998). Os usuários puderam compartilhar arquivos e relatórios com facilidade e realizar pesquisas em bases de dados tanto corporativos como na Intermet. Conseqüentemente, pode-se notar um alto crescimento de utilização da rede a partir do acesso dos usuários aos servidores de correio eletrônico, servidores Web, FTP, via Proxy, Firewall, VPNs, roteadores. Se o crescimento de demanda de dados não for bem planejado e organizado, pode-se ter uma saturação dos servidores, além de acarretar atraso das respostas de requisições e perda de produtividade. Em conseqüência, variados tipos de usuários navegam na Intranet em busca de informação, nesta situaçăo usuários indevidos podem acessar informaçōes importantes caso a politica de segurança não seja bem planejada e implementada.

\subsection{Motivações}

Com o crescimento das informações dentro de uma Intranet, torna-se dificil para um Administrador de Web verificar o seu conteúdo e garantir o seu desempenho. Isto ocorre em parte porque o Administrador de Web despende a maior parte o seu tempo na criação e alteração de layout das páginas Web e geração de softwares aplicativos, e outra em conseqüência do variados tipos de dados que trafegam na Intranet.

Desta maneira, um sistema que possibilite o monitoramento do um ambiente de Intranet pode auxiliar o Administrador de Web a conhecer melhor: 
- Sobrecarga nos Servidores - determinar se um servidor Web ou Proxy está com sobrecarrega de requisiçōes, o que acarretaria em atraso de resposta.

- Gargalos de tráfegos na rede - determinar se algum departamento ou usuário realiza várias requisições para um servidor o que acarretaria em um congestionamento no tráfego da rede.

- Possiveis pontos vulneráveis de segurança - determinar se algum usuário tem acesso indevido a documentos particulares ou a sites.

- Acesso dos usuário - a partir dos históricos de acessos dos servidores de Web, Proxy e Firewall, pode-se conhecer a frequêricia e os modos de acessos dos usuários. $O$ que possibilitaria reconhecer possiveis intrusőes na rede.

- Permitir melhor expansão da rede - com valores referentes à demanda de carga dos servidores Web, Proxy, Firewall e hosts, pode-se avaliar melhor a compra de novos equipamentos ou expansão dos mesmos.

\subsection{Objetivo}

Este trabalho tem como objetivo o projeto de um Data Warehouse que auxiliará o Administrador de Web no monitoramento de um ambiente de Intranet.

O projeto contará também com um ambiente operacional composto pelos arquivos de Logs (acessos de usuários) e de dados descritivos dos Servidores Web, Proxy e Firewall que serão armazenados no Data Warehouse, conforme esquematizado na Figura 1. Posteriormente, estes dados servirăo de suporte a tomada de decisão para auxiliar o monitoramento de uma Intranet.

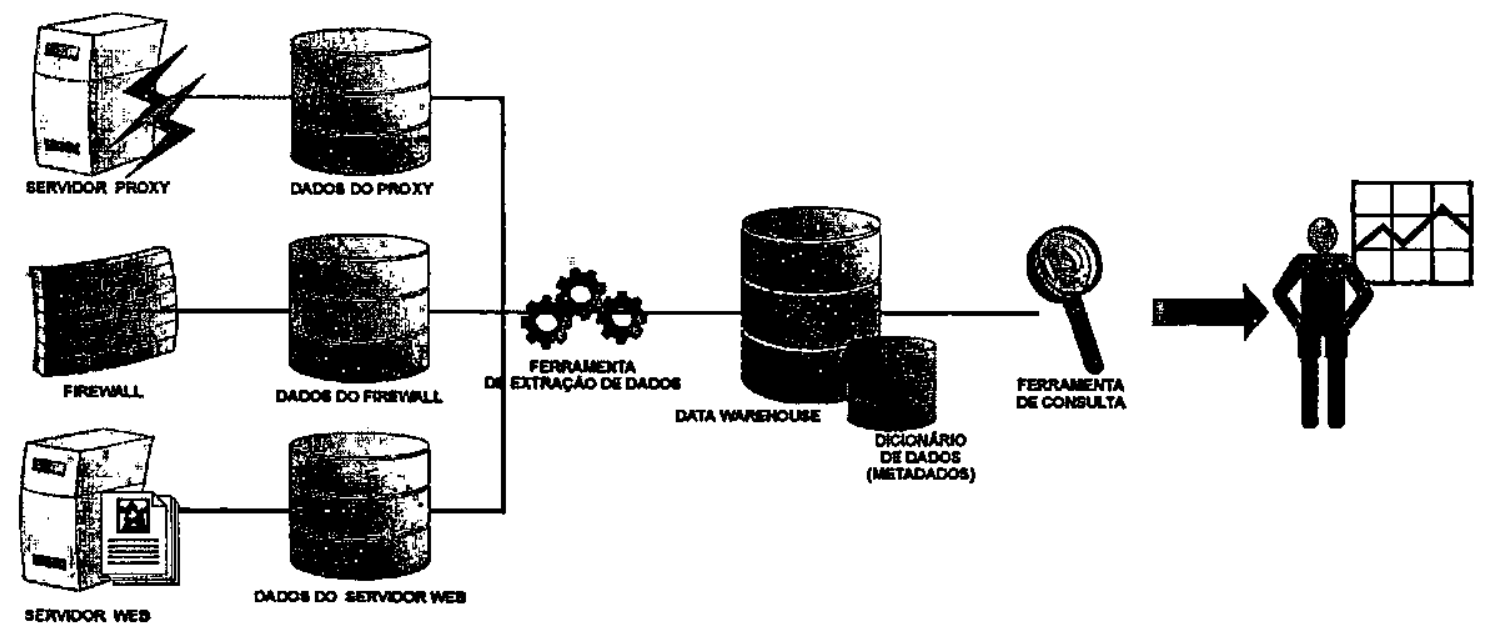

Figura 1 - Esquema de um Data Warehouse para um sistema de monitoramento de Intranet 
O monitoramento dos acessos de usuários dentro de uma rede corporativa é importante para compreender o crescimento e estrutura da Intranet, verificar falhas e niveis de segurança, localizar pontos de sobrecarga de tráfego de dados na rede, verificar se os servidores Web ou Proxy estão sendo bem acessados e utilizados, entre outros.

\subsection{Organização do Trabalho}

O capitulo 2 desta monografia é descrito descreve os principais conceitos para estudo e compreensão do trabalho: Sistemas de Informação; Internet, Intranet e Extranet; Data Warehouse, Servidores Web, Proxy e Firewall .

No capítulo 3 mostra como foi organizado o Ambiente de Monitoramento, no capítulo 4 é descrito como foi impiementado.o Data Warehouse e finalmente no capítulo 5 são apresentadas as conclusōes finais deste trabalho bem como as próximas pesquisas a serem realizadas. 


\section{IDÉIAS BÁSICAS}

\subsection{Sistemas de Informação}

Sistemas de Informaçăo é um termo muito utilizado tanto nas áreas de Administração, Relaçőes Públicas, Telecomunicaçőes ou mesmo Informática. Para todos, o significado básico é o mesmo: manter um fluxo de informaçőes entre várias entidades envolvidas, advindos de pesquisas, dados coletados ou armazenados. Na informática esse fluxo de informações é melhor compreendido sobre o aspecto de um sistema que integra várias partes de uma organizaçăo; e, esse sistema normalmente trabalha sobre uma rede de computadores.

Conforme Kugler e Fernandes (Kugler \& Fernandes, 1984), o surgimento dos Sistemas de Informação decorreu-se pelo fato que se precisava sanar vários problemas gerenciais de muitas organizações, pois estas criavam sistemas sem integração entre si, com a conseqüência de redundâncias de esforços de desenvolvimento e manutençăo, ocorrência de informaçōes contraditórias e dificuldade de compatibilizar arquivos e relatórios pertencentes a diferentes sistemas da organização. E, dos vários problemas como aquisiçăo e o mal de recursos computacionais decorrem normalmente da ausência de planejamento e controle.

Atualmente, tornou-se um consenso que a área de informática deve estabelecer planos de longo prazo, visando atender tanto necessidades atuais quanto futuras e melhorar o gerenciamento e utilização de recursos.

Os principais objetivos esperados ao se fazer um planejamento formal de atividades relacionadas com sistemas de informação por grandes organizações norte-americanas e européias, conforme uma pesquisa realizada por Soden (Soden, 1975) mostra os mesmos objetivos que atualmente muitas empresas tentam alcançar:

- Incrementar a comunicação e a colaboração entre a área de informática, seus usuários e a alta administração da empresa;

- Desenvolver e aperfeiçoar a previsão de futuras necessidades de informação, a alocação dos recursos computacionais e as decisőes de curto prazo efetuadas pela área de informática;

- Identificar oportunidades para aperfeiçoamento e redução de custos nas atividades de informática; 
- Identificar as aplicaçס̃es em computador que apresentam os melhores indices de retorno dos investimentos, diminuindo esforços secundários;

- Adquirir, dentro da área de informática, um maior entendimento e melhor visão da organização como um todo e de seus objetivos.

Em Bowman et al (Bowman et al, 1981), os principais problemas no planejamento de sistemas são:

- Assegurar que os esforços despendidos na área de informática sejam consistentes com as estratégias, politicas e objetivos da organização como um todo;

- Proporcionar uma estrutura de serviços na área de informática que responda adequadamente às necessidades urgentes, de curto prazo, quanto aos de longo prazo;

- Proporcionar alocação uniforme de recursos entre as diversas aplicaçð̃es, muitas vezes concorrentes entre si;

- Selecionar e usar metodologias adequadas para determinar requisitos e alocação de recursos.

Atualmente, com a implantação de uma rede Intranet e Banco de Dados Distribuidos, muitas empresas puderam reformular e melhorar a organização de trabalho e de colaboração entre os funcionários, além de minimizar os custos operacionais e de infra-estrutura como: atualização de computadores e diminuição de uso de papéis. Com o surgimento da tecnologia de Data Warehouse na década de 90 , as empresas puderam ter acesso rápido às informações, melhorando a competitividade no mercado; os usuários puderam ter maior entendimento e melhor visão da organização, facilitação de gerenciamento dos recursos (Tanler, 1997).

\subsection{Breve Histórico sobre Internet}

A Internet é um conjunto de várias redes de computadores interligadas no mundo inteiro que utilizam um mesmo conjunto de protocolos (padrões de comunicação) e serviços, tais como correio eletrônico, News, FTP, WMW, entre outros. Dentro da Internet, há a possibilidade de se enviar e receber mensagens, acessar gráficos, transmitir imagens e som, acessar bases de dados de variados temas, e realizar compras e operaçőes financeiras.

A Internet teve origem como uma rede experimental chamada ARPANET, conectada aos laboratórios de pesquisa ligados à agência governamental ARPA (Advanced Research Projects Agency), do Departamento de Defesa dos Estados Unidos, em 1969. Era o auge da 
guerra fria, e desejava-se obter uma rede de comunicações que continuasse a operar mesmo em caso de bombardeios a pontos estratégicos. Ao invés de se ter o controle centralizado em um único ponto, a nova rede possuiria vários nós com os mesmos privilégios e autoridade para receber e enviar mensagens organizadas em pacotes independentes. As mensagens poderiam percorrer uma rota arbitrária, a partir do nó original, até chegar ao seu destino. Dessa forma, um ataque nuclear a alguns nós da rede não comprometeria a segurança total. $O$ principal objetivo era permitir a partilha de recursos computacionais, tais como banco de dados, computadores de alto desempenho $\theta$ dispositivos gráficos, entre os pesquisadores e fornecedores contratados pelo departamento. Logo, ela passou também a ser usada como meio de cooperação entre os participantes do projeto, possibilitando o uso de correio eletrônico, dentre outros serviços, sendo utilizada em 4 localidades (Universidade da Califórnia em Los Angeles e Santa Barbara, Universidade de Utah e Instituto de Pesquisa de Stanford).

$\mathrm{Na}$ década de 70 , pesquisadores projetaram um conjunto de protocolos conhecidos como TCP/IP (Transfer Control Protocol//nternet Protocol), que se tornou o alicerce da Intemet. No inicio da década de 80, a ARPA iniciou a integração das redes de computadores de outros centros de pesquisa à ARPANET e implantou os protocolos TCP/IP para o Sistema Operacional Unix, possibilitando a integração de várias universidades à ARPANET. Em 1981, foram criadas a Bitnet (Because It's Time Network) e a CSNET (Computer Sclence Network), redes de intercâmbio cientifico, utilizando computadores de grande porte para a comunicaçăo entre vários paises.

Em 1985, a entidade norte-americana NSF (National Science Foundation) interligou os supercomputadores de seus centros de pesquisa, resultando na rede conhecida como NSFNET, e que em 1986 foi conectada à ARPANET. O conjunto de todos esses computadores e redes ligados a esses backbones (espinhas dorsais de uma rede) passou a ser denominado como Internet. Em 1988, a NSFNET passou a ser mantida com apoio das organizações IBM, $\mathrm{MCl}$ (empresa de telecomunicaçőes) e MERIT (instituição responsável pela rede de computadores de instituiçőes de ensino de Michigan), que formaram uma associação denominada ANS (Advanced Network and Services).

Em 1990 o backbone ARPANET foi desativado, surgindo em seu lugar o backbone DRI (Defense Research Internet); entre 1991 e 1992 a ANS desenvolveu um novo backbone, conhecido como ASNET, que passou a ser o backbone principal da Internet; nesse mesmo periodo iniciou-se o desenvolvimento de um backbone europeu (EBONE), interllgando alguns paises da Europa à Internet. Dessa forma, a Internet passou a ser definida como uma rede de redes baseadas no protocolo TCP/IP ou como uma comunidade de pessoas que usam e 
desenvolvem essas redes, ou ainda como uma coleção de recursos dos mais variados que podem ser compartilhados através dessas redes.

Durante cerca de duas décadas, a Internet ficou restrita ao meio acadêmico e científico. Em 1987, o uso da rede foi liberado para área comercial nos EUA. Porém, somente em 1992 com o surgimento da WMW (World Wide Web) que a rede tornou-se conhecida e se popularizou. A evolução dos serviços prestados na Internet foi um dos elementos determinantes da popularização da Internet. Inicialmente, o serviço principal era o correio eletrônico, baseado em recursos não gráficos, o que possibilitava troca de mensagens muito mais rapidamente do que o serviço de correio tradicional. $O$ surgimento de interfaces amigáveis, on-line, multimidia e a filosofia hipertexto da $\mathrm{W} W \mathrm{~W}$ possibilitaram às empresas disponibilizar várias informações na rede, tais como notícias, publicidades, vídeos, sons, o que provocou uma adesão em massa de milhóes de usuários, seduzidos pela interatividade da midia emergente (Ver Figura 2).

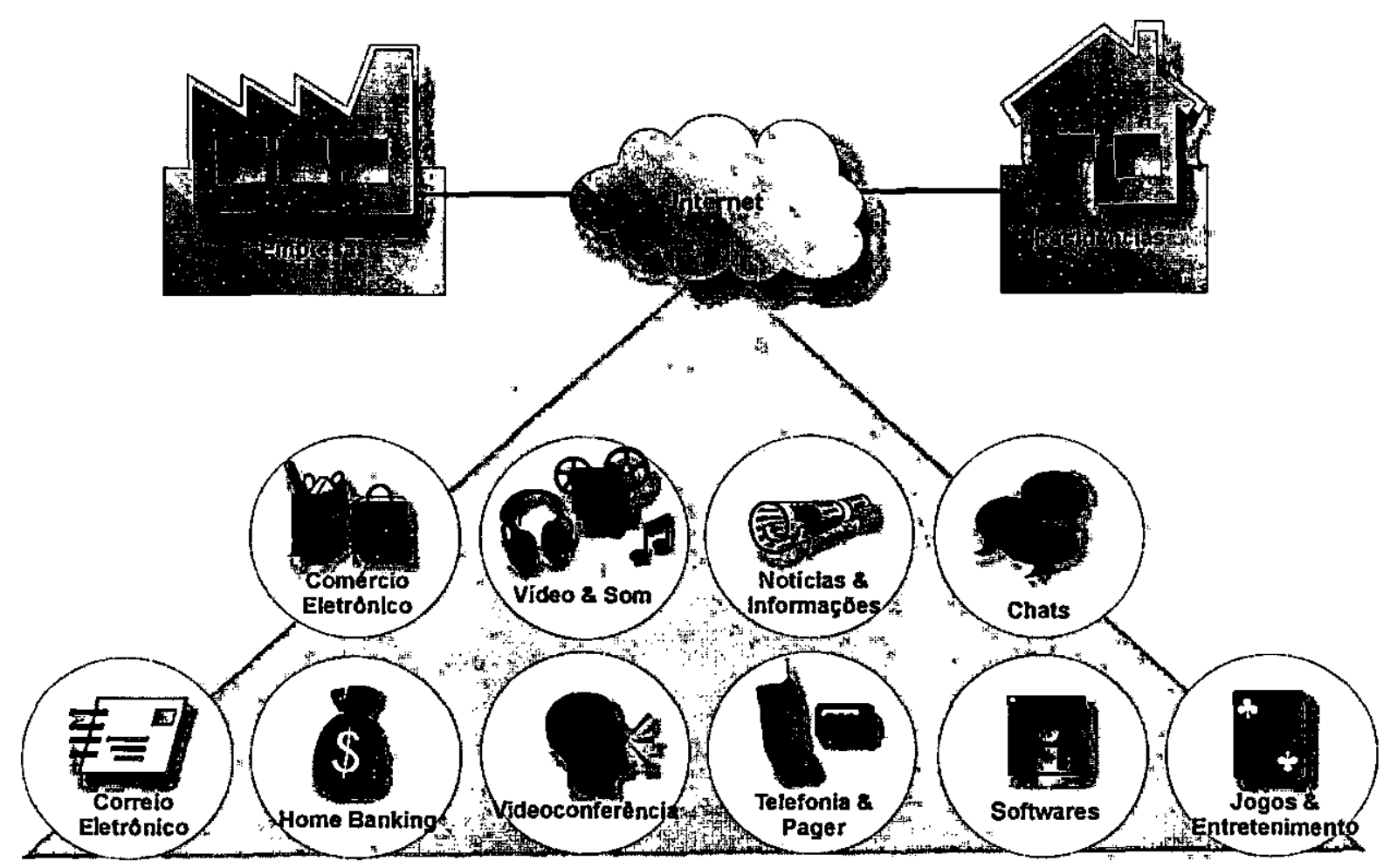

Figura 2 - A Internet e serviços

\subsubsection{A Internet no Brasil}

A Internet chegou ao Brasil em 1988 por iniciativa da comunidade acadêmica de São Paulo sendo que as primeiras conexões foram feitas através da FAPESP (Fundação de Amparo à Pesquisa do Estado de São Paulo) e do LNCC (Laboratório Nacional de 
Computação Científica, no Rio de Jareiro). Artes destes marcos oficiais, alguns centros de pesquisa já possulam acesso à rede. É o caso, por exemplo, do Instituto de Física de São Carlos, que se conectava via HEPriet, a antiga rede muridial de pesquisa em física de alta energia.

Em 1989 foi criada, pelo Ministério de Ciência e Tecnologia, a Rede Nacional de Pesquisas (RNP), uma irıstituição com os objetivos de iniciar e coordenar a disponibilização de serviços de acesso à Internet no Brasil; como ponto de partida foi criado um backbone conhecido como RNP (Rede Nacional de Pesquisa), interligando instituições educacionais à Internet. Esse backbone inicialmente interligava 11 estados a partir de Portos de Presença (POP - Point of Presence) em suas capitais; ligados a esses pontos foram criados alguris backbones regionais, a fim de integrar instituições de outras cidades à Internet; como exemplos desses backbones temos em São Paulo a ANS (Academic Network at São Paulo) e ro Rio de Janeiro, a Rede Rio.

A exploração comercial da Iriternet foi iniciada em dezembro de 1994 a partir de um projeto-piloto da Embratel, onde foram permitidos acessos à Iriternet através de linhas discadas, e posteriormente (abril de 1995) através de acessos dedicados via RENPAC ou linhas E1. Em paralelo a isso, a partir de abril de 1995 foi iniciado pela RNP um processo para a implantação comercial da Internet no Brasil, com uma série de etapas, entre as quais a ampliação do backbone RNP no que se refere à velocidade e número de POPs, a fim de suportar o tráfego comercial de futuras redes conectadas a esses POPs; esse backbone a partir de eritão passou a se chamar Internet/BR.

\subsection{Intranet e Extranet}

Intranet é uma rede corporativa baseada no protocolo TCP/IP que se caracteriza pelo uso da tecnologia $\mathrm{WWW}$ no ambiente privativo de uma empresa. Composta por um ou mais servidores $W e b$, a Intranet é disporível aos usuários através de uma rede irterna ou acesso discado privativo, fornecendo várias informaçöes a partir de um único front-end, o ravegador de Web (Web browser).

Além de fornecer todas as caracteristicas da Irternet, a Intranet de uma empresa pode utilizar ou não uma estrutura de comuricação de dados da própria rede pública para se comuricar com filiais ou variadas empresas coriectadas à Internet.

A Intranet não precisa estar necessariamente conectada à Intemet (Módulo, 1999), porém, é desejável que a rede Web corporativa possa trocar e receber irformaçőes de outros 
sites. Para uma rede privada corporativa possa ser denominada Intranet, ela precisa ser baseada no protocolo TCP/IP e possuir algumas características e serviços da tecnologia Web: correio eletrônico, grupos de discussão e de notícias (newsgroups), páginas Web , áudio, video e formulários com acesso a Banco de Dados, etc.

A Intranet teve origem quando muitas organizações descobriram as facilidades e as funcionalidades da Internet, e quiseram disponibilizar as usas informações, ou como negócios ou como serviços, para várias pessoas de fora de suas empresas. Assim, muitas empresas começaram a instalar servidores de Web em suas dependências. Com estes servidores, as empresas também puderam utilizar outros serviços da Internet para se comunicar com o Mundo, como o correio eletrônico, FTP, News, Gopher, entre outros.

Algumas organizaçőes notaram que muitas informaçōes de seus servidores, tais como manual e documentações de produtos, eram também acessadas pelos próprios usuários das empresas e que havia muita troca de correspondência eletrônica com dúvidas entre os funcionários. Rapidamente, começaram a surgir servidores especificamente dedicados a notícias internas da empresa (newsgroups). Algumas companhias chamaram esta rede interna de Web corporativa ou Web privada. Somente em 1995, algumas mídias de comunicação denominaram esta rede corporativa como sendo Intranet (Intra- dentro, net - rede).

Uma rede Intranet permite a disponibilização de diversas informações aos funcionários de uma empresa, em um ambiente já familiarizado na internet: o Web Browser. Dessa forma, não há necessidade de cursos e de treinamentos demorados, pois é mais intuitivo e de simples navegação e de entendimento.

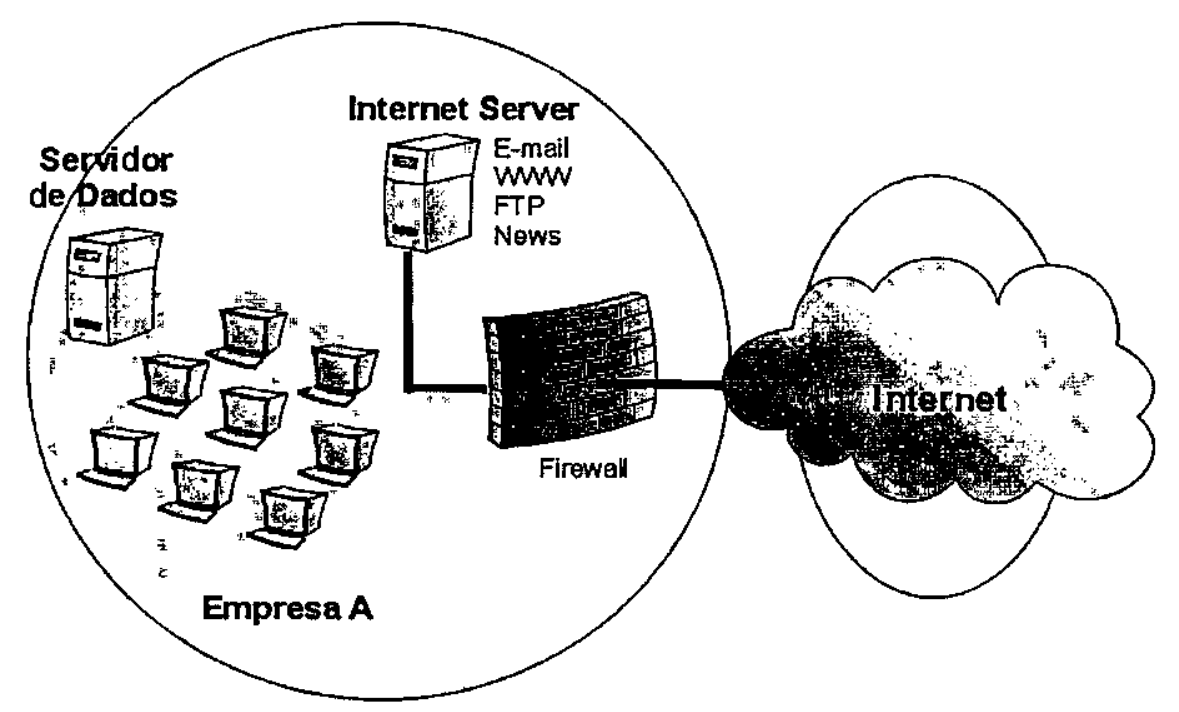

Figura 3 - Exemplo de uma rede intranet com conexăo à internet 
O conceito Extranet (Extra - fora, net - rede) surgiu da necessidade de nomear uma rede privada (Intranet) de uma empresa que se comunica e compartilha informações com Intranets de empresas parceiras ou usuários remotos a partir da Internet. Neste caso, há a necessidade da empresa utilizar uma política de acesso e mecanismos de segurança e privacidade para proteger os seus dados internos.

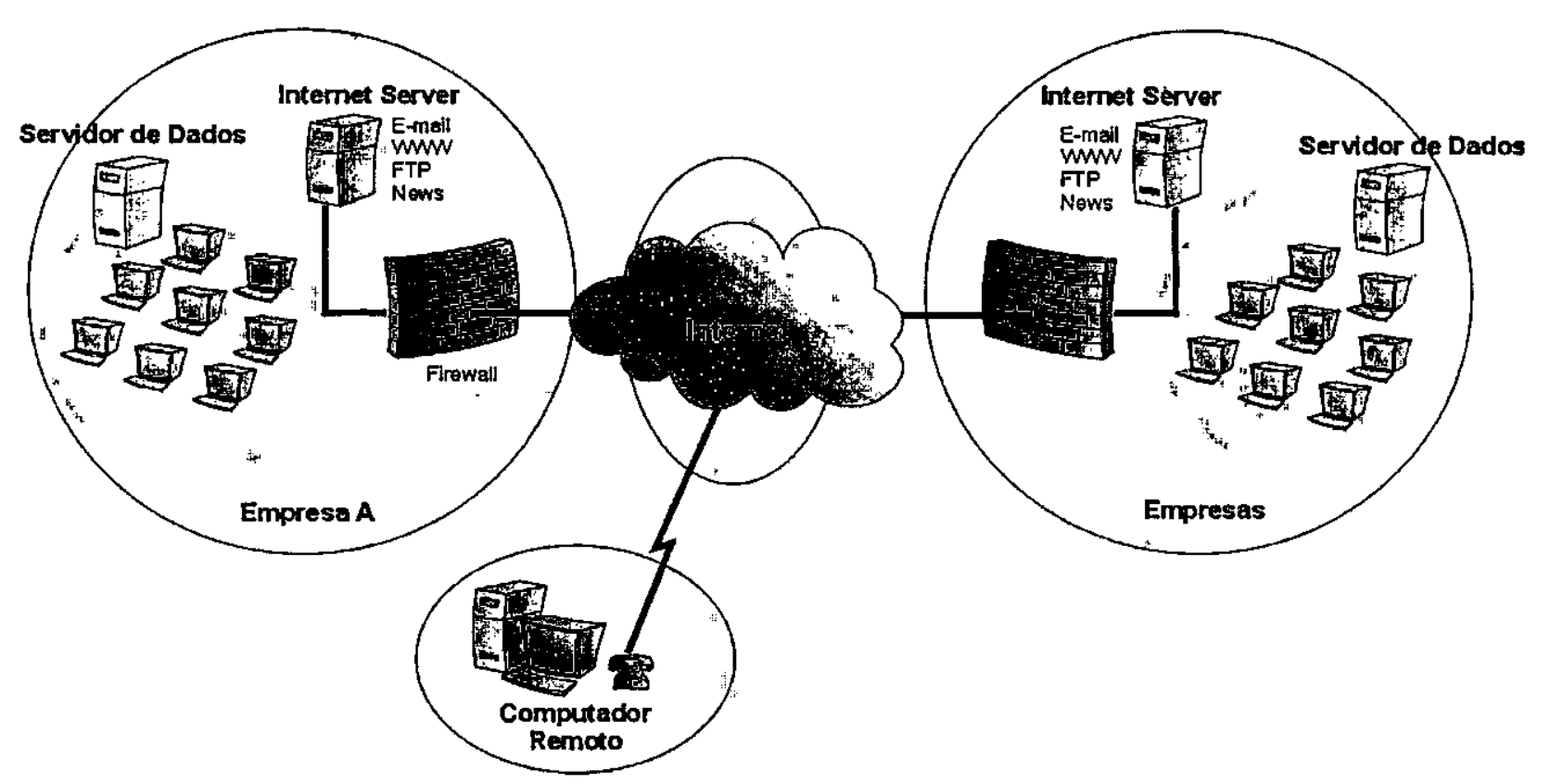

Figura 4 - Exemplo de uma rede Extranet

\subsubsection{Aplicações da Intranet}

A Intranet pode facilitar a publicação de informaçōes e aumentar a comunicação dentro de uma corporação. Ela pode até mesmo ter a funçăo de groupware, e com um custo muito mais barato.

Algumas de suas utilizações podem ser muito simples, requerendo nada mais do que a publicaçăo de simples páginas Web criadas em HTML. Outras são muito sofisticadas e requerem links para Banco de Dados, enquanto outras podem requerer uma programaçăo mais avançada. Alguns de seus usos são:

- Troca de mensagens (E-mail)

- Distribuiçăo de Memorandos

- Divulgaçăo de Manuais de produtos 
- Publicação de notícias

- Newsgroups

- Sistema de documentaçăo

- Divulgação de Relatórios de Vendas, Finanças e Contabilidade

- Informação e Controle de Vendedores

- Publicidade \& propaganda, video e apresentaçōes

- Treinamento

- Gerenciamento e Controle de rede

- Controle de Processos

Atualmente, com as corporações sob uma imensa pressão para melhorar o nível e a utilização dos recursos de informaçōes internas, a Intranet tornou-se uma plataforma de comunicação altamente efetiva, muito flexivel e extensivel. Uma Intranet simples para uma empresa pode ser configurada em pouco tempo e pode se comportar como um "concentrador de informaçőes" para empresa inteira, seus escritórios remotos, parceiros, fornecedores e clientes.

A Intranet, pela sua própria natureza, pode oferecer as seguintes caracteristicas de aplicação (Levitt, 1998):

A descrição do seu projeto é muito mais simples e rápido do que os projetos tradicionais;

- Escalável (pode começar com um projeto simples e consistente, podendo ser aumentado quando necessário, levando-se em conta alguns requisitos);

- Fácil navegação (home page interna provê links para as informações);

- É acessivel para muitas plataformas existentes (Unix, Windows, Machintosh, etc.);

- Pode integrar estratégias distribuídas (as informaçőes podem ser distribuidas em vários servidores);

- Pode armazenar várias fontes de informação ( Banco de dados, documentos, outras aplicaçöes de groupware);

- Extensivel a vários tipos de mídia (áudio, vídeo, aplicações interativas).

- Alguns dos beneficios destas características incluem: 
- Baixo custo de implantação, requerendo relativamente pouco investimento ou em dinheiro ou em infra-estrutura;

- Significativamente muito mais rápido e menos caro do que os tradicionais meios de divulgação de informaçőes (como o papel);

- Os usuários estão mais familiarizados com o conceito de links;

- Rede de arquitetura totalmente aberta, possibilitando incrementar o número de máquinas.

As maiores conseqüências da implantação da Intranet dentro de uma corporação não são somente a facilidade de comunicação e beneficios estruturais, como também as mudanças de comportamento que ela exercerá sobre o grupo operacional (funcionários, chefias e diretores). Dentre essas mudanças destacam-se (Hills, 1997a):

Compartilhamento de Conhecimento. A partir das divulgações de dados, colaboração de trabalho em grupo, trocas de mensagens, videoconferências, pode-se compartilhar as informações e conhecimentos de um grupo de pessoas para outras. Além disso, conhecimento pode representar o quanto se sabe sobre um concorrente e seus produtos dentro de um ambiente de mercado. Conhecimento também pode representar o quanto se sabe sobre um cliente e suas necessidades. Quanto mais de conhecimento se obtém sobre um determinado assunto, mais será a vantagem da empresa na competição. Assim, "O Conhecimento será a moeda do futuro" (Hills, 1997a).

Melhora da competitividade através de eficiência e produtividade. Com a integração das bases de dados e aplicações na Intranet, isso permitirá ao grupo operacional um nivel de informação que melhorará a tomada de decisões, produtividade e serviços aos clientes. Isto também pode estimular a criatividade e inovação, valores que melhoram a competitividade da corporação.

Quebra de barreiras e construção de uma cultura de compartilhamento e colaboração. A Intranet facilita a comunicação e colaboração entre os funcionários que começam a compartilhar informaçōes entre si, distribuindo as tomadas de decisōes, nivelando assim a hierarquia e a organização.

Além disso, com o planejamento de uma Intranet com uma Data Warehouses (Figura 5) pode-se acelerar a comunicação de informações e a colaboração dentro de uma empresa e melhorar o planejamento de estratégias de negócios (Tanler, 1997). Pode-se também minimizar redundância de esforços de desenvolvimento e manutenção, e facilitar a compatibilização de arquivos e relatórios pertencentes a diferentes bases de dados. Dessa 
maneira, o usuário final pode a partir de uma única interface (Web Browser) realizar consultas de diferentes Bases de Dados (Cobol, Oracle, Sybase, Informix, Paradox, páginas Web).

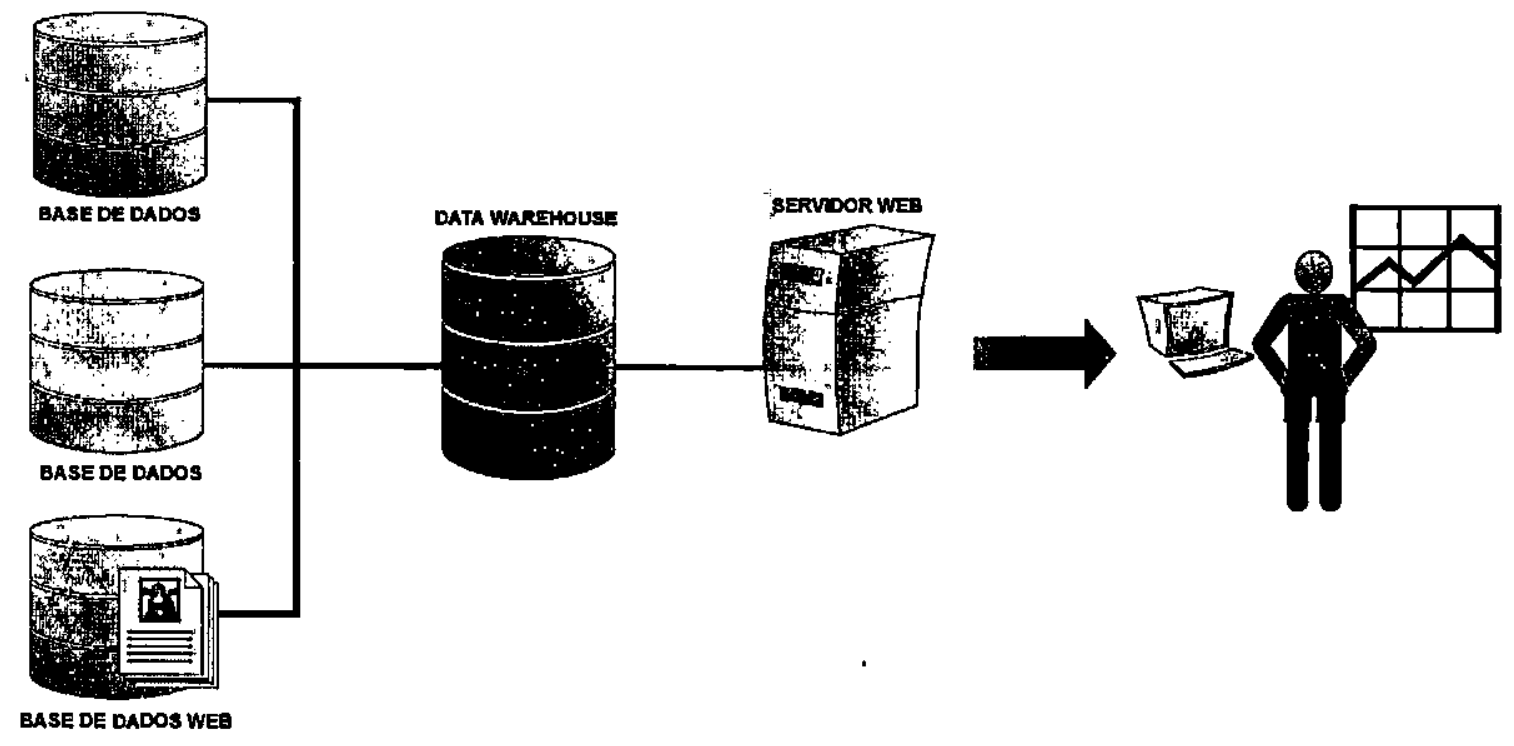

Figura 5 - Intranet com Data Warehouse

\subsubsection{Como as Empresas estão usando as Intranets e Extranets}

As empresas que implantaram suas redes de Intranet há mais tempo são as que melhores podem descrever os beneficios de se implantar uma rede Web Interna em suas corporações. A Hewllett-Packard, por exemplo, opera uma das maiores Intranets do mundo, a Eletronic Sales Partner (ESP), voltada para a comunicação com os seus distribuidores e revendedores. Nela estăo disponiveis mais de 13.000 documentos, o que totaliza 5.000 gigabytes de informação. Entre eles, há manuais técnicos, catálogos, listas de preços, anúncios e materiais promocionais consultados por 7.000 usuários. A sua rede engloba aproximadamente 400 sites em todo o mundo com 82.000 PCs, 23.000 desktops Unix, 6.000 servidores e 2.500 servidores de Web (Bremmer et al, 1998).

A área de relações com revendedores da companhia estima que, para cada manual ou catálogo publicado na ESP, há uma economia média de 10.000 dólares, valor que seria gasto se fosse imprimir o documento e remetê-lo para 2.000 pessoas em todo o mundo. A HP fez uma pesquisa com seus representantes de vendas e descobriu que cada um desses profissionais economiza, em média, cinco horas por semana graças à Intranet. Se a rede interna não existisse, esse tempo seria gasto folheando-se documentos técnicos e comerciais em busca de informações. Em uma Intranet, um arsenal de mecanismo de busca torna essa tarefa muito mais rápida. 
A SunSoft, subsidiária da Sun Microsystems, usa a sua Intranet para distribuir catálogos de preço para os seus representantes de vendas em todo o mundo (Extranet). O pessoal de vendas tem acesso imediato aos novos preços assim que são disponibilizados. A SunSoft também disponibilizou em sua Web Interna todo o catálogo de representantes, que inclui informações sobre mais de 12.000 produtos de 6.000 representantes do mundo inteiro. Além disso, os representantes também podem realizar atualizaçőes de informaçőes sobre alguns produtos em um catálogo on-line conforme surgirem necessidades. O Catálogo on-line implantado economizou tempo, dinheiro e possibilitou o acesso a informações atualizadas e mais precisas.

Na AT\&T, uma das maiores empresas do mundo com cerca de 127.000 funcionários, a Intranet possibilita o gerenciamento de seu Centro de Informações de Seguro e Saúde. Os funcionánios da AT\&T podem acessar a Intranet de suas residências ou do escritório para gerenciar os seus próprios benefícios, acessar informaçס̋es sobre o programa médico e preencher formulários localizados na Intranet. Os aplicativos de rede que a AT\&T construiu incluem serviço integrados de cobrança, interface com seus serviços de Biblioteca, notícias externas, um sistema de pedido de suprimento para escritório e interface para um banco de contatos dos funcionários que contém mais de 300.000 registros.

Em muitos casos, os benefícios de uma Intranet podem ser medidos pela redução de custos que ela proporciona. Em outros, os beneficios não são traduzidos facilmente em espécie, aumento de produtividade dos funcionários ou melhora do atendimento aos clientes. As Intranet permitiram às organizações desenvolver relações de maior proximidade com seus clientes, representantes e fornecedores. Por exemplo, a Federal Express desenvolveu um site Web (http://www.fedex.com) que permite aos clientes acessar à base de dados interno da Federal Express para rastrear remessas. Os usuários podem fazer consulta em um sistema de pesquisa poderoso para saber qual a posição da remessa. Os clientes podem também rastrear até 20 números de remessas por vez enviando um e-mail para a própria Federal Express.

\subsection{Breve Histórico de SGBD}

Desde a década de 70 a Computação, mais especificamente a área de Banco de Dados, tem sido beneficiada com o advento da tecnologia de armazenamento em disco ou DASD (Direct Acess Storage Device - Dispositivo de Armazenamento de Acesso Direto). Com - DASD, surgiu-se um novo tipo de software conhecido como SGBD (Sistema de Gerenciamento de Banco de Dados). Neste mesmo perlodo, surgiu o processamento de transações on-line que permitiu utilizar o computador para tarefas que não eram possiveis 
anteriormente, como controlar sistemas de reservas, sistemas de caixas bancários, sistemas de controle de produção e outros.

Até o início da década de 80 , novas tecnologias, como o surgimento do PC permitiram uma autonomia maior para o usuário no processamento das aplicaçōes de seu interesse, permitindo um controle direto dos sistemas e dos dados. E, com o surgimento de L4Gs, aliadas ao PC, surge a possibilidade de utilização dos dados para aplicaçőes e funções diferentes do processamento de transações on-line, para os quais eles foram inicialmente concebidos. Surgem-se os MIS (Management Information System ou Sistemas de Informações Gerenciais) que são atualmente conhecidos como SAD (Sistemas de apoio à decisão). O MIS consistiam em processamento utilizado para direcionar decisões gerenciais, o que fez surgir um novo paradigma: um único banco de dados poderia atender simultaneamente ao processamento de transaçőes on-line de alta performance e ao processamento analítico, ou de SAD.

Em 1985, surge um programa bem simples conhecido como "programa de extração". Ele vasculha um arquivo ou um banco de dados, utilizando-se alguns critérios de seleção, e, ao encontrar dados que atendam aos critérios, transporta os dados para outros arquivos ou banco de dados. Até o início da década de 90 , havia-se variados programas de extração, e de sua popularização surge a arquitetura de desenvolvimento espontâneo. Inicialmente havia extraçōes, posteriormente extraçōes de extraçōes, e subseqüentemente, extraçőes de extraçð̋es de extraçőes. Essa nova arquitetura surgiu quando se perdeu o controle do processamento de extraçőes. Porém, segundo Inmon (Inmon, 1997), o status quo da arquitetura de desenvolvimento espontâneo, no qual se encontra atualmente a maioria das organizações, não basta para atender às necessidades futuras. O que se faz necessário é uma mudança de arquitetura. É neste contexto que surge o ambiente projetado de Data Warehouse.

\subsubsection{O Ambiente de Aplicações e de Dados}

Segundo Inmon, no cerne de um ambiente em estudo para projetar um Banco de Dados (ambiente projetado), está a percepção de que há fundamentalmente duas espécies de dados: dados primitivos e dados derlvados. Na Tabela 1, tirado do mesmo autor, pode-se ver a ênfase na mudança de enfoque. 
Tabela 1 - Diferenças entre os dados primitivos e dados derivados

\begin{tabular}{|c|c|}
\hline Dados Primitivos/Dados Operacionaís & Dados Derivados/Dados SAD \\
\hline Baseados em aplicaçర్es & Baseados em assuntos ou negócios \\
\hline Detalhados & Resumidos ou refinados \\
\hline Exatos em relaçăo ao momento de acesso & $\begin{array}{l}\text { Representam valores já superados no momento } \\
\text { da busca instantânea }\end{array}$ \\
\hline Atendem à comunidade funcional & Atendem à comunidade gerencial \\
\hline Podem ser atualizados & Năo săo atualizados \\
\hline São processados repetitivamente & Processados de forma heurlstica \\
\hline $\begin{array}{l}\text { Requisitos de processamento conhecidos com } \\
\text { antecedência }\end{array}$ & $\begin{array}{l}\text { Requisitos de processamento nâo săo conhecidos } \\
\text { com antecedencia }\end{array}$ \\
\hline $\begin{array}{l}\text { Compativeis com o Ciclo de Vlda de } \\
\text { Desenvolvimento de Software }\end{array}$ & Ciclo de vida completamente diferente \\
\hline Performance fundamental & Performance atenuada \\
\hline Acessados uma unidade por vez & Acessados um conjunto cada vez \\
\hline Orientado para transaçōes & Orientado para anállse \\
\hline $\begin{array}{l}\text { O controle de atualizaçőes é atribuiçăo de quem } \\
\text { tem a posse }\end{array}$ & O controle de atualizaçőes năo é problema \\
\hline Alta disponibilldade & Disponibilidade atenuada \\
\hline Gerenciados em sua totalidade & Gerenciados por subconjuntos \\
\hline Não contemplam a redundância & A redundância năo pode ser ignorada \\
\hline Estrutura flxa: conteúdos variáveis & Estrutura flexivel \\
\hline $\begin{array}{l}\text { Pequena quantidade de dados usada em um } \\
\text { processo }\end{array}$ & $\begin{array}{l}\text { Grande quantidade de dados usada em um } \\
\text { processo }\end{array}$ \\
\hline Atendem às necessidades do cotidiano & Atendem às necessidades gerenciais \\
\hline Alta probabilidade de acesso & Baixa, ou modesta probabilidade de acesso \\
\hline
\end{tabular}

\subsection{Data Warehouse}

Atualmente, uma das importantes tecnologias que possibilitam acelerar tomadas de decisões eficazes é o Data Warehouse, que permite criação e o gerenciamento de um repositório completo e preciso de dados (Tanler, 1996).

O Data Warehouse, conforme William Inmon (Inmon, 1997), é um banco de dados "orientado a assunto, integrado, passivel de variação conforme o tempo, uma coleção não volátil de dados com suporte a processos de gerenciamento de tomada de decisões".

Os sistemas clássicos de Banco de Dados, que operam em nivel de transação - OLTP (Online transaction processing - processamento de transação on-line), são modelados e organizados em torno das aplicações da empresa. No caso do Data Warehouse, os dados operaclonais são considerados dados primitivos que precisam ser primeitamente tratados para depois gerar informações úteis para determinados assuntos de interesse para os negócio da 
empresa, tal como o nivel de influência de marketing para uma determinada classe consumidora de um produto $X$. Este tratamento dos dados pode se dar através de agregação, somatória, mediana, etc.

A integridade dos dados pode ser considerada a característica mais importante do Data Warehouse. A fase de verificação de integridade ocorre quando os dados passam do nível operacional para o Data Warehouse. O processo de inserçăo dos dados no Data Warehouse é conduzido sempre tendo em vista a preocupação de se eliminar muitas inconsistências das aplicaçరes no que se refere a codificação, convençర̃es de atribuição de nome, atributos físicos, unidades de medida, etc. Ao proceder a codificação para o Data Warehouse, deve-se assegurar de que ela seja feita de forma consistente e independente da aplicação de origem. Por exemplo, quando dados referentes ao sexo do cliente estiverem codificados como M/F em uma aplicação, e como masc/fem em outra, isso deverá ser tratado e uniformizado.

Dentro do Data Warehouse os dados armazenados săo năo-voláteis. No nivel operacional (dados primitivos), os dados são acessados com regularidade e tratados um registro de cada vez, e podem sofrer atualizações no decorrer de periodos. Porém, os dados existentes no Data Warehouse possuem características diferentes. São carregados e armazenados, normalmente em grande quantidades (em lote), e depois acessados; porém, a sua atualização năo é feita dentro do ambiente de Data Warehouse.

Uma outra característica do Data Warehouse é que seus dados săo variáveis em relaçăo ao tempo. Se uma empresa tivesse dados a respeito sobre um cliente e este tivesse mudado de endereço, em sua base operacional (OLTP) estariam representados os úitimos dados atualizados a seu respeito. Porém, em um ambiente de Data Warehouse, os dados antigos do endereço seriam mantidos e não haveria atualizaçăo dos mesmos, o que há é a inclusão de novos dados a respeito desse cliente, com o tempo associado às informações, mantendo-se assim um histórico das informaçסes a seu respeito dentro da empresa, o que será útil para se levantar algum interesse de negócio da empresa.

\subsubsection{Granulosidade}

Um outro importante aspecto do projeto de um Data Warehouse é a sua granulosidade. A granulosidade diz respeito ao nível de detalhamento ou de resumo contido nas unidades de dados existentes no Data Warehouse. Quanto mais detalhado, mais baixo será o nível de granulosidade. Quanto menor for o detalhamento das informaçöes, mais resumido e mais elevado será o nível de granulosidade. 
A razão pela qual a granulosidade é a principal questão de projeto consiste no fato de que ela afeta profundamente o volume de dados armazenados. Quanto maior o nível de granulosidade, menor será o volume dos dados armazenados devido a sumarização. Um conjunto de dados sumarizados é elevado a um outro nivel, liberando assim espaço relativo aos respectivos detalhes.

\subsubsection{Exemplo de Granulosidade}

A figura $X X X$ mostra um exemplo de questőes referentes à granulosidade. No lado esquerdo há uma base com baixo nivel de granulosidade . Cada atividade - neste caso, uma chamada telefónica - é registrada em detalhes. No fím de cada mês, cada cliente possui em média 200 registros (um para cada chamada telefónica registrada durante o mês) que demandam ao todo algo em torno de $\mathbf{4 0}$ mil bytes.

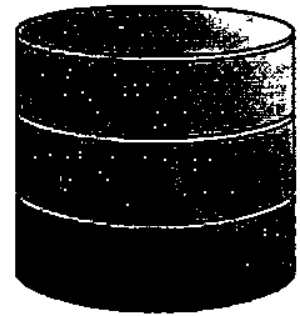

Alto nivel de detalhes Baixo nivel de granulosidade

Exemplo:

os detalhes de cada chamada telefónica feita por um cllente em um mês

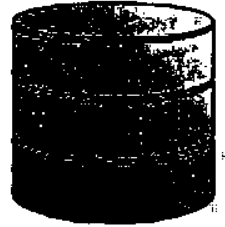

Bäixo nivel de detalhes Alto nivel de granulosidade

Exemplo: resumo das chamadas telefónicas feitas por um cliente em um mês

Figura 6 - Granulosidades

No lado direito da figura, um nivel mais alto de granulosidade pode ser visto. Os dados representam as informaçס̋es resumidas referentes a um cliente em um mês. Para cada mês, há um registro para cada cliente, e esse registro requer aproximadamente 200 bytes.

Pode-se notar que o espaço é um grande problema para a construção de um Data Warehouse e que o volume de dados é considerado a primeira e principal questão do Data Warehouse (Inmon, 1997). Um alto nivel de granulosidade consiste em uma maneira muito mals eficiente de representar os dados do que uma representação que utilize um nivei baixo de granulosidade.

Com um nivel mais alto de granulosidade, não somente são necessários muitos bytes a menos, como são necessários menos indices. Porém, o volume de dados e a questão do espaço bruto não săo as únicas questões relevantes. Frente a uma grande quantidade de 
dados, o nivel de processamento que precisa ser empregado para acessar os dados também é um fator importante.

A medida que o nivel de granulosidade aumenta, a possibilidade de utilização dos dados para atender as consultas diminui. Ou seja, com um nivel mito baixo de granulosidade, é possivel responder a qualquer tipo de consulta. Entretanto, com um alto nivel de granulosidade, o número de questões a que os dados podem satisfazer é limitado.

\subsubsection{Projeto de um Data Warehouse}

Existem dois importantes aspectos vinculados à construção de um Data Warehouse: o projeto da interface com os sistemas operacionais e o projeto do Data Warehouse propriamente dito. O projeto não é uma descrição exata do que acontece durante a construção do Data Warehouse, uma vez que ele é construido de modo heurístico (Inmon, 1997). Na primeira fase, o Warehouse é povoado com alguns dados. Tais dados são, então, usados e minuciosamente analisados pelo Administrador. Em seguida, com base na avaliação e críticas (ciclo de feedback) proporcionados pelo usuário final, os dados são então modificados e/ou outros dados são adicionados ao Data Warehouse.

Conforme Inmon, o ciclo de feedback tem continuidade por toda a vida do Data Warehouse. Engana-se pensar que os erifoques de projetos de sistemas clássicos que já funcionaram serão úteis para a construação do Data Warehouse. Os requisitos para a criação do Data Warehouse não podem ser conhecidos até que ele esteja parcialmente povoado e sendo usado pelo Administrador. Portanto, ele não pode ser projetado da mesma maneira pela qual são construído os sistemas tradicionais baseados em requisitos. Por outro lado, é um engano pensar também que não prever requisitos seja uma boa idéia. Encontrar um ponto intermediário é o melhor meio para se projetar o Data Warehouse.

\subsubsection{Dados Operacionais}

A maioria dos dados operacionais é armazenada em aplicaçōes já existentes dentro de uma empresa. Na época da criação das aplicações, a possibilidade de futura integração das mesmas não era relevante. Cada aplicação possuía seu conjunto único e particular de requisitos e, durante o processo de desenvolvimento, as demais aplicações não eram levadas em conta. Por isso, não é de admirar encontrar mesmos dados em vários lugares com nomes diferentes; ou que alguns dados apresentem o mesmo nome em todos os lugares mas com diferentes unidades de medidas, e assim por diante. Tentar extrair dados de diversos lugares em que eles existem é um problema muito complexo (Inmon, 1997). 
A questão de falta de integração é um dos pesadelos dos programadores responsáveis pelos programas de extração. Há vários detalhes a observar na programação apenas para extrair dados operacionais de forma correta.

Um exemplo simples de falta de integração é o fato de os dados não poderem ser codificados de forma coerente, como exemplificado na codificação de gênero. Em uma aplicação o gênero é codificado como " $\mathrm{m} / \mathrm{f}$ " e em outra é "masc/fem". Na realidade, näo importa como será feita a codificaçäo do gênero dentro do Data Warehouse, desde que seja feita de forma coerente.

Um outro exemplo de falta de integridade pode-se ser vista em um campo de distâncias geográficas. $O$ campo pode ser utilizado por várias aplicações com diferentes unidades de medida. Em uma aplicação, a distância pode ser medida em jardas e em outra em metros ou mesmo em quilómetros. No ambiente de Data Warehouse, não há uma preocupação especifica de qual unidade de medida será usada, desde que ela seja medida de forma coerente.

A transformação de campos é outra questăo importante de integração. O mesmo campo pode existir em cinco aplicações com cinco nomes diferentes7. Para que os dados sejam passados corretamente para o Data Warehouse, é necessário que ocorra um rastreamento comparativo entre os diferentes campos existentes e os campos do Data Warehouse.

Além disso, a falta de integração entre os sistemas existentes näo é a única dificuldade na passagem dos dados do ambiente operacional para o ambiente de Data Warehouse. Outro importante problema diz respeito ao acesso eficiente aos dados dos sistemas existentes. Como saber quais os dados já foram varridos dos sistemas operacionais, visto que realizar varreduras completas toda vez que há a necessidade de enviar dados ao ambiente de Data Warehouse é custoso e trabalhoso.

Há três tipos de cargas que podem ser feitos do ambiente operacional para o Data Warehouse (Inmon, 1997):

- Carregamento de dados histórico - os dados são carregados no Data Warehouse verificando-se o histónico do ambiente operacional.

- Carregamento de dados de valor corrente do ambiente operacional - os dados operacionais são descarregados em um arquivo seqüencial para posterior carregamento no ambiente Data Warehouse. 
- Carregamento de alterações do Data Warehouse, a partir de alterações (atualizações) que tenham ocorrido no ambiente operacional desde a última atualização do Data Warehouse.

\subsubsection{Modelo de Dados}

A técnica do modelo de dados para um projeto de Data Warehouse é útil para a criação de um completo arquivo histórico de dados. O modelo entidade-relacionamento produz um projeto otimizado para acessar os dados registro por registro (linha por linha), num nivel mais básico - o nivel de transações ou ocorrências. Em um modelo entidade-relacionamento, os registro são armazenados um após o outro em bytes contiguos no disco, para que a extração dos dados seja eficlente. As metodologias de projeto de Banco de Dados para esse tipo de acesso são otimizadas para que a criação, atualização e exclusão de registros sejam eficientes. A Figura 7 mostra um exemplo da estrutura de tabelas que é típico de um modelo entidade-relacionamento.

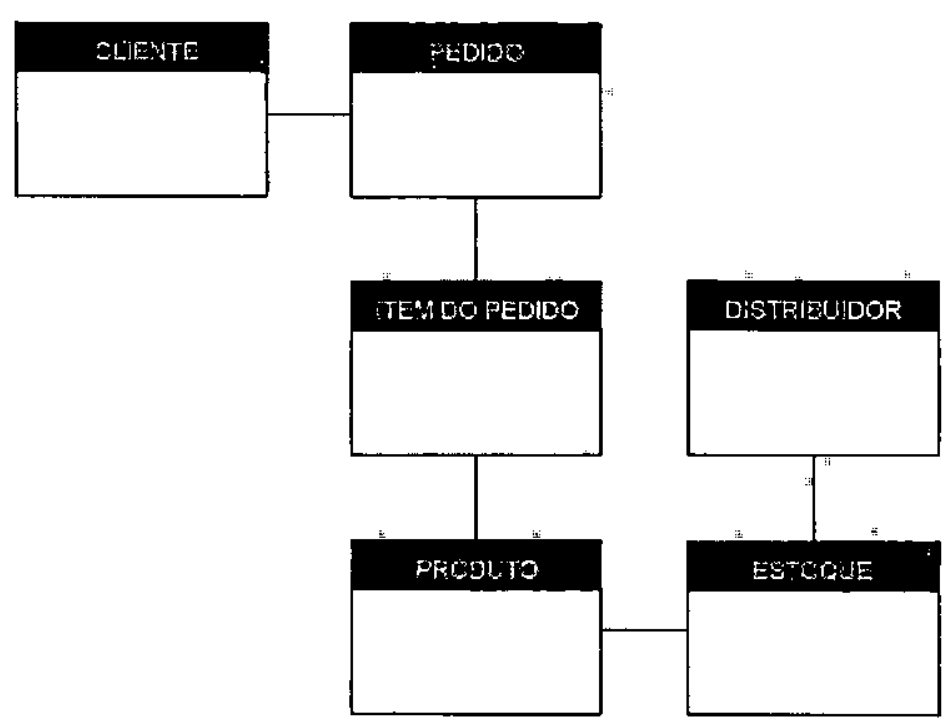

Figura 7 - Exemplo de um projeto lógico de um modelo de dados ER

Normalmente, as organizações criam um Data Warehouse sob o modelo entidaderelacionamento somente para arquivar dados. Neste caso, a principal meta é garantir que os dados mantenham a integridade. Ferramentas de consulta e de relatórios proporcionam aos usuários a habilidade de recuperar informaçōes de um arquivo de dados, mas seus recursos analíticos são limitados pelo projeto de Banco de Dados, assim como os recursos de relatório. Na maioria dos casos, o relatório se limlta a gerar uma lista de registros. 
Ao contrário do modelo entidade-relacionamento, a análise de dados requer acesso aos dados campo a campo (coluna por coluna). Por exemplo, a resposta a uma pergunta como "Qual é o total de vendas de camisas brancas em São Paulo no mês de maio?" requer a seleção de todos os registros que possuam "camisa" no campo "Tipo de Produto"; a seleção de todos os registros que possuam "branca" no campo "Cor"; a seleção de todos os registros que possuam "São Paulo" no campo "Cidade; e a seleção de todos os registros que possuam "maio" no campo "mês" - retornando o valor do campo "Volume de Vendas" de todos os registros que preencham os critérios.

Nesta situação, os dados são analisados por período de tempo, ao invés de transações ou níveis de ocorrência, para produzir comparações compreensiveis. No exemplo, o "total de vendas de camisas brancas em São Paulo no mês de maio" é melhor compreendido quando as vendas são comparadas em relação às vendas do mês ou ano anterior ou se as vendas de camisas forem classificadas por cor, gerando uma estruturação dimensional.

A estrutura dimensional (modelo dimensional) produz um projeto de Banco de Dados consistente com o modo como o usuário entra e navega no Data Warehouse. $O$ modelo dimensional é referido na maioria das vezes como "protocolo em estrela" (star scheme) devido à aparência do projeto lógico de Banco de Dados.

O modelo dimensional combina tabelas de armazenamento de dados históricos em séries temporais (normalmente numéricas), indexados em chaves dimensionais, e descritas em tabelas dimensionais correspondentes.

As tabelas dimensionais contêm informações sobre as dimensões dos dados, como período de tempo, produtos, mercados, organizações, contas, fornecedores e clientes. Essas informações incluem descrições e atributos de dimensão, como grupos de produtos em marcas e categorias, em cidades e estados, em distritos e regiōes, e assim por diante.

As tabelas de fatos ("fact tables") incluem dados temporais nos niveis indicados na estrutura das tabelas dimensionais. Assim, se a tabela de dimensão contém uma estrutura que reflete a cidade, estado, região e o total de uma dimensão, então a tabela de fatos contém também informações sobre cidade, estado, região e os totais. O nível mais baixo dos dados é resumido em períodos de tempo, ao invés de ser organizado de acordo com a transação ou ocorrência como no OLTP.

Uma consulta nesse modelo multidimensional pesquisa inicialmente as tabelas dimensionais, traduzindo regras de filtragem em chaves, acessando então as tabelas de fatos maiores. Isso garante a precisão do acesso a dados através de uma estrutura de chave completa, eliminando pesquisas em tabelas e resulta em maior desempenho possível na 
tecnologia relacional. O conceito de armazenamento de dimensöes separadamente assegura que o Banco de Dados mantenha matrizes esparsas com eficácia (sem armazenar lacunas) e garante o acesso mais eficiente possivel (Harrison, 1998)

\subsubsection{Tabelas de Fatos}

O histórico das medidas de negócios de uma organização, ou fatos, é mantido em linha - registro (em vez de coluna - por campo) em uma ou mais fact tables históricas. Cada fact table possui uma chave primária indexada composta de várias colunas, cada qual correspondente logicamente a uma dimensão relevante de negócios como periodo de tempo, produto ou mercado. A dimensão de periodo de tempo é sempre representada como parte da chave primária.

A Figura 8 ilustra uma tabela de fatos que contém vendas, unidades e histórico de estoque. Um única linha com detalhes é recuperada utilizando-se apenas uma chave primária composta de chave de período de tempo, chave de produto e chave de mercado.

\begin{tabular}{l} 
CHFVES PRIMARAAS \\
(COMBINADAS COM IABELAS DIMENSIONAS) \\
\hline
\end{tabular}

Figura 8 - Exemplo de uma Tabela de Fatos

Cada chave de dimensão deve ser representada e descrita em uma tabela dimensional correspondente, que se combina logicamente às fact tables através de colunas de chaves primárias idênticas.

Um erro muito comum na criaçăo de Data Warehouse a partir de informações normalizadas na fact table é que a chave significativa usada para definir uma entidade dentro do sistemas de transaçōes (OLTP) é também usada como chave primária nas tabelas de dimensões do sistema de informações, restringindo assim a flexibilidade, diminuindo o desempenho e aumentando a necessidade de manutençăo. Ao contrário, se as chaves 
primárias forem geradas pelo sistema sem relação significativa com os dados que descrevem, proporcionará uma melhor flexibilidade e maior desempenho do Data Warehouse.

As diferenças entre as chaves significativas e chaves não-significativas existem em vários níveis. Através da normalizaçăo de dados transacionais, as chaves significativas são representadas freqüentemente por mais de uma coluna (dependendo do nivel de sumarização que representam). Ao contrário, as chaves geradas são sempre mantidas em uma única coluna de dimensão. Usar chaves geradas ao invés de chaves significativas oferece três vantagens:

- Flexibilidade - uma definição única de metadados pode ser usada novamente para qualquer nível se sumarização (granulosidade) que compartilhem a chave gerada.

- Estrutura consistente - à medida que o Data Warehouse amadurece (novos niveis de sumarização são acrescentados ou removidos), a estrutura física das tabelas que compartilham a chave gerada não mudam, somente o conteúdo das chaves e o número de linhas se modificam.

- Tamanho - redução significativa do tamanho da chave primária indexada (por ter menos colunas no índice), possibilitando que uma maior parte da tabela de índices seja mantida na memória, aumentando assim o desempenho.

\subsubsection{Tabelas Dimensionais}

As tabelas dimensionais contêm informaçōes sobre as dimensões dos dados (períodos de tempo, produtos, compradores, organização, etc.). As tabelas dimensionais são normalmente projetadas de uma perspectiva centrada no usuário. Em outras palavras, as colunas de descriçăo e de atributos devem conter descrições de textos que sejam significativos aos usuários finais e apropriados para exibiçāo em um relatório. Não é boa idéia comprometer o projeto de tabela dimensional para economizar espaço em disco (Tanler, 1998).

Cada tabela dimensional deve incorporar múltiplos campos de atributos contendo textos e códigos que descrevam melhor a chave. Os campos de atributos são usados para delimitar ou filtrar o conteúdo da dimensão. As tabelas dimensionais devem ser utilizadas para suportar variados tipos de inquiriçסరes como "E se...?" necessários para o suporte a decisões. Além disso, usar tipos inteiros como atributos quando for apropriado (tamanho, idade, salários, etc.) facilita o uso de regras de filtragens matemáticas como "maior que", "menor que" e "entre". 
CHAVE PRIMARIA

(Unitro kgico corn as

Tabelas de Fotos]

\begin{tabular}{|l|l|c|c|c|}
\hline & DESCRICAO DO MERCAD & REGLAO & ESTADO & PAIS \\
\hline 207 & FOZ DO IGUAÇ: & S & PR & BRASIL \\
305 & AMERICANA & SE & SP & BRASIL \\
310 & SÄO CARLOS & SE & SP & BRASIL \\
311 & SÄO JOSE DO RIO PRETO & SE & SP & BRASIL \\
401 & CAMPO GRANDE & CO & MS & BRASIL \\
604 & RONDONOPOLIS & CO & MT & BRASIL \\
\hline
\end{tabular}

ATRIBUTOS

Figura 9 - Exemplo de uma Tabela Dimensional

\subsubsection{Dimensão de Período de Tempo}

Uma tabela dimensional de períodos de tempo é necessária para identificar com precisão a data dos dados disponiveis na tabela de fatos (fact tables). Um periodo de tempo pode parecer desnecessário em um Data Warehouse uma vez que a coluna chave "período de tempo" das tabelas de fatos usam um formato tipo "DATA" que identifica todas as datas válidas, mas se esse formato não é substituto suficiente para a tabela de periodo de tempo. Caso não haja uma tabela dimensional descrevendo o tempo (identificando chaves de datas válidas antes de acessar a tabela de fatos), os acessos à tabela de fatos não serăo precisos, acarretando perda de tempo. Além disso, muitos algoritmos de filtragem de dados não podem ser aplicados sem a tabela dimensional de período de tempo.

A tabela de periodos de tempo deve conter uma coluna ou mais colunas chaves que se conectam logicamente com colunas idênticas existentes nas tabelas de fatos. Como em qualquer tabela dimensional, a tabela dimensional em periodo de tempo deve conter uma descrição única para cada período de tempo assim como colunas de atributos que proporcionem controles de filtro na tabela.

\subsubsection{Arquitetura do Data Warehouse}

Nos últimos anos o conceito de Data Warehouse evoluiu rapidamente de um considerável conjunto de idéias relacionadas para uma arquitetura voltada para a extraçăo de informaçăo especializada e derivada a partir dos dados operacionais da empresa. $O$ estudo de uma arquitetura descrevendo o ambiente de Data Warehouse permite compreender melhor e 
apresentação dos dados que servirão para subsidiar o processo de tomada de decisão nas organizações.

\subsubsection{Arquitetura Genérica}

Uma arquitetura genérica proposta por Orr (Orr, 1996) é mostrada na Figura 10 e seus componentes descritos a seguir:

Camada de Banco de Dados Operacionais e Fontes Externas - corresponde aos dados das bases de dados operacionais da organização junto com dados provenientes de outras fontes externas que serão tratados e integrados para compor o Data Warehouse.

Camada de Acesso à Informação - é a camada com a qual os usuários finais interagem. Representa as ferramentas que o usuário utiliza no dia adia, tal como Excel e entre outras. Também envolvem o hardware e software utilizado para obtenção de relatórios, planilhas, gráficos e outros. A cada dia surgem sistemas mais sofisticados para manipulação, análise e apresentação dos dados incluindo-se ferramentas de data mining e visualização.

Camada de Acesso aos Dados - é a camada responsável pela ligação entre as ferramentas de acesso à informação e os bancos de dados operacionais. Esta camada se comunica não só com diferentes SGBDs e sistemas de arquivos de um mesmo ambiente como também, idealmente, com outras fontes sob diferentes protocolos de comunicação. Essa camada é chamada de acesso universal de dados.

Camada de Metadados (Dicionários de Dados) - Metadados são as informações sobre os dados mantidos pela empresa (descriçōes de registros em um programa COBOL, comandos CREATE do SQL, informações em um diagrama E-R, dados em um dicionário de dados - são exemplos de metadados). Para poder manter a funcionalidade de um ambiente de Data Warehouse é necessário ter disponivel uma grande variedade de metadados, desde dados sobre as visões dos usuários até dados sobre os Bancos de Dados operacionais. Idealmente o usuário deve poder ter acesso aos dados de um Data Warehouse sem que tenha que saber onde residem estes dados ou a forma como estão armazenados.

Camada de Gerenciamento de Processos - envolve o controle das diversas tarefas a serem realizadas para construir e manter as informaçōes do dicionário de dados e do Data Warehouse. Esta camada é responsável pelo gerenciamento dos processos que contribuem para manter o Data Warehouse atualizado e consistente.

Camada de Transporte ou Middleware - gerencia o transporte de informações pelo ambiente de redes. É usada para isolar aplicações, operacionais ou informacionais, do formato real dos dados e entregá-las em locais e tempos determinados. 
Camada do Data Warehouse - é o Data Warehouse, propriamente dito, corresponde aos dados usados para fins "informacionais". Em alguns casos, Data Warehouse é simplesmente uma visão lógica ou virtual dos dados, podendo de fato não envolver o armazenamento destes dados. Em um Data Warehouse que exista fisicamente, cópias dos dados operacionais e externos são de fato armazenadas, de modo a prover fácil acesso e alta flexibilidade de manipulação.

Camada de Gerenciamento de Repilicação - inclul todos os processos necessários para selecionar, editar, resumir, combinar e carregar o Data Warehouse as correspondentes informações de acesso a partir das bases operacionais e fontes externas. Normalmente isto envolve programação complexa, mas cada vez mais são disponibilizadas ferramentas para facilitar essa etapa.

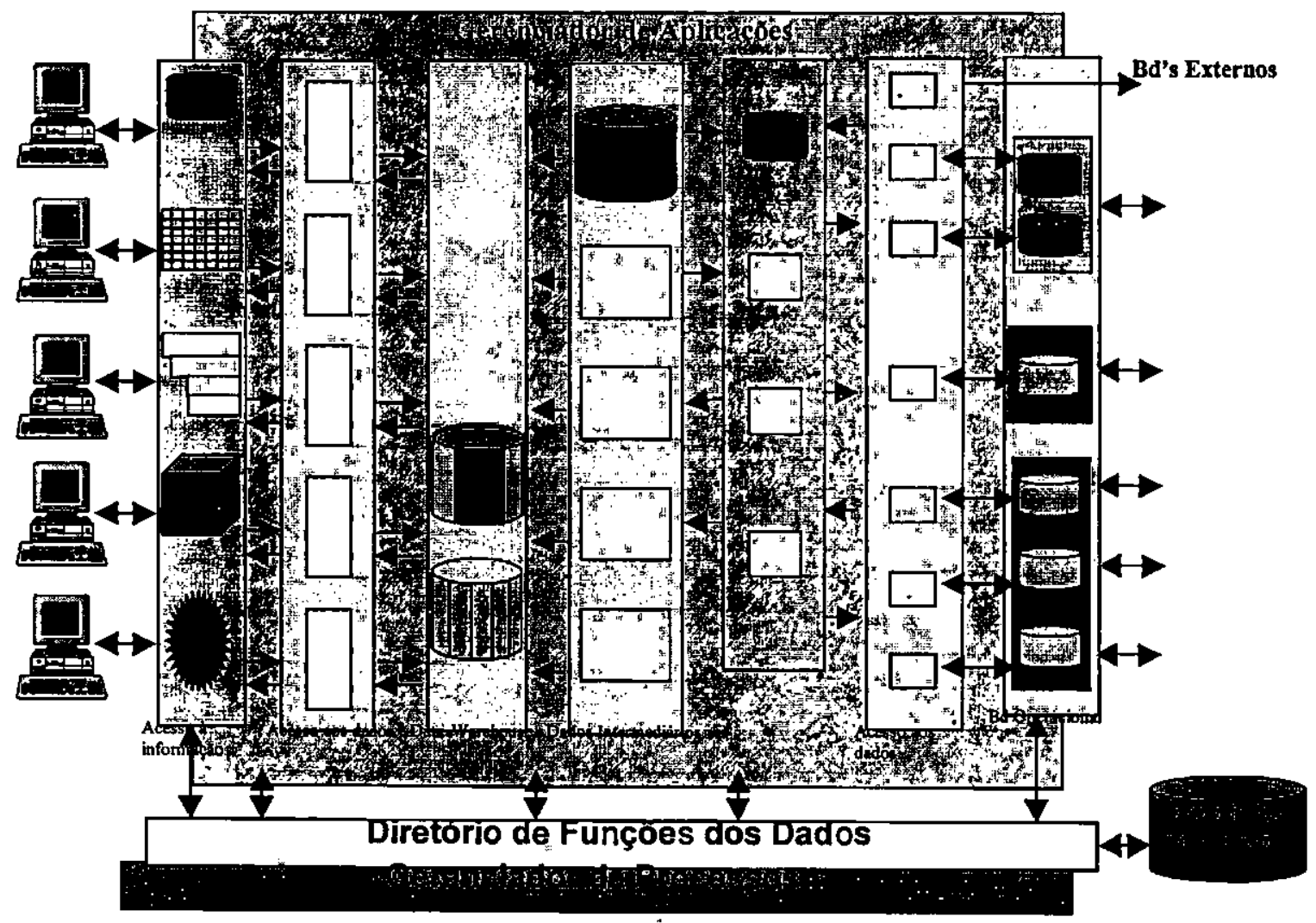

Flgura 10 - Arquitetura de Data Warehouse genérica proposta por Orr (Orr, 1996) 


\subsubsection{Arquitetura de dados}

Em termos de ambiente físico de dados, o Data Warehouse pode ser centralizado em um único local ou distribuído setorialmente. A primeira alternativa significa consolidar o banco de dados em uma base integrada. Esta abordagem procura maximizar o poder de processamento disponivel. Em uma segunda abordagem, pode-se considerar uma arquitetura federativa, distribuindo as informaçōes por função, com dados financeiros em um servidor, dados de marketing em outro local, e dados de manufatura em um terceiro lugar.

Em uma terceira abordagem, considera-se uma arquitetura de Data Warehouse por camadas, armazenando dados altamente resumidos em um servidor, dados resumidos em nivel de detalhe intermediário em um segundo servidor, e os dados mais detalhados (atômicos) em um terceiro servidor. O primeiro servidor atende a maior parte dos pedidos, com um número menor de pedidos passando para a camada 2 e camada 3 . Os computadores da primeira camada podem ser otimizados para carga pesada de usuários e baixo volume de dados enquanto servidores nas outras camadas estão mais adequados para processar grandes volumes de dados, mas baixo número de usuánios.

\subsubsection{O papel dos metadados}

Diferentes apiicações desenvolvidas em tempos diferentes no âmbito operacional da empresa, geralmente contêm dados que são inconsistentes ou redundantes. A menos que seja guiado pelos princípios de uma administração de dados efetiva, um Data Warehouse não atingirá seu objetivo de integração dos dados. Os metadados constituem-se no principal recurso para a administração de dados e assumem maior importância ainda no ambiente de Data Warehouse.

Metadados săo normalmente definidos como "dados sobre dados". Talvez uma definição mais exata seja a de que metadado é uma abstração dos dados, ou ainda, dados de mais alto nivel que descrevem dados de um nível inferior. Sem metadados, os dados não têm significado. São exemplos de metadados as descriçőes de registros em um programa de aplicação ou o esquema de um banco de dados descrito em seu catálogo ou ainda as informações contidas em um dicionário de dados.

Em um ambiente operacional, os metadados são especialmente valiosos para o desenvolvedores de aplicaçăo e os administradores do banco de dados. Os bancos de dados operacionais săo usualmente utilizados via aplicações, que já contém as definições de dados embutidas. Seus usuários simplesmente interagem com as telas do sistema, sem precisar conhecer os dados que são mantidos pelo Banco de Dados. 
O ambiente de suporte à decisão, por sua vez, é bastante distinto. Nele, analistas de dados e executivos procuram por fatos não usuais e correlações que serão reconhecidas quando encontradas. Aplicações rotineiras e predefinidas não fazem sentido neste ambiente. Os usuários de um Data Warehouse precisam examinar seus dados e para tal, conhecer sua estrutura e significado.

De modo geral existem três camadas de metadados em um Data Warehouse:

- Metadados operacionais (do nivel das aplicações) - definem a estrutura dos dados mantidos pelos bancos operacionais, usados pelas aplicações de produção da empresa;

- Metadados centrais do Data Warehouse - mantidos no catálogo do Data Warehouse. Distinguem-se por serem orientados por assunto, definindo como os dados transformados devem ser interpretados. Incluem definiçōes de agregados e campos calculados, assim como visões sobre cruzamento de assuntos.

- Metadados do nivel do usuário - mapeiam os metadados do Data Warehouse para conceitos que sejam familiares e adequados aos usuários finais.

Os metadados associados a um Data Warehouse podem ser classificados segundo diversas classes de componentes, dentre elas:

- Mapeamento - descreve como os dados de banco de dados operacionais são transformados para chegarem ao Data Warehouse. Incluem identificação de campos fontes, mapeamento entre atributos, conversões, codificações, defaults, etc.

- Histórico - mantém o histórico de mudanças das regras do negócio, pois as regras certas devem ser aplicadas aos dados certos, quando se consideram evoluções ao longo do tempo;

- Miscelânea - aliases (apelido), informações de status sobre estágios de desenvolvimento de partes do Data Warehouse, informações sobre volume dos dados (para estimativas de tempo e recursos), dentre outros;

- Algoritmos de sumarizaçăo - mostram a relaçăo entre os diferentes níveis de detalhe dos dados, indicando inclusive que nivel de sumarização é mais adequado para um dado objetivo;

- Padrōes de acesso - mantêm informações sobre freqüência e tipo de acesso aos dados. 
Como se pode notar, dados sobre desempenho e monitoramento também se qualificam como metadados. Os processos que monitoram o ambiente de um Data Warehouse (tais como extração, carga e uso) criam metadados que são usados para determinar como o sistema vem atuando em termos de desempenho. Da mesma forma, dados que identificam questöes relativas a quantidade dos dados deletados durante os processos de extração e carga devem também estar disponíveis para os usuários, para que estes possam julgar a validade de suas análises.

\subsubsection{Ferramentas Utilizadas em Data Warehouse}

Existem várias ferramentas utilizadas em um Data Warehouse:

- Ferramenta para armazenamento - são os bancos de dados (SGBD), considerados o coração do Data Warehouse e parte imprescindivel do projeto.

- Ferramenta para extração de dados - busca na base de dados operacionais os dados que serão armazenados em um Data Warehouse.

- Ferramenta para a transformação de dados - ajusta os dados para o formato do Data Warehouse. Este formato auxilia as futuras pesquisas.

- Ferramenta para a limpeza de dados - faz os ajustes necessários nos dados, fazendo correções, desmembramentos e fusōes de dados, quando necessário, visando melhorá-los para facilitar as futuras pesquisas.

- Repositórios de metadados - estão intimamente relacionados às ferramentas de extração. Metadados são as definições dos dados que permitem saber a origem da informação, bem como todas as vezes que ela foi alterada. Sua função é manter a consistência dos dados.

- Transferência de dados e replicação - pode ser considerada um subconjunto das ferramentas de extração. Não faz nenhum tipo de processamento e transformação, apenas transfere um dado de um lugar "A" para " $B$ ". Geralmente é utilizado para facilitar e dar uma resposta mais rápida às consultas ou análises, movendo os dados para um lugar apropriado e fazendo o que for necessário para agilizar o serviço solicitado.

- Gerenciamento e administração - é a típica ferramenta que só faz sentido depois que o Data Warehouse está construído. Monitora o dia-a-dia, como a performance e segurança do sistema. 
- Query ou ferramentas para gerenclamento de consultas - fazem consultas e/ou geram relatórios retirando os dados do Data Warehouse, resumindo-os e apresentando-os em um formato apropriado.

- Ferramentas para gerenciamento de relatórios - são semelhantes às ferramentas do item anterior, porém elas estăo voltadas para a geração de relatórios mais complexos, contendo, por exemplo, relatórios sintéticos e analíticos em conjunto, gráficos e outros tipos de visualizaçăo dos dados.

- OLAP - é a parte mais visivel do Data Warehouse porque é por meio dessas ferramentas que se faz a análise dos dados. Ajudam os gerentes a sintetizarem as informações sobre a empresa através de comparaçőes, visőes personalizadas, análise histórica e projeçăo de dados.

- Data Mining - ferramenta utilizada para descobrir novas correlaçōes, padrões e tendências entre as informações de uma empresa, através da análise de grandes quantidades de dados armazenados em Data Warehouse usando técnicas de reconhecimento de padrőes, estatisticas e matemáticas.

- Simulação - projeta cenários respondendo perguntas do tipo "e se", por exemplo:

"e se os juros aumentarem, qual será o comportamento de minhas vendas?"

Uma organização não terá necessariamerite que usar todas as categorias existentes de ferramentas de Data Warehouse. No minimo, precisará considerar e avaliar todas para saber quais serão importantes para o que se pretende construir.

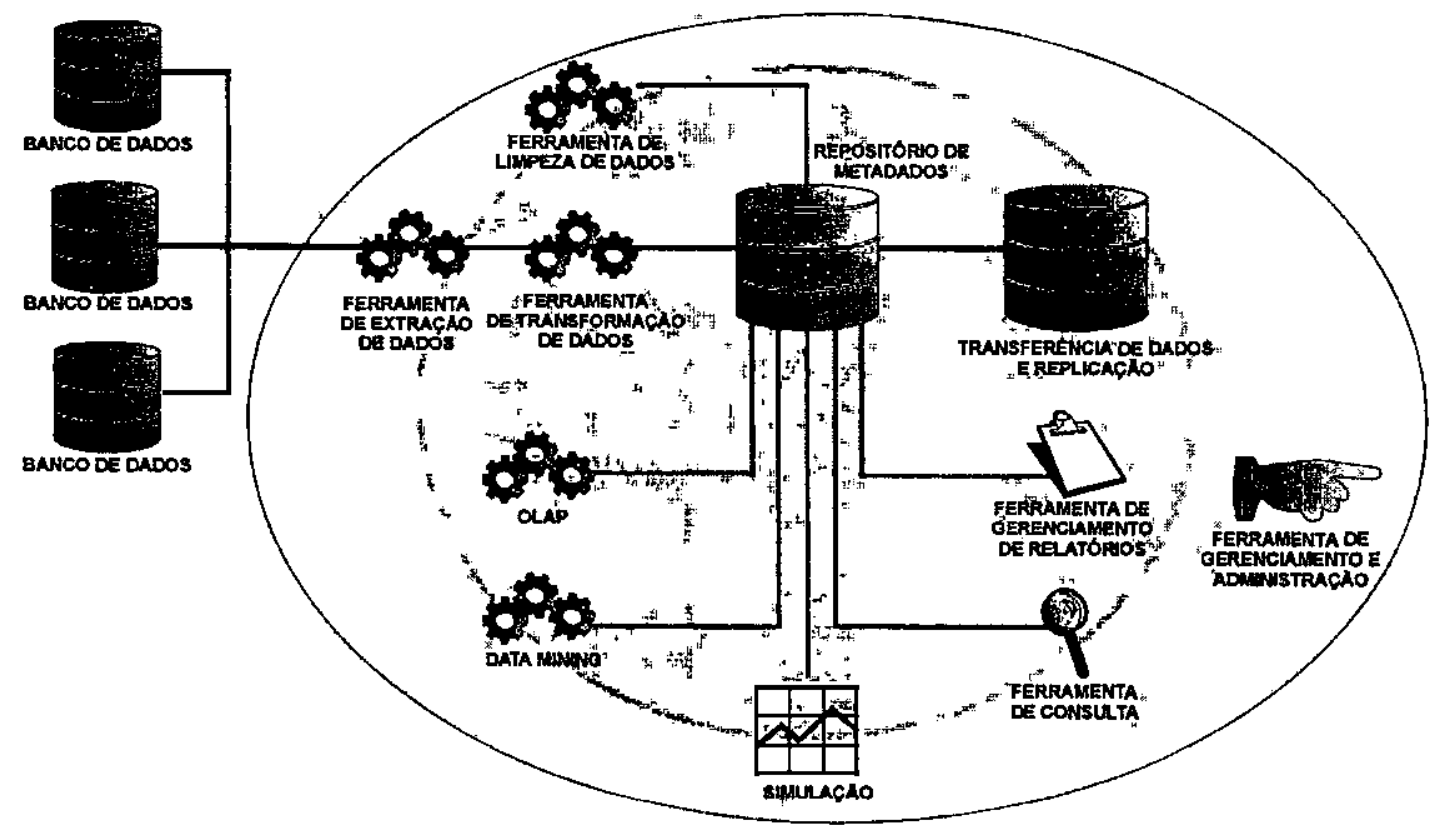

Figura 11 - Ferramentas utilizadas em Data Warehouse 


\subsubsection{OLAP}

Uma outra tecnologia importante para auxiliar e acelerar a tomada de decisões é a ferramenta OLAP(online analytical processing - processamento analítico online) (Harrison, 1998). O OLAP é uma ferramenta que possibilita acessar e analisar dados contidos em um banco de dados, preferencialmente Data Warehouse. As funções OLAP incluem consultas e relatórios (o que simplifica a geraçăo de códigos SQL), análise multidimensional, análise estatística (também conhecida como reduçăo de dados).

Em geral, os produtos de software com aplicaçōes OLAP possuem cinco funçōes básicas (Tanler, 1998):

- Interface: Telas e métodos utilizados para enviar instruçöes internas para outras funçöes com base em escolhas do usuário

- Consulta: Parte do aplicativo utilizado para gerar códigos SQL.

- Processamento: Parte do aplicativo responsável pela análise de dados no conjunto de valores resultantes da consulta do banco de dados

- Formatação: Parte do aplicativo necessário para formatar de maneira adequada as linhas e colunas dos dados retornados pelo processamento e gerar um arquivo padrăo (relatórios ou arquivos HTML).

- Exibição: parte do aplicativo responsável pela visualizaçăo do resultado para o usuário final, como um relatório ou gráfico.

\subsubsection{A evoluçăo do OLAP}

Em 1993, em um relatório, E. F. Codd descreveu 12 regras para o OLAP para diferenciar consultas simples de banco de dados e ferramentas para relatórios com sofisticadas formas de análise das informaçöes. Ao descrever uma tecnologia, Codd reservou o termo OLAP para descrever análises "multidimensionais" sofisticadas.

Antes de Codd introduzir o termo OLAP, muitos fabricantes de software utilizavam um punhado de outros termos, inclusive DSS (Decision Support Systems - Sistemas de Suporte a Decisão), EIS (Executive Information Systems - Sistemas de Informações executivas), DIS (Data Interpretation Systems - Sistemas de Interpretação de Dados) e BIS (Business Intelligence Systems - Sistemas de Inteligência Comercial), para descrever o processamento de alto nivel utilizado na recuperação, análise e interpretação de dados não processados. Entretanto, apesar de toda a gama de tópicos englobados por toda essa terminologia, o objetivo do sotware no que diz respeito à análise de dados e criaçăo de relatórios sempre foi o 
mesmo: fornecer aos responsáveis pelo processo de tomada de decisões com um número cada vez maior de informaçőes atualizadas com as quais possam trabalhar de modo a tirarem conclusões.

\subsection{Servidores Web}

Um Servidor Web é um serviço que usufrui do modelo cliente-servidor e do protocolo HTTP (Hypertext Transfer Protocol - Protocolo de transferência de hipertextos) e/ou do protocolo FTP (File Transfer Protocol - Protocolo de Transferência de Arquivos) para transferir documentos e páginas Web para o cliente (normalmente um Web Browser).

$\mathrm{Na}$ visão do sistema operacional de rede, quando o cliente (Web Browser) faz a requisiçăo para o servidor Web, ele envia uma solicitação HTTP ou FTP contendo o endereço (URL) do objeto (página Web, imagem, etc.) a ser acessado, o método de acesso (GET/POST, etc.) e qual o host que está fazendo a solicitação. Caso o objeto existir, o Servidor Web retorna o objeto solicitado, senão retorna um erro (status de HTTP) ao cliente.

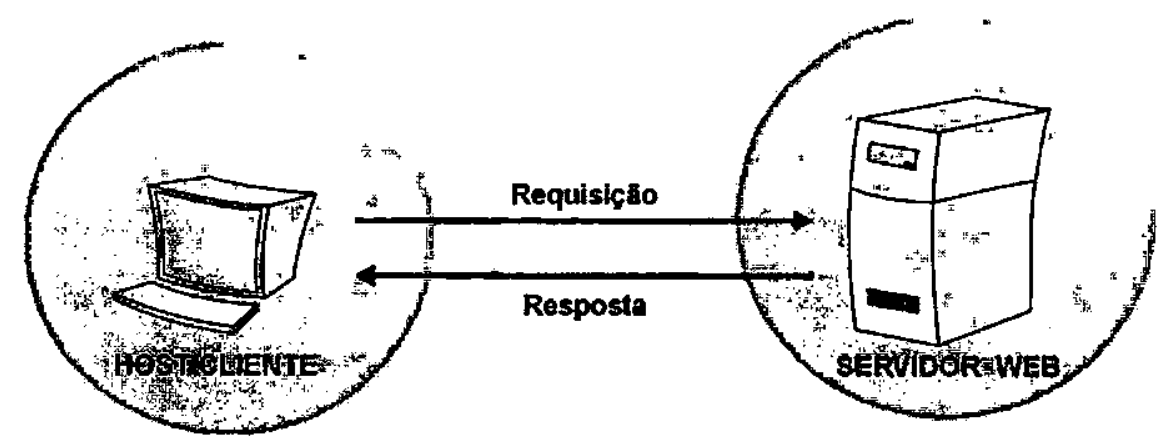

Figura 12 - Exemplo de uma requisição ao Servidor Web

\subsection{Servidores Proxies}

Um servidor Proxy é um agente intermediário entre o cliente, usuário final usando um browser, e o Servidor $W e b$. Ele recebe as requisições dos clientes e repassa-as aos servidores Web. As respostas são então recebidas pelo servidor Proxy que as envia de forma transparente ao cliente que originou a requisição (Fonseca et al, 1998).

Por centralizar vários pedidos de conexāo, o servidor Proxy se torna um ótimo ponto de armazenamento de informaçōes que trafegam entre os clientes e a Internet. Desta forma, os servidores Proxies tornam-se um grande "cache" temporário de informações, diminuindo consideravelmente o tráfego de pacotes entre a rede corporativa e a Internet. 
Com o uso de servidores Proxies, as consultas que eram feitas diretamente aos servidores na Intemet passam a ser feitas através dos caches dos servidores Proxies. Assim, a primeira vez que uma página Web é solicitada, a requisição é encaminhada ao servidor Proxy que busca diretamente no servidbr Web da Internet, armazena-a localmente e a repassa ao cliente que fez o pedido. Para todas as outras consulta a essa mesma página, será apenas repassada a cópia anteriormente armazenada. Existem servidores para uma diversidade de protocolos, mas a implantação do cache se torna particularmente interessante para o HTTP e para o FTP, uma vez que a maior parte do tráfego da Internet se dá através destes dois protocolos (Fonseca et al, 1998).

$\mathrm{Na}$ visão do sistema operacional de rede, quando o cliente faz a requisição para o servidor Proxy, ele envia uma solicitaçăo HTTP ou FTP contendo qual é o servidor Web e o objeto (página Web, imagem, etc.) a ser acessado, e qual o host que está fazendo a solicitação. Se o objeto requisitado estiver no cache, o Servidor Proxy automaticamente repassa a cópia para o cliente. Caso contrário, ele faz a solicitação para o Servidor Web na Internet contendo qual é o objeto solicitado. Caso o objeto existir, o Servidor Web retorna o objeto solicitado, senão retorna um erro ao servidor Proxy. Existindo o objeto, será feita uma cópia do mesmo no cache do Servidor Proxy e retorna-se a o objeto solicitado para o cliente, caso contrário, será retornado um erro (status de HTTP) ao cliente.

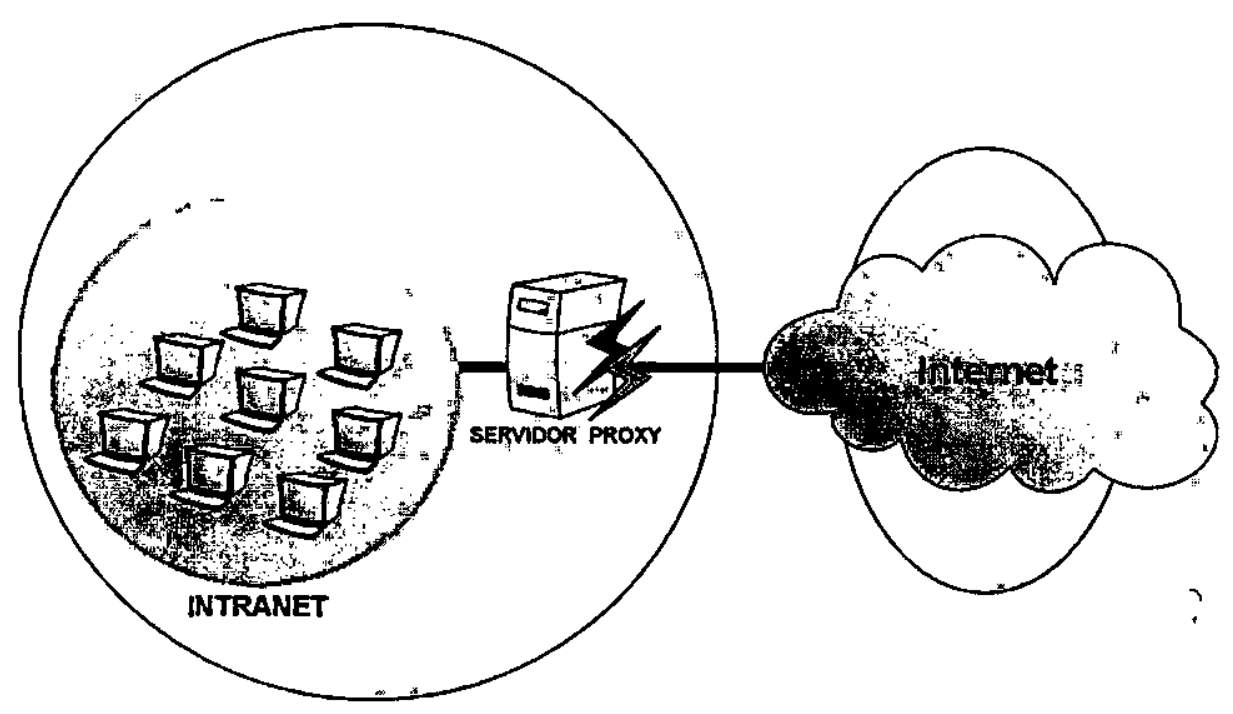

Figura 13 - Exemplo um servidor Proxy em uma rede Intranet 


\subsection{Firewall}

O Firewall é um sistema que é executado normalmente em um gateway ou roteador, e que permite controla o acesso e o fluxo de tráfego entre duas redes, colocando uma "barreira" entre elas ( ver figura Figura 14).

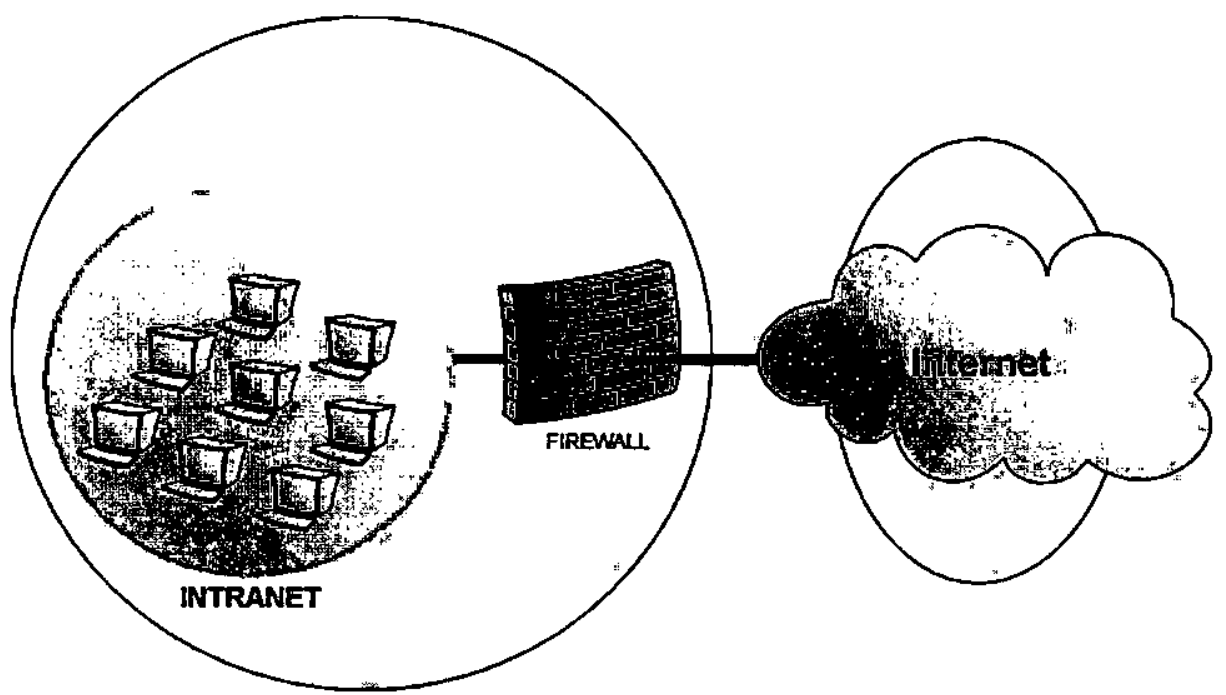

Figura 14 - Exemplo de uma rede privada com acesso à Internet com Firewall 


\section{AMBIENTE DE MONITORAMENTO}

Neste trabalho, propőe-se modelar um Sistema de Monitoramento que será composto por um ambiente operacional (Logs de acessos e os dados descritivos dos servidores) e um ambiente Data Warehouse que servirá como base para se extrair as informações necessárias para a tomada de decisão.

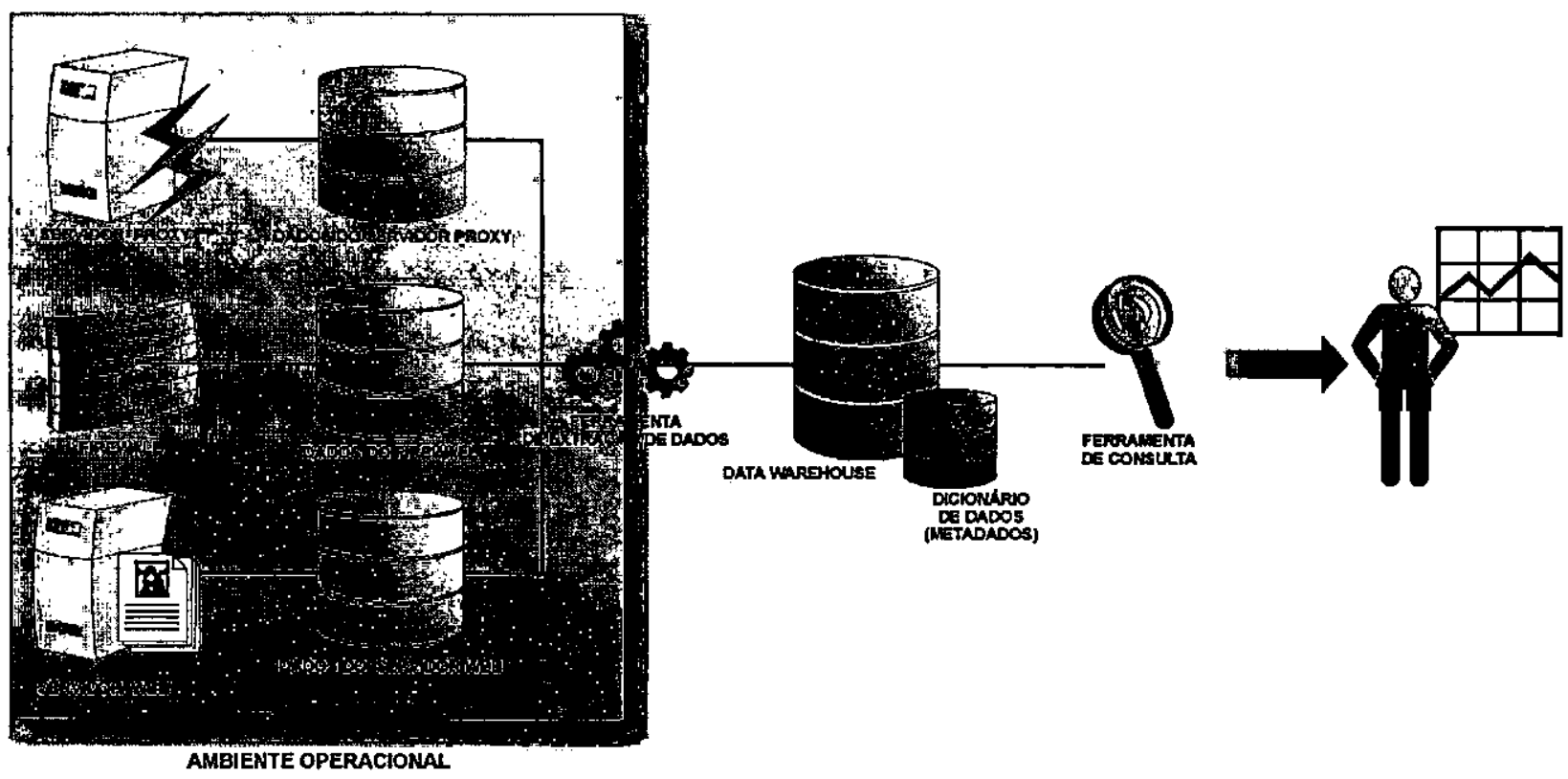

Figura 15 - Ambiente Operacional

\subsection{Ambiente Operacional}

Para um melhor controle e avaliação do Ambiente de Intranet foi necessário criar uma modelagem de um ambiente operacional (Figura 15)que representa-se as fontes de dados a serem armazenados no Data Warehouse. Este ambiente será composto de dados oriundos dos Logs de acesso e detalhes das características dos Servidores Web, Proxy e Firewall; informaçð̄es sobre os hosts e os usuários que usufruem dos serviços dos mesmos.

\subsubsection{Definição dos formatos de Logs}

Para possibilitar que este trabalho fosse bastante abrangente, pensou-se em criar uma modelagem independente do fabricante dos Servidor de Web, Proxy e Firewall, e independente de sistema operacional. Para tanto, foi necessário estudar os variados formatos de Logs existentes para os Servidores de Web, Proxy e Firewall. 
Para os servidores Web e de Proxy, atualmente há o Formato Comum de Log (Commum Log Format) (Ver Anexo I), conhecido também como formato NCSA ${ }^{1}$, suportado pela maioria dos fabricantes de servidores Web e de Proxy, e outros formatos proprietários.

Em 1996, a W3C propôs uma extensão ao Formato Comum de Log para solucionar algumas deficiências existentes, como ser um formato eficiente para resumir os acessos dos Servidores Proxies (Ver Anexo I). Esta extensão tenta solucionar as seguintes necessidades (Hallam-Baker \& Behlendorf, 1996):

- Permitir melhor controle sobre os dados gravados (histórico de acessos);

- Suportar necessidades de Proxies, clientes e servidores em um formato comum;

- Fornecer um formato robusto e extensivel;

- Permitir mudança de dados demográficos;

- Permitir a customização do Log em um formato compreensível para as maiorias das ferramentas de análise genérica.

Neste trabalho será utilizado o Formato Estendido de Log proposto pelo W3C por ser um formato mais abrangente que o NCSA (Formato Comum de Log), e por possibilitar melhor controle dos acessos de dados dos Servidores Web e Proxy.

Porém, a maioria dos servidores Web possui como formato padrão de Log o formato NCSA (Formato Comum de Log), tais como Apache HTTP Server (Apache HTTP Server Project), NCSA HTTPd (NCSA HTTPd Development Team). Entretanto, a maioria dos servidores compativeis com o padräo "NCSA httpd" como o Apache HTTP Server e NCSA HTTPd possuem um arquivo de configuração (httpd.conf) onde permite-se modificar o formato de $\log$ de acesso. Desta maneira, é possivel modificá-lo para um formato que possa ser compativel com o Formato Estendido de Log.

Os principais campos do Formato Estendido de Log utilizados neste trabalho são mostrados na Tabela 2.

\footnotetext{
1 National Center for Supercomputing Appllcations - University of Illinois at Urbana - Champaign, IL, USA.
} 
Tabela 2 - Principais Campos de Formato Estendido de Log utilizados para Servidores Web

\begin{tabular}{|l|l|l|}
\hline Formato W3C & Descriçăo & \multicolumn{1}{l|}{ Exemplo } \\
\hline date & Data de Acesso & $1999-12-09$ \\
\hline time & Horário de Acesso & $19: 27: 52$ \\
\hline c-ip & Endereço IP & 10.108 .34 .17 \\
\hline cs-username & Identificaçáo do Usuário & - \\
\hline s-computername & Nome do Servidor Web & WEBSERVER \\
\hline s-ip & IP do Servidor Web & 10.108 .1 .17 \\
\hline s-port & Porta do Servidor & 80 \\
\hline cs-method & Método de Acesso & GET \\
\hline cs-uri-stem & Parte Principai do URI & /pics/publicacoes.htm \\
\hline cs-uri-query & Query do URi & Opcao=1 \\
\hline sc-status & Status do Http & 200 \\
\hline sc-bytes & Bytes Enviados & 1507 \\
\hline cs-bytes & Bytes Recebidos & 273 \\
\hline time-taken & Tempo Despendido & 62 \\
\hline cs-version & Versão do Protocolo & HTTP/1.1 \\
\hline cs(user-agent) & Agente do Browser & Mozilla/4.0+(compatible;+MSIE+4.01;+Windows+NT) \\
\hline cs(cookie) & Cookie & - \\
\hline cs(referrer) & URI que fez referência & http://10.108.231.1/index.portu.html \\
\hline
\end{tabular}

Onde:

date - é a data que 0 acesso foi realizado

time - é o horário que o acesso foi realizado

c-ip - é o endereço IP do host cliente que realizou a solicitaçăo

cs-usemame - é o nome do usuário (apelido) que realizou a solicitaçăo

s-computername - nome do servidor Web

s-ip - endereço IP do servidor Web

s-port -- porta do servidor Web que o host cliente se conectou

cs-method - método de acesso (GET, POST, HEAD, etc.)

cs-uri-stem - parte principal do URI.

cs-uri-query - parte "query" do URI.

sc-status - Status do protocolo HTTP

sc-bytes - bytes enviados do servidor Web para o host cliente.

cs-bytes - bytes envidados do host cliente para o servidor Web

time-taken - tempo despendido. Tempo decorrido desde a solicitaçăo do cliente até a resposta do

servidor.

cs-version - versåo do protocolo HTTP.

cs(user-agent) -Agente de Usuário - identificaçăo do browser ou crawler

cs(cookie) - valor do cookie enviado para o Servidor de Web

cs(referrer) - URI que fez referência ao URI atual

Para que os Logs dos servidores Web de padrão "NCSA httpd" possam ser compativeis com o Formato Estendido de Log, é necessário inserir a seguinte linha no arquivo de configuração (httpd.conf):

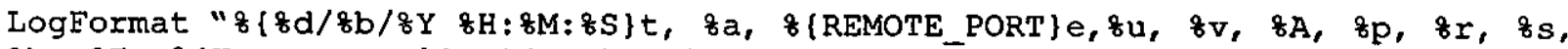

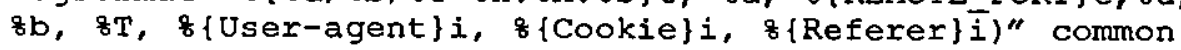


Desta maneira os arquivos de Logs terão os seguintes valores de saída:

16/Dec/1999 14:03:58, 10.108.34.17, -, --, 10.108.34.19, 80, GET

/index.php3?=PHPE9568F35-D428-11d2-A769-00AA001ACF42 HTTP/1.1, 200, 4453, 0, HTTP/1.1, Mozilla/4.0 (compatible; MSIE 5.0; Windows 98; DigExt),

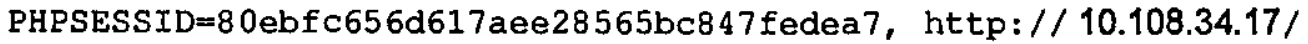

Para os servidores Proxy, os campos do arquivo de Log são um pouco diferentes do servidor Web, pelo fato dos servidores Proxies trabalharem como "cachen e "gateway". Por isso, neste trabalho são utilizados os seguintes campos para prover um Log de servidor Proxy eficiente:

Tabela 3 - Principais Campos de Formato Estendido de Log utilizados para Servidores Proxies

\begin{tabular}{|l|l|l|}
\hline Formato W3C & Descriçäo & $1999-12-09$ \\
\hline date & Data de Acesso & $20: 17: 12$ \\
\hline time & Horário de Acesso & 10.108 .34 .17 \\
\hline c-ip & Endereço IP & - \\
\hline cs-username & Identificação do Usuário & - \\
\hline s-computername & Nome do Servidor & - \\
\hline s-jp & IP do Servidor Proxy & 10.108 .36 .17 \\
\hline s-port & Porta do Servidor Proxy & 80 \\
\hline r-computername & Nome do Servidor Remoto & - \\
\hline r-ip & IP do Servidor Remoto & 10.108 .4 .178 \\
\hline r-port & Porta do Servidor Remoto & 80 \\
\hline cs-method & Método de Acesso & GET \\
\hline cs-uri-stem & Parte Principal do URI & /pics/publicacoes_main_on.gif \\
\hline cs-uri-query & Query do UR! & - \\
\hline sc-status & Status do HTTP & 200 \\
\hline sc-bytes & Bytes Enviados & 1507 \\
\hline cs-bytes & Bytes Recebldos & 273 \\
\hline time-taken & Tempo Despendido & 62 \\
\hline cs-version & Versão do Protocolo & HTTP/1.1 \\
\hline cs(user-agent) & Agente do Browser & Mozilla/4.0+(compatible;+MSIE+4.01;+Windows+NT) \\
\hline s-result & Código Resultante & NO_CACHE \\
\hline Ondo: & &
\end{tabular}

Onde:

date - é a data que o acesso foi realizado

time - é o horário que o acesso foi realizado

c-ip - é o endereço IP do host cliente que realizou a solicitaçăo

cs-usemame - é o nome do usuário (apelido) que realizou a sollcitaçăo

s-computername - nome do servidor Proxy

s-jp - endereço IP do servidor Proxy

s-port -- porta do servidor Proxy que o host clierte se conectou

r-computername - nome do servidor Remoto (Servidor Web)

s-ip - endereço IP do servidor Remoto (Servidor Web)

s-port - porta do servidor remoto (Servidor Web)

cs-method - método de acesso (GET, POST, HEAD, etc.)

cs-uri-stem - parte principal do URi.

cs-uri-query - parte "query" do URI. 
sc-status - Status do protocolo HTTP

sc-bytes - bytes enviados do servidor Web para o host cliente.

cs-bytes - bytes envidados do host cliente para o servidor Web

time-taken - tempo despendido. Tempo decorrido desde a solicitação do cliente até a resposta do

servidor.

cs-version - versão do protocolo http.

cs(user-agent) -Agente de Usuário - identificaçăo do browser ou crawler

s-result - Código Resultante da solicitação, se a página estava no Cache ou não.

Conforme verificado em vários fabricantes de Firewall (Check Point, CISCO, Web Trends, Fuego Firewall, entre outros), os arquivos de Logs de Firewall não possuem um padrão comum de formato de Logs. Cada fabricante gera um formato proprietário e normalmente os arquivos de Log são armazenados com criptografia.

Para que este trabalho pudesse abranger vários tipos de Logs existentes, é proposto um formato que selecione os campos mais usados e considerados importantes para realizar análise. O formato proposto é visualizado na Tabela 4.

Tabela 4 - Principais campos utilizados no Log de Firewall

\begin{tabular}{|l|l|l|}
\hline \multicolumn{2}{|l|}{ Descrição } & Exemplo \\
\hline Date & Data de Acesso & $1999-12-09$ \\
\hline Time & Horário de Acesso & $20: 17: 12$ \\
\hline Username & Nome do Usuário & Jose \\
\hline Source IP & IP do host de origem & 10.17 .231 .119 \\
\hline Destination IP & IP do host destino & 10.17 .231 .161 \\
\hline Destination Port & Porta do host destino & 4561 \\
\hline Firewall Name & Nome do Firewall & Firewall 1 \\
\hline Interface IP & IP da Interface do Firewall & 10.17 .231 .107 \\
\hline Protocol & Nome do Protocolo usado & TCP \\
\hline Service & Nome do Serviço acessado & SMTP \\
\hline Rule & Regra de acesso usada & Complete Access \\
\hline Action & Ação realizada pelo Firewall & Accept Access \\
\hline Action Type & Tipo de Ação & Log \\
\hline Bytes transfered & Bytes Transferidos & 567890 \\
\hline
\end{tabular}

\section{Onde:}

Date - é a data que o acesso foi realizado

Time - é o horário que o acesso foi realizado

Username - é o nome do usuário (apelido) que realizou a solicitação

Source IP - é o endereço IP do host que originou a solicitação

Destination IP - é o endereço IP do host que receberá a solicitação

Destination Port - é a porta do host servidor que o host cliente se comunicou

Firewall Name - é o nome do Firewall

Interface IP - é o endereço IP da Interface do Firewall

Protocol - é o nome do protocolo usado para realizar a comunicaçăo (TCP, UDP)

Service - é o nome do serviço que foi solicitado (SMTP, POP3, HTTP, FTP, etc.)

Rule - é a regra de acesso utilizada para realizar a comunicaçăo.

Action - Ação realizada pelo Firewall (aceito ou rejeitado a conexão, autenticação, etc.)

Type Action - Tipo da Ação (Log, Controle, Alerta, etc.) 


\subsubsection{Características das Entidades}

Além dos valores extraídos do Logs de acessos dos servidores de Web, de Proxy e de Firewall, é importante se conhecer também as características das entidades envolvidas no acesso, tais como os próprios servidores de Web, Proxy e Firewall, os hosts e os usuários que geraram a solicitação de acesso. A partir das entidades, pode-se ter um melhor conhecimento do funcionamento do ambiente de Intranet e desta forma seu melhor controle e avaliação.

Neste trabalho, as entidades envolvidas no ambiente de Intranet são descritas pensando-se em serem genéricas, independendo do domínio de aplicação, seja em uma empresa comercial, instituição acadêmica ou órgão público.

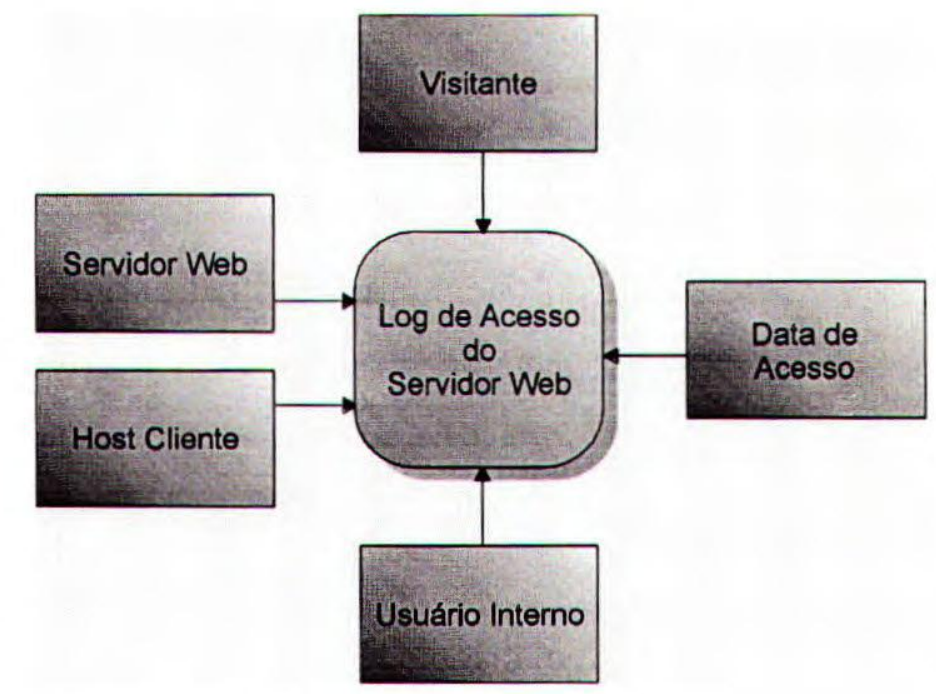

Figura 16 - Entidades envolvidas no acesso ao Servidor Web

Quando ocorre um acesso ao Servidor $W e b$, informações são armazenadas no Log, como foi visto na Tabela 2. Porém, somente os dados do Log de Acesso não são eficientes para se fazer uma análise ou avaliação do Ambiente de Intranet. Para tanto, neste trabalho foram verificadas cinco principais entidades envolvidas no acesso ao Servidor de Web:

- Servidor de Web - A partir das características físicas do servidor pode-se ter um melhor conhecimento da performance da rede e as influências no congestionamento de tráfego.

- Usuário Interno da rede privativa - Dependendo do nível de segurança da rede privada, é interessante conhecer quais os usuários internos que acessam o servidor de Web. Quais as páginas que são acessadas por cada usuário, se há acesso indevido em páginas importantes, etc. 
- Visitante do Site - O visitante é o usuário que realiza acessos ao Servidor Web e que pode ou não ser um usuário interno da rede privada. As informações sobre o visitante são importantes para se conhecer a assiduidade da visita, as regióes geográficas de maior acesso ao site, etc.

- Data de Acesso - Data e o horário que o acesso ao Servidor de Web se realizou. É importante para se conhecer quais os horários e os periodos que ocorrem maior acesso ao Servidor.

- Informações sobre o Host Cliente - detalhes sobre o host (computador) que solicitou a requisiçăo ao servidor de Web.

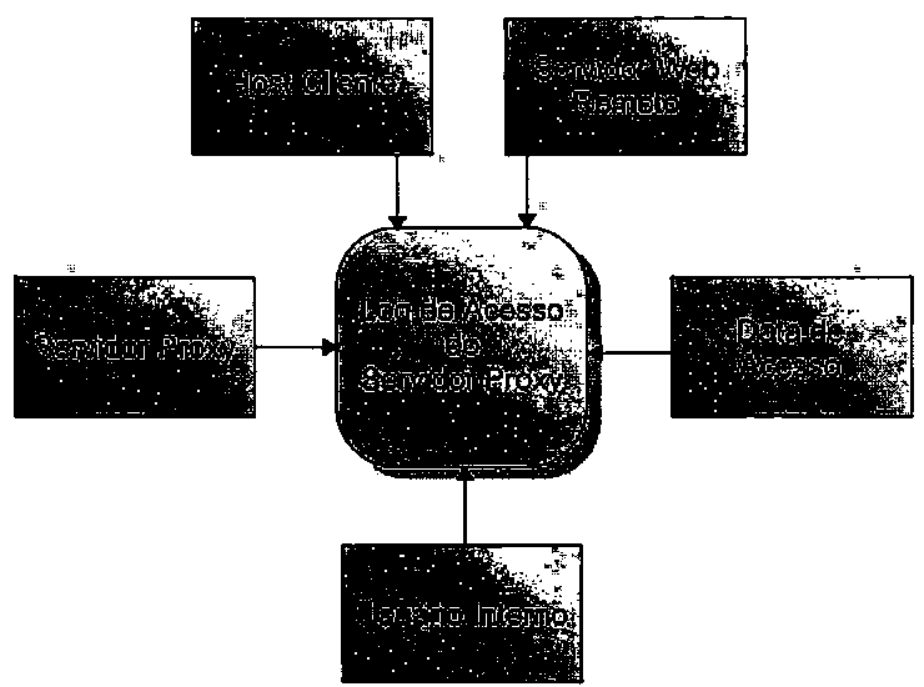

Figura 17 - Entidades envolvidas no acesso ao Servidor Proxy

Tal como o acesso ao Servidor de Web, neste trabalho o acesso do Servidor de Proxy (Figura 17) envolve cinco entidades principais para o controle de performance da rede:

- Servidor Proxy - descrição das caracteristicas físicas do servidor Proxy,

- Usuário Interno da rede - detalhes sobre os usuários que acessam o serviço de Proxy;

- Servidor de Web remoto - descrição do Servidor de Web externo que receberá a requisição;

- Host Cliente - detalhes sobre o host que solicitou a requisição;

- Data de Acesso - data e o horário que o acesso ao Servidor Proxy se realizou; 


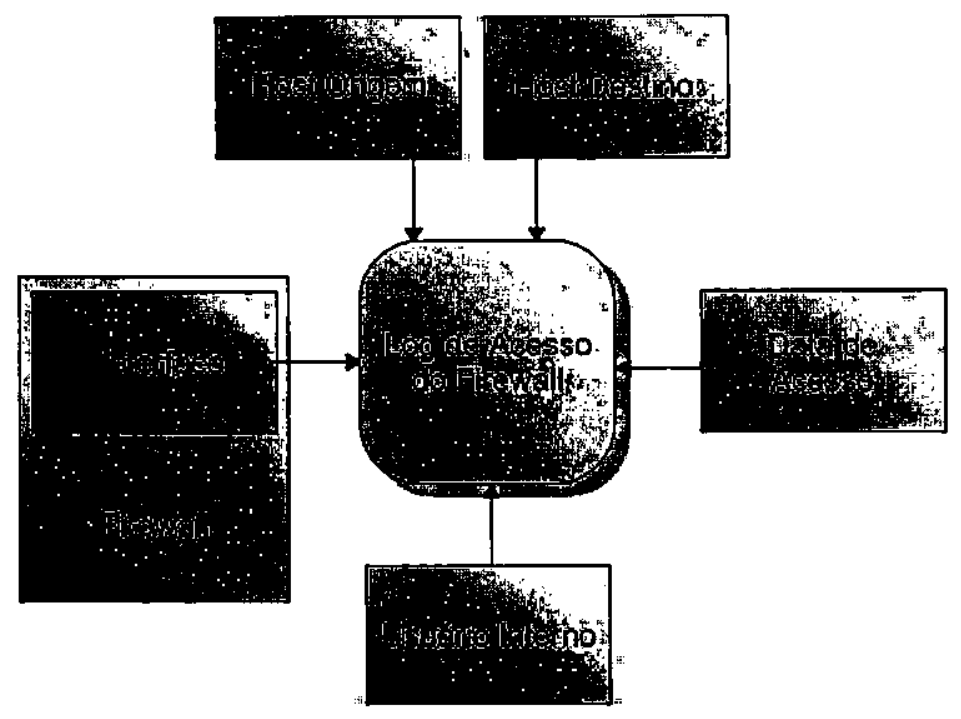

Figura 18 - Entidades envolvidas no acesso ao Firewall

As principais entidades envolvidas no acesso ao Firewall (Figura 18) também podem se resumir a cinco:

- Usuário Interno da Rede - detalhes sobre o usuário que realizou a solicitação de serviço através do Firewall;

- Data de Acesso - data e o horário que acesso ao Firewall se realizou;

- Firewall - descrição das caracteristicas físicas do Firewall e da interface que foi utilizada.

- Host Origem - informações sobre o host que originou o pedido de serviço (SMTP, HTTP, FTP, Ping, etc.) ;

- Host Destino - informações sobre o host que recebeu a requisição de serviço;

\subsection{Ambiente Warehouse}

A partir do Ambiente Operacional já totalmente modelado, foi possivel verificar quais são as informações necessárias e importantes para a modelagem do esquema de Warehouse. Conforme pode-se ver na Figura 19, as entidades que foram descritas no item 3.1.2 tornaramse as tabelas dimensionais na modelagem do esquema de Warehouse. $E$ as informações sobre os acessos armazenados nos arquivos de Log dos Servidores Web, Proxy e Firewall serviram de base para a modelagem das tabelas de fatos (Acesso do Servidor Web, Acesso do Servidor Proxy, Acesso do Firewall). 


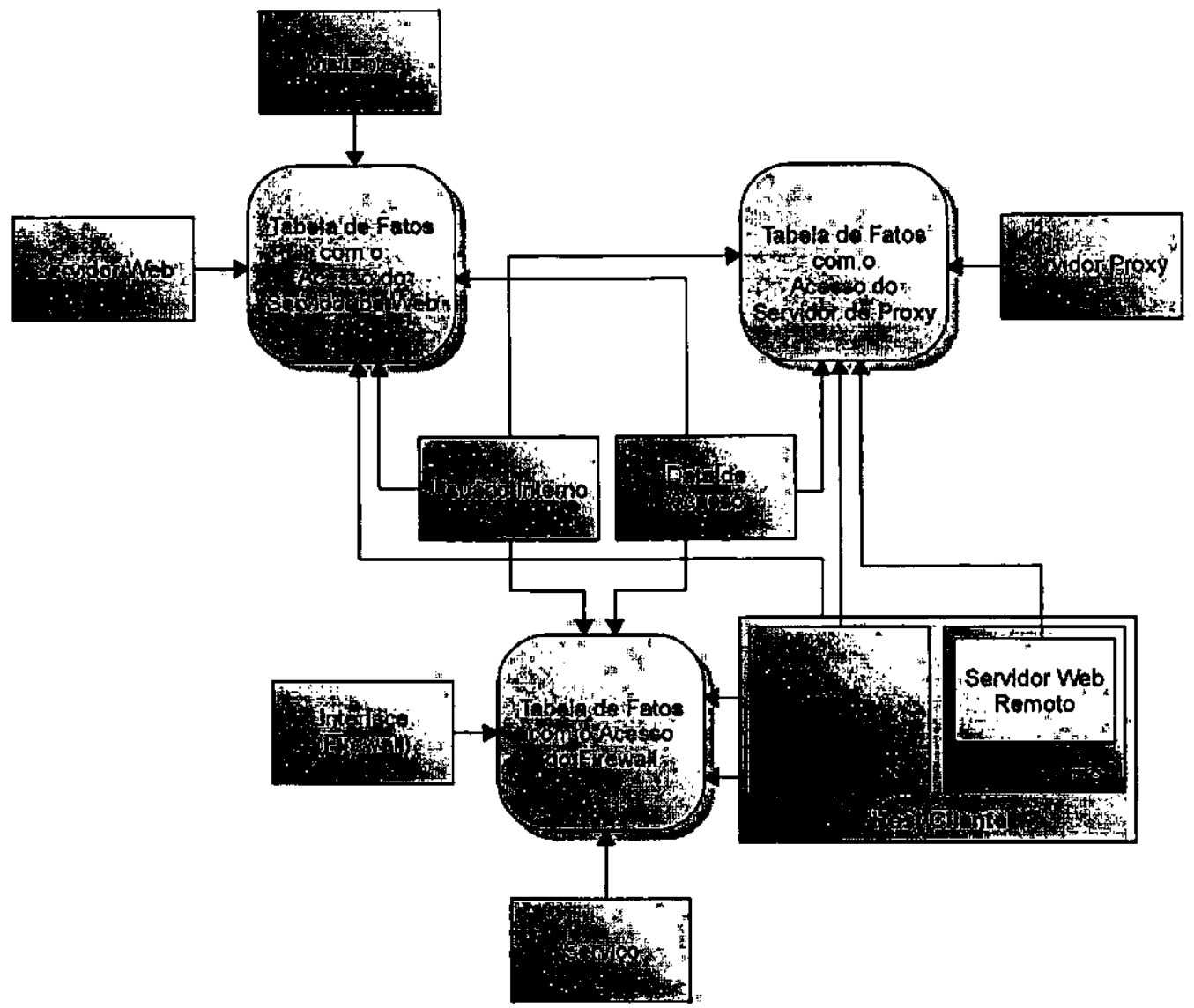

Figura 19 - Modelo Estrela do Sistema de Monitoramento

Todas as informações descritivas das entidades "Servidor de Web", "Servidor de Proxy", "Firewall", "Visitante", "Usuário Interno", "Data de Acesso", "Firewall" (com Interface) que estavam na modelagem operacional foram copiadas integralmente para as tabelas dimensionais correspondentes na modelagem Warehouse. Já as entidades como "Host Cliente", "Host Origem", "Host Destino" e "Servidor de Web Remoto" por possuírem caracteristicas muito semelhantes, foram modeladas como sendo uma única tabela dimensional denominada "Host Cliente" na modelagem Warehouse. Para diferenciar os hosts clientes que estão dentro da rede privada e os hosts externos a ela, foi acrescentado um campo "Localização" (Localization) para informar se o host é interno ou externo a Intranet (Ver Tabela 36). Foi necessário acrescentar também a tabela dimensional "Serviço" na modelagem Warehouse, para possibilitar pesquisas avançadas por tipos de serviços suportados pelo Firewall.

Neste trabalho, a modelagem das tabelas de fatos do Warehouse foi projetada em duas granulosidades:

- Granulosidade fina - com os dados referentes a cada acesso realizado nos Servidores Web, Proxy e Firewall. Os dados armazenados nesta granulosidade são 
semelhantes aos dados operacionais de tal maneira que năo haja perda de informaçăo. Ver Tabelas 32, 33, 34 no anexo IIl.

- Granulosidade grossa - com valores calculados e derivados a partir dos dados da granulosidade fina. Estes valores são resumidos em periodos de hora. Ver as tabelas 29, 30 e 31 do anexo III. 


\section{PROJETO DO DATA WAREHOUSE COM ORACLE 8.i}

Neste trabalho, para a construção do ambiente de Data Warehouse, foram escolhidos o Banco de Dados Relacional Oracle 8 Enterprise e suas ferramentas de gerenciamento e produtividade, desenvolvidos pela empresa Oracle Corporation.

A Oracle Corporation possui atualmente um pacote completo de aplicativos para a construção e gerenciamento de um Data Warehouse (Business Intelligence Tools), e que pode ser adquirido diretamente no site da empresa (http://technet.oracle.com) com licença de desenvolvedores de software. Dentre estes aplicativos podem-se citar:

- Oracle Enterprise Edition (EE) - é um banco de dados relacional (SGBD) da Oracle. Possuj suporte a aplicações OLTP, Warehouse e Multimidia. $O$ banco também possui uma linguagem procedural (PL/SQL) para a criaçăo de procedimentos, funçōes e gatilhos (triggers).

- Oracle Enterprise Manager (OEM) - é o aplicativo que permite gerenciar as bases de dados, esquemas, e os usuários do banco de dados. Possui interface gráfica para facilitar as configuraçōes e políticas de segurança; um agente que permite o controle de jobs e tarefas importantes para a manutenção do banco de dados.

- Oracle Data Mart Builder - é o gerenciador de esquemas de Datamart/Data Warehouse. Possibilita a criação e a modelagem de um ambiente Data Mart no banco de dados. Permite especificar as ferramentas de transferência e de transformação utilizadas para a modelagem. Possibilita também a criação de listas de usuários que possuem acesso ao Datamart.

- Oracle Data Mart Designer - aplicativo que permite projetar e modelar esquemas OLTP e Datamart no banco de Dados.

- Oracle Developer - possibilita a criação de aplicativos (com interface gráfica) que acessarăo o Datamart/ Data Warehouse.

- Oracle Reports - possibilita gerar relatórios em vídeo, impressora e páginas Web a partir de consultas realizadas.

- Oracle Express - possibilita gerenciar agentes que analisam, agregam e sumarizam dados contidos no DatamartIData Warehouse a partir de regras pré-estabelecidas. 
- Oracle Discover - permite ao usuário acessar e analisar dados contidos no Datamart/Data Warehouse. Pode ser considerado como uma ferramenta OLAP de consulta e visualização.

- Oracle Aplication Server (OAS) - é um servidor de Web, e possibilita o gerenciamento de páginas dinâmicas com acesso ao banco de dados Oracle, utilizando tanto scripts PLSQL e JScripts.

- Oracle Warehouse Builder (OWB) - possibilita a criação e a modelagem de esquemas de Datamart/Warehouse. Com o Oracle Data Mart Builder pode-se especificar quais são as funçōes de transferência e de transformação utilizadas na modelagem, porém não possui um agente para gerenciamento de segurança de usuários. Para isso, utiliza os recursos do Oracle Enterprise Manager para o gerenciamento de usuários e controle de jobs e tarefas. A interface do OWB é mais intuitiva e de melhor aprendizagem do que a do Oracle Data Mart Builder.

\subsection{Criação do Projeto de Data Warehouse}

Neste trabalho, o esquema Warehouse do sistema de monitoramento foi projetado com a ferramenta Oracle Warehouse Builder (OWB) da Oracle Corporation. A OWB é uma ferramenta escrita em linguagem Java que possibilita criar esquemas Warehouses, defirir quais são as bases com os dados operacionais, as operaçס̋es de mapeamento, transformação e transferência de dados para o Data Warehouse, conforme visto na Figura 20.

Para facilitar a criação do projeto de Data Warehouse com OWB, o trabalho foi divido em 3 fases:

1) Fase de Definição - nesta fase foram descritas grande parte das definiçőes formais do projeto como o esquema Warehouse do Projeto de Monitoramento, quais são as forites dos dados operacionais e a definição do mapeamento, transformação e as operações de transferência de dados.

2) Fase de Geração - nesta fase foram gerados scripts para a criação do Data Warehouse a partir das definiçōes formais descritas na fase anterior. É também nesta fase que são configurados e validados as funções e os scripts. Os seguintes itens foram realizados: 
3) Fase de Gerenciamento - nesta fase é definida a parte gerencial do Data Warehouse onde o Oracle Enterprise Manager é configurado para gerenciar os esquemas; controlar os Jobs de transferência, transformação e limpeza de dados.

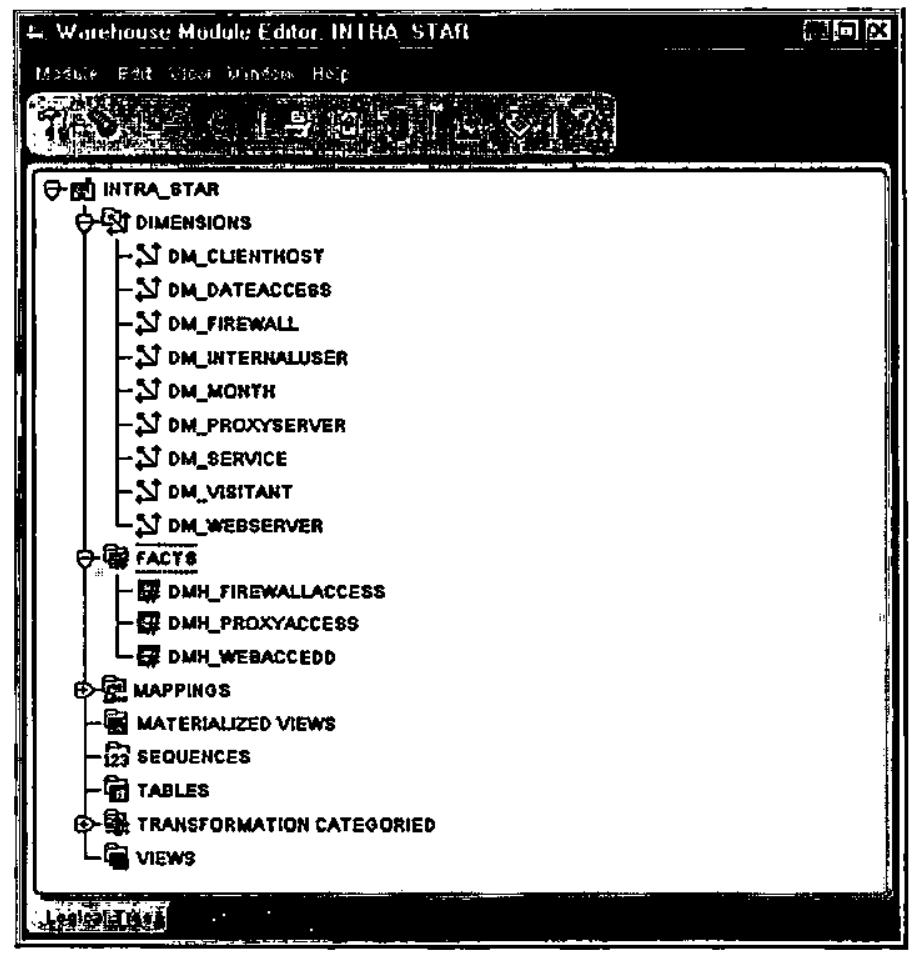

Figura 20 - Esquema Warehouse do Sistema de Monitoramento projetado com OWB

\subsubsection{Fase de Definição}

Nesta fase foram definidas e projetadas quais săo as tabelas dimensionais e as tabelas de fatos que irăo gerar o esquema Warehouse. Como foi visto no capítulo 3 , o sistema de monitoramento foi projetado em modelo estrela (Star Model) possuindo três tabelas de fatos para granulosidade grossa, mais três tabelas de fatos para a granulosidade fina (acesso do servidor de Web, acesso do servidor de Proxy e acesso do Firewalli) e nove tabelas dimensionais (Servidor Web, Servidor Proxy, Firewall, Data de Acesso, Hosts Clientes, Usuários Internos, Visitantes, Serviços de Firewall, Arquivos - utilizado somente na granulosidade fina)

É também nesta fase que são definidas quais são as fontes dos dados operacionais que alimentarão o Data Warehouse. No banco de dados Oracle 8.i as fontes podem ser oriundas de banco de dados relacionais, arquivos de texto formatados, ou projetos modelados com Oracle Designer. 
Neste trabalho, as fontes de dados podem ser de um banco de dados relacional contendo as tabelas operacionais com os dados descritivos dos servidores, hosts e usuários como definidas no capítulo anterior, e/ou os arquivos textuais de Logs dos servidores Web, Proxy e Firewall.

Antes que os dados do ambiente operacional possam ser transferidos para o ambiente Warehouse (Figura 21), há a necessidade que os dados sejam editados, limpos, transformados e integrados em um padrão coerente. Por isso, foi preciso criar várias tabelas intermediárias (áreas transitórias) para auxiliar a transformaçăo. Cada tabela possui uma fase de transformação ou limpeza de dados, e o relacionamento entre essas tabelas é denominado mapeamento.

As fases de transformaçăo e limpeza foram muito trabalhosas pela necessidade de realizar vários agrupamentos, somatória de valores numéricos, conversão de tipos de dados, 0 que consumiu aproximadamente 2 tabelas intermediárias para gerar uma tabela dimensional e 4 tabelas intermediárias para gerar uma tabela de fatos. Pode-se notar que as tabelas de fatos ocupam mais tabelas intermediárias do que as tabelas dimensionais na fase de transformaçăo por agruparem muitos valores calculados.

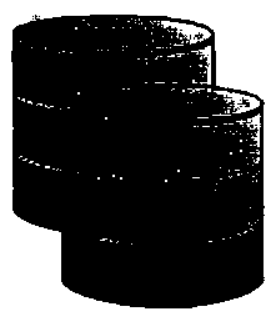

Dados Operacionais

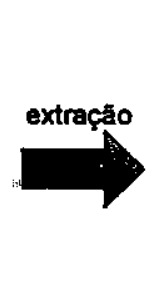

$$
\text { (As }
$$

는

lo anterior, o projeto de Data Warehouse possui 2 granulosidades distintas:

- Uma fina - onde as tabelas de fatos possuem valores não agrupados e não calculados, e que são semelhantes aos valores operacionais. A tabela dimensional de tempo é subdivida em unidade de segundos

- Uma grossa - onde as tabelas de fatos possuem valores dos acessos de Log calculados e agrupados por hora, o que despende várias tabelas intermediárias na fase de transformaçăo.

Neste projeto, uma chave primária warehouse é gerada pelo sistema no mapeamento da última tabela intermediária para a tabela dimensional. Dessa forma a tabela dimensional é utilizada com mais flexibilidade, além de ter uma chave primária com tamanho menor. 


\subsubsection{Fase de Geração}

Após a finalização da fase de definição, o projeto de Data Warehouse contém todas as definiçōes formalizadas do esquema Warehouse, as tabelas intermediárias e as funções de transformação.

A partir dessas formalizações, com o auxílio do Oracle Warehouse Builder, foram gerados scripts que possibilitam a criação do Data Warehouse físico. Os principais scripts são:

- Scripts DDL que possibilitaram a criação de um link entre o banco de dados Warehouse com 0 banco de dados operacional; e a criação das tabelas intermediárias, tabelas dimensionais e de fatos.

- Scripts com rotinas PUSQL para a extração dos dados, transformação, e transferências de dados do ambiente operacional para o Warehouse; e arquivos batchs contendo SQL"Loader para realizar a transferência dos dados dos arquivo de Logs de acesso (arquivo de texto) para uma tabela intermediária.

- Scripts TCL (Tool Command Language) para serem registrados no Oracle Enterprise Manager (OEM), onde seräo convertidos em Jobs que realizam automaticamente as tarefas de extraçăo, transformaçāo e transferência de dados.

\subsubsection{Fase de Gerenciamento}

Após o registro dos scripts TCL no Oracle Enterprise Manager, os Jobs contendo as tarefas de extração, transformação e transferência de dados são colocados no agerıdador de Jobs para que possam ser monitorados e gerenciados. Dependendo do horário e a data definidos no agendador de Jobs, os Jobs são então executados para permitir que dados operacionais (Logs de acessos e as informações dos Servidores Wev, Proxy, Firewall, hosts e dos usuários) sobre possam ser transferidos para dentro do Data Warehouse.

A partir do povoamento do Data Warehouse,

\subsection{Como alimentar o Data Warehouse}

Como foi verificado no capitulo anterior, os arquivos de Logs de Acessos dos servidores de Web, Proxy precisaram ser adaptados para o Formato Estendido de Logs para aumentar a quantidade de campos informativos sobre os acessos na Intranet. Porém, esses históricos de acessos são gravados diretamente em arquivos de texto, o que dificulta a manipulaçăo e 
recuperação dos dados, e há a necessidade da intervenção do Administrador para transferir o arquivo de Logs para o Data Warehouse.

A seguir são sugeridos dois métodos para a alimentação do Data Warehouse.

\subsubsection{Método de alimentação direta do Log para um banco de dados}

Os servidores de Web compativeis com o padrão NCSA possibilitam o armazenamento do arquivo de $\log$ em um canal de stream. Desta forma pode-se utilizar a saida do stream para realizar uma chamada de um comando externo ao servidor. Neste caso, será executado um programa cliente que possibilite acessar e escrever uma linha de comandos SQL em um banco de dados relaclonal.

Por exemplo, deseja-se armazenar os Logs de um servidor Apache em um banco de dados relacional como o PostgreSQL, as seguintes linhas deverão ser colocadas no arquivo de configuraçőes (httpd.conf) do servidor de web:

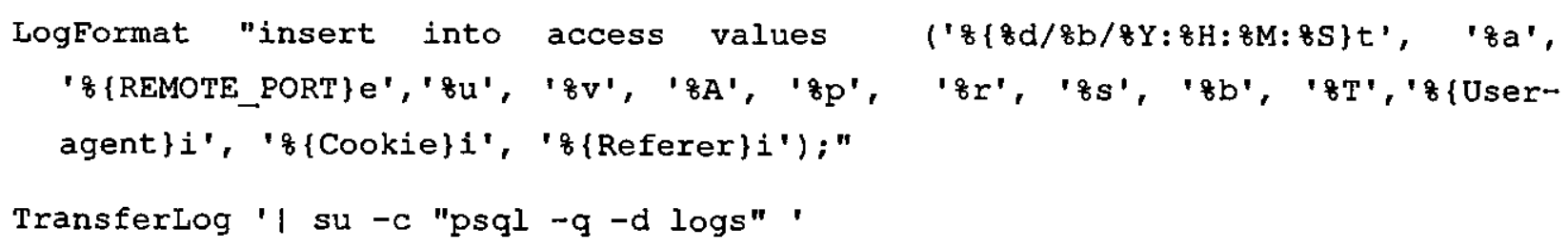

Pode-se notar que a primeira linha cria um formato de Log como sendo uma chamada de comando SQL e a segunda linha com a diretiva TransferLog irá transferir o formato de Log para um canal stream onde será executará o comando 'su -c "psql -q-d logs". O programa psql é o software cliente que irá acessar o database "logs" do banco de dados PostgreSQL.

Outros servidores Web, como o Internet Information Server, possibilitam gravar seus logs diretamente em um banco de dados através do ODBC (Open Database Conective). Neste caso não há necessidade de mudar muitas configurações no servidor Web, somente criar um DSN (Data Souce Name) para acessar o banco de dados desejado.

Este método é bem eficiente pois permite inserir todos os acessos dos servidores diretamente em um banco de dados para posterior manipulação e recuperação.

\subsubsection{Método de alimentação indireta do Log para um banco de dados}

Neste método, os logs de acesso ainda são armazenados como arquivos de textos, porém, é criado um arquivo de lote contendo comandos que possibilitem transferir os dados do arquivo de Log para o Banco de Dados. Para que não haja a necessidade da interferência do Administrador, esse arquivo de lote é colocado em um agendador de tarefas do sistema. 
Por exemplo, para transferir os dados de um arquivo de Log para o banco de dados Oracle o arquivo de lote deverá conter uma chamada ao comando SQL Loader. Além disso, o arquivo de lote deverá ser registrado no agendador de Jobs do Oracle Enterprise Manager para que realize essa tarefa periodicamente

Pode-se notar que este método é muito mais trabalhoso e lento que o método de alimentaçăo direta, porém é também eficiente. 


\section{CONCLUSÕES}

\subsection{Conclusões Finais}

Com o grande crescimento das informaçōes dentro de uma Intranet, torna-se diffcil para um Administrador de Web garantir o desempenho do tráfego de dados e o uso adequado da rede. $E$, além disso, na rede trafegam vários tipos de usuários que acessam uma diversidade de informaçőes, o que torna inviável a monitoraçăo manual.

Desta forma, este trabalho foi projetado com o objetivo de auxiliar o Administrador de Web no monitoramento do acesso da rede, através da análise do histórico de acesso (Logs) dos servidores $W e b$, Proxy e Firewall, das características dos hosts e servidores, e detalhes sobre os usuários que realizaram os acessos. Para suportar a gama de dados a serem armazenados e analisados é proposta a utilização da tecnologia de Data Warehouse para fornecer informações atualizadas e que possam servir de base para alguma conclusão.

Neste trabalho, foi verificado que fabricantes de servidores Web e Proxy trabalham com variados formatos de arquivos de $\log$, por isso, foi necessário padronizar as saidas dos históricos de acesso conforme o Formato Extendido de Logs (Anexo I) que mostrou-se bem abrangente com vários campos de dados para análise. Os Logs de Firewall, diferentes dos Logs dos Servidores de Web e Proxy, não seguem um formato ou padrão comum, por isso foi necessário criar um formato que fosse compativel com os Firewalls comerciais existentes.

Além da padronizaçăo dos formatos dos arquivos de Logs, foi verificada também a necessidade de modelar um ambiente operacional que possibilitasse relacionar os Logs de acessos com os respectivos servidores, os usuários e os hosts que geraram o acesso. A partir da modelagem do ambiente operacional, tornou-se fácil a modelagem do ambiente Warehouse onde as informaçōes descritivas dos servidores, usuários, hosts geraram as tabelas dimensionais, e os resumos dos históricos de acesso geraram as tabelas de fatos.

Com a modelagem do Data Warehouse, nota-se que o monitoramento da rede privada não se restringe somente na simples análise dos Logs de acesso, mas também a possibilidade de conhecer as características de acesso de cada usuário, o nível de utilização dos servidores Web, Proxy e do Firewall. 


\subsection{Trabalhos futuros}

A partir do trabalho realizado, constatou-se que existem outras atividades a serem realizadas para dar continuidade ao sistema de monitoramento, e que de certa forma, pode-se também expandir em outras direçőes.

A seguir, são citadas algumas áreas que podem ser estudadas em trabalhos futuros:

1) Necessidade da criação de módulo de relatório e gráfico que possibilitem a visualização dos dados armazenados no Data Warehouse.

2) Estudos de casos com o uso de Logs de acesso de servidores Web, Proxy e Firewall.

Estudo sobre o povoamento do Data Warehouse com histórico de acessos de diferentes Intranets;

Estudo sobre o monitoramento de visitantes em sites de Comércio Eletrônico e Portais.

3) Estudo do uso de Logs com atividades do protocolo SNMP (Simple Network Management Protocol) em roteadores, hosts, servidores Web, Proxy e Firewall.

Estudo sobre a expansão da modelagem do Data Warehouse para que possa trabalhar com valores advindos de atividades do protocolo SNMP em roteadores, hosts, servidores Web, Proxy e Firewall. 


\title{
ANEXO I - DEFINIÇÃO DE LOGS PARA SERVIDORES WEB E PROXIES
}

A maioria dos servidores Web oferecem a opçăo de armazenar arquivos de Logs ou em formato comum de Log (Common Log Format) ou em um formato proprietário (Hallam-Baker \& Behlendorf, 1996). O formato comum de $\log$ é um formato suportado pela maioria das ferramentas de análises existentes.

\section{Formato de Arquivo de Log Comum (Common Logfile Format)}

O formato do arquivo de Log comum possui os seguintes campos:

\author{
Host-remoto rfc931 autenticação-do-usuário [data] "requisição" status bytes \\ host-remoto Nome do host remoto (ou endereço IP, caso o servidor DNS năo estiver \\ disponivel) \\ RFC931 O logname remoto do usuário \\ autenticaçăo do usuário O nome do usuário que fez a solicitaçăo da requisiçăo \\ [date] \\ Data e o horário da requisiçăo \\ "request" \\ a linha da requisiçăo tal como ela é enviada pelo cliente. \\ status \\ $O$ código de status http retornado para o cliente. \\ bytes \\ $O$ tamanho do documento transferido em bytes
}

\section{Formato de Log Estendido}

Um arquivo de Log estendido contém uma sequência de linhas contendo caracteres ASCII terminados ou por LF (Line Feed) ou pelo par CR+LF (Car Return, Line Feed). Cada linha pode conter ou uma diretiva (directive) ou uma entrada (entry).

Uma entrada consiste de uma sequencia de registros relacionados a uma simples transação HTTP. Cada registro é separado um do outro por espaços em branco, e o uso de caracteres TAB para este propósito năo é recomendado. Se um dos campos năo é usado em uma entrada particular colocase entăo o caracter "-" no lugar do campo omitido.

As diretivas săo linhas iniciadas com o caracter \# e que guardam informaçōes sobre o processo do Log. A seguir săo mostradas as diretivas definidas pelo W3C:

Version: <inteiro>.<inteiro>

A versăo do arquivo de $\log$ estendido usado.

Fields: [ <especificaçőes>...]

Especifica quais săo os campos armazenados no Log

Software: string 
Identifica o software que gerou o Log

Start-Date: <data> <hora>

A data e a hora que o Log foi iniciado

End-Date: <data> <hora>

A data e a hora que o Log fol encerrado

Date: <data> <hora>

A data e a hora que uma entrada foi adicionada no Log

Remark: <text>

Comentários e informaçర̄es.

As diretivas Version e Fields sấo imprescindiveis e precedem todas as entradas de um arquivo Log. A diretiva Fields especifica os dados armazenados em cada registro de cada entrada.

Exemplo: Abaixo, é exemplificado um arquivo com o formato de Log estendido.

\#Version: 1.0

\#Date: 12-Jan-1996 00:00:00

\#Fields: time cs-method cs-uri

$00: 34: 23$ GET /foo/bar.html

12:21:16 GET /foo/bar.html

12:45:52 GET /foo/bar.html

12:57:34 GET /foo/bar.htm1

\section{Campos}

A diretiva \#Fields mostra uma sequência de campos com identificadores que especificam as informaçőes armazenadas em cada entrada. Os campos podem ter um dos seguintes formatos:

Identificador Identificador relata a transaçăo como um todo.

Prefixo-Identificador Identificador relata a informaçăo transferida entre as partes definidas pelo prefixo.

Prefixo(cabeçalho) Identificada o valor do cabeçalho do campo header para transferir entre as partes definidas pelo valor prefixo.

Os seguintes prefixos sắo definidos:

c - cliente

s - servidor

$r$ - remoto

cs - cliente para o servidor

sc - servidor para o cliente

sr - servidor para o servidor remoto (este prefixo é usado pelos Proxies) 
rs - servidor remoto para o servidor (este prefixo é usado pelos Proxies)

$x \quad$ - identificador especifico da aplicaçăo

$O$ identificador cs-method consequentemente se referencia ao método em a requisiçăo é feita pelo cliente para o servidor enquanto o sc(referer) referencia ao campo "referer:" de uma resposta. $O$ identificador c-ip referencia ao endereço IP do cliente.

\section{Identificadores}

Os

Os seguintes identificadores năo requerem um prefixo:

Date: Data em que a transaçăo é completada

Time: $\quad$ Hora em que a transaçăo é completada

Time-taken Tempo despendido para transaçăo ser completada em segundos

Bytes Bytes transferidos

Cached Registra se um cache hit ocorreu. $O$ valor 0 (zero) indica que houve um cache miss (não foi encontrado no cache).

Os seguintes identificadores requerem um prefixo:

IP

Endereço IP e a porta.

DNS Nome do DNS.

Status Código de Status.

Comment Comentério retornado com o Código de Status.

Method Método de acesso.

Uri URI

Uni-stem Porçăo principal do URI, omitindo-se a parte Query.

Uri-query Porçăo posterior ao sinal "?" do URI. 


\section{ANEXO II - CÓDIGOS DE STATUS HTTP}

Tabela 5 - Descriçăo dos Códigos de Status de HTTP

\begin{tabular}{|c|c|c|}
\hline Cód. & Status & Descrição \\
\hline $1 \times x$ & Informational: & 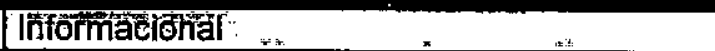 \\
\hline 100 & Continue & Continuar \\
\hline 101 & Switching Protocols & Mudança de protocolo \\
\hline $2 x x$ & Successfül. & Sucesșa \\
\hline 200 & $\overline{\mathrm{OK}}$ & OK \\
\hline 201 & Created & Criado \\
\hline 202 & Accepted & Aceito \\
\hline 203 & Non-Authoritative Information & Informaçăo sem necessidade de autorizaçăo \\
\hline 204 & No Content & Sem conteúdo \\
\hline 205 & Reset Content & Conteúdo resetado \\
\hline 206 & \begin{tabular}{|l} 
Partial Content \\
\end{tabular} & Conteúdo parcial \\
\hline $3 x x$ & Rêdirection & Redireçáo \\
\hline 300 & Multiple Choices & Múltiplas escolhas \\
\hline 301 & Moved Permanently & Movido Permanentemente \\
\hline 302 & Found & Encontrado \\
\hline 303 & See Other & Ver Outro \\
\hline 304 & Not Modified & Nâo Modificado \\
\hline 305 & Use Proxy & Uso do Proxy \\
\hline 306 & \begin{tabular}{|l} 
(Unused) \\
\end{tabular} & (Código náo utilizado) \\
\hline 307 & Temporary Redirect & Redirecionamento temporário \\
\hline $4 x x$ & Client"Errór $r^{4}$ & Erro:do Clieñte. \\
\hline 400 & Bad Request & Requisiçăo mal elaborada \\
\hline 401 & Unauthorized & Náo autorizado \\
\hline 402 & Payment Required & Requerido pagamento \\
\hline 403 & Forbidden & Acesso Proibido \\
\hline 404 & Not Found & Náo encontrado \\
\hline$\overline{405}$ & Metido Not Allowed & Método de acesso náo disponivel \\
\hline $40 \overline{6}$ & Not Acceptable & Náo aceitável \\
\hline 407 & Proxy Authentication Required & Requerida autenticaçăo do Proxy \\
\hline 408 & Request Timeout & Timeout da Requisiçăo \\
\hline 409 & Conflict & Conflito \\
\hline 410 & Gone & Perdido \\
\hline 411 & Length Required & Tamanho requerido \\
\hline 412 & Precondition Failed & Falha na Pré-condiçăo \\
\hline 413 & Request Entity Too Large & Requisiçăo da entidade muito longa \\
\hline$\overline{414}$ & Request-URI Too Long & URI requisitado muito longo \\
\hline 415 & Unsupported Media Type & Tipo de Midia não suportada \\
\hline 416 & Requested Range Not Satisfiable & Faixa requerida năo satisfeita \\
\hline 417 & Expectation Failed & Falha na expectativa \\
\hline $5 \dot{x} x^{2+4}$ & Senver Elror $_{2}$ & Errơ do Sévividor \\
\hline 500 & Intemal Server Error & Erro intemo no Servidor \\
\hline 501 & Not Implemented & Náo implementado \\
\hline 502 & Bad Gateway & Gateway Inválido \\
\hline 503 & Service Unavailable & Serviço náo disponivel \\
\hline 504 & Gateway Timeout & Timeout no Gateway \\
\hline 505 & HTTP Version Not Supported & Versáo do HTTP náo suportado \\
\hline
\end{tabular}




\section{ANEXO III - ESQUEMA DE DATA WAREHOUSE PARA CONTROLE E AVALIAÇÃO}

\section{Ambiente Operacional}

A seguir săo mostradas as estruturas ffsicas das tabelas operacionais do Sistema de Controle

Tabela 6 - Tabela Operacional com os Acessos ao Servidor Web (Log)

\begin{tabular}{|c|c|c|c|}
\hline Campo: & Tipot. & Tân & Destriçá \\
\hline Webserver_id & NUMBER & - & ID do Servidor Web \\
\hline Visitant_id & NUMBER & - & ID do Visitante \\
\hline date_access_id & NUMBER & - & ID da Data de Acesso \\
\hline Internal_user_id & NUMBER & - & ID do Usuário \\
\hline client_address & VARCHAR & 15 & Endereço do host cliente \\
\hline client_region & VARCHAR & 256 & Regiăo do host cliente \\
\hline user_agent & VARCHAR & 256 & Agente do navegador \\
\hline server_port & NUMBER & - & Porta acessada no host servidor \\
\hline Method_access & VARCHÁR & 10 & Método de Acesso (GET/POST/HEAD) \\
\hline Protocol_version & VARCHAR & 10 & Versão do Protocolo HTTP \\
\hline uri_stem & VARCHĀR & 512 & Corpo Principal do UR! \\
\hline uri_query & VARCHAR & 512 & Query do URI \\
\hline Directory & VAR̄CHAR & 512 & Díretório que se encontra do objeto \\
\hline Referrer & VARCHAR & 512 & URL que fez referéncia ao URL atual \\
\hline bytes_sent & NUMBER & - & Bytes enviados \\
\hline time_taken & NUMBER & - & Tempo Despendido \\
\hline http_status_id & NUMBER & - & ID do Status do HTTP \\
\hline
\end{tabular}

Tabela 7 - Tabela Operacional com os Acessos ao Servidor Proxy (Log)

\begin{tabular}{|c|c|c|c|}
\hline Campo & TIpo & Tâñ : & Déșcriçăo \\
\hline proxyserver id & NUMBER & - & ID do Servidor Proxy \\
\hline internal_user_id & NUMBER & - & ID do Usuário \\
\hline date_access_id & NUMBER & - & ID da Data de Acesso \\
\hline user_agent & VARCHAR & 256 & Agente do navegador \\
\hline authentiction_status & VARCHAR & 256 & Status da Autenticaçăo \\
\hline proxy_port & NUMBER & - & Porta utilizada no Servidor Proxy \\
\hline referring_server_address & NUMBER & - & Endereço do Servidor que faz Referencia \\
\hline method & VARCHAR & 10 & Método de Acesso \\
\hline protocol_name & VARCHAR & 10 & Nome do Protocolo utilizado \\
\hline bytes_sent & NUMBER & - & Bytes Enviados ao Host Destino \\
\hline bytes received & NUMBER & - & Bytes Recebidos do Host Destino \\
\hline time_taken & NUMBER & - & Tempo Despedido \\
\hline destination_name & VARCHAR & 256 & Nome do Host Destino \\
\hline destination_address & VARCHAR & 15 & Endereço IP do Host Destino \\
\hline destination_port & NUMBER & - & Porta do Host Destino \\
\hline object & VARCHAR & 512 & Objeto da solicitaçăo \\
\hline object_source & VARCHAR & 512 & Origem do Objeto \\
\hline code_result & VARCHAR & 10 & Código Resultado da solicitação \\
\hline
\end{tabular}


Tabela 8 - Tabela Operacional com os Acessos ao Firewall (Log)

\begin{tabular}{|l|l|l|l|}
\hline Campo & Tipó & \multicolumn{1}{l|}{} \\
\hline date_access_id & NUMBER & - & Descriçăo \\
\hline interface_id & NUMBER & - & ID da Data de Acesso \\
\hline user_id & NUMBER & - & ID da Interface do Firewall \\
\hline source & VARCHAR & 15 & Endereço IP da Origem do Acesso \\
\hline destination & VARCHAR & 15 & Endereço IP do Destino \\
\hline action_id & NUMBER & - & ID da Açăo \\
\hline protocol_id & NUMBER & - & ID do Protocolo \\
\hline Service_id & NUMBER & - & ID do Serviço \\
\hline rule_id & NUMBER & - & ID da Regra \\
\hline Action_type_id & NUMBER & - & ID do tipo da Açăo \\
\hline Server_port & NUMBER & - & Porta do Servidor \\
\hline bytes transfered & NUMBER & - & Bytes transferidos \\
\hline destination_key_identify & VARCHAR & 512 & Chave Secreta do Destinatário \\
\hline source_key_identify & VARCHAR & 512 & Chave Secreta da Origem \\
\hline
\end{tabular}

Tabela 9 - Tabela Operacional com as caracter!sticas do Servidor Web

\begin{tabular}{|c|c|c|c|}
\hline Campo & Tipo & Tam & Déscriçăo \\
\hline Webserver id & NUMBER & - & ID do Servidor Web \\
\hline Webserver_address & VARCHAR & 15 & Endereço do Servidor $W e b$ \\
\hline Gateway & VARCHAR & 15 & Gateway \\
\hline Submask & VARCHAR & 15 & Máscara da Sub-rede \\
\hline Server_name & VARCHAR & 256 & Nome do Servidor \\
\hline Description & VARCHAR & 512 & Descriçăo \\
\hline Operation_system & VARCHAR & 256 & Sistema Operacional \\
\hline Amount_of_processors & NUMBER & - & Quantidade de Processadores (Unitário) \\
\hline Processor & VARCHAR & 256 & Modelo do Processador \\
\hline clock_of processor & NUMBER & - & Clock do Processador (MHz) \\
\hline Amount_of_memories & NUMBER & - & Quantidade de Memória RAM (Mb) \\
\hline Network adapter & VARCHĀR & 256 & Modelo do Adaptador de Rede \\
\hline speed_of_network_adapter & NUMBER & - & Velocidade do Adaptador de Rede (bits/s) \\
\hline
\end{tabular}

Tabela 10 - Tabela Operacional com as caracteristicas do Servidor Proxy

\begin{tabular}{|c|c|c|c|}
\hline Gampo & $\pi p_{0}$ & Tam & Déscriçăo: \\
\hline Proxyserver_id & NUMBER & - & ID do Servidor Proxy \\
\hline Proxyserver_address & VARCHAR & 15 & Endereço do Servidor Proxy \\
\hline Gateway & VARCHAR & 15 & Gateway \\
\hline Submask & VARCHAR & 15 & Máscara da Sub-rede \\
\hline server_name & VARCHAR & 256 & Nome do Servidor \\
\hline description & VARCHAR & 512 & Descriçăo \\
\hline operation_system & VARCHAR & 256 & Sistema Operacional \\
\hline amount_of_processors & NUMBER & 1- & Quantidade de Processadores (Unitário) \\
\hline processor & VARCHAR & 256 & Modelo do Processador \\
\hline clock_of_processor & NUMBER & - & Clock do Processador (MHz) \\
\hline amount_of_memories & NUMBER & - & Quantidade de Memória RAM (Mb) \\
\hline network_adapter & VARCHAR & 256 & Modelo do Adaptador de Rede \\
\hline speed_of_network_adapter & NUMBER & - & Velocidade do Adaptador de Rede (bits/s) \\
\hline
\end{tabular}


Tabela 11 - Tabela Operacional com as características do Visitante que acessa o Servidor Web

\begin{tabular}{|c|c|c|c|}
\hline \multicolumn{4}{|l|}{ HA MA } \\
\hline Gaimpo: & 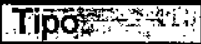 & Tann & Bescrica \\
\hline visitant_id & NUMBER & - & ID do Visitante \\
\hline date_of_first_visit & DATE & - & Data da Primeira Visita \\
\hline e-mail & VARCHAR & 256 & E-mail \\
\hline first name & VARCHAR & 50 & Primeiro Nome \\
\hline middle_name & VARCHAR & 50 & Nome do Meio \\
\hline last_name & VARCHAR & 50 & Sobrenome \\
\hline $\operatorname{sex}$ & CHAR & 1 & Sexo (M/F) \\
\hline blithday & DATE & - & Data de nascimento \\
\hline address & VARCHAR & 256 & Endereço \\
\hline Complement & VARCHAR & 256 & Complemento \\
\hline telephone & VARCHAR & 20 & \begin{tabular}{|l} 
Telefone \\
\end{tabular} \\
\hline city & VARCHAR & 256 & Cidade (Município) \\
\hline state & VARCHAR & 256 & Estado (UF) \\
\hline zip & VARCHAR & 10 & CEP \\
\hline Region & VARCHAR & 2 & Regiăo do País (S, SE, NE, CO, N) \\
\hline country & VARCHAR & 256 & País \\
\hline
\end{tabular}

Tabela 12 - Tabela Operacional com as descriçరees do Status do HTTP

\begin{tabular}{|c|c|c|c|}
\hline $\begin{array}{l}\text { TB He } \\
\text { Campo. }\end{array}$ & Tipo: & Täm & Dëscriçá. \\
\hline http status id & NUMBER & - & ID do Status do HTTP \\
\hline description & VARCHAR & 512 & Descriçáo \\
\hline
\end{tabular}

Tabela 13 - Tabela Operacional com os possiveis Códigos Resultantes do Acesso do Proxy

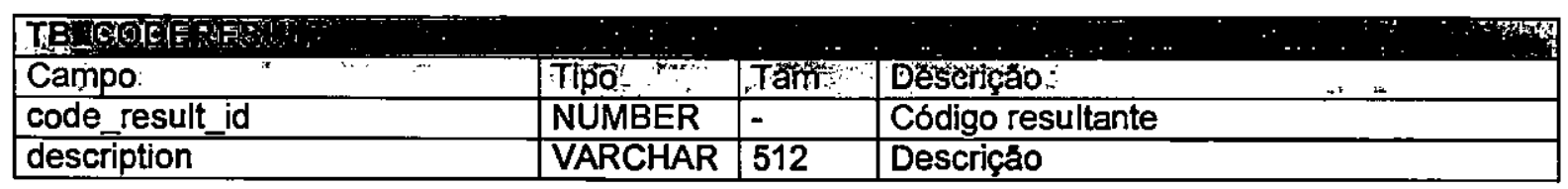

Tabela 14 - Tabela Operacional do com as descriçōes do Usuário da Intranet

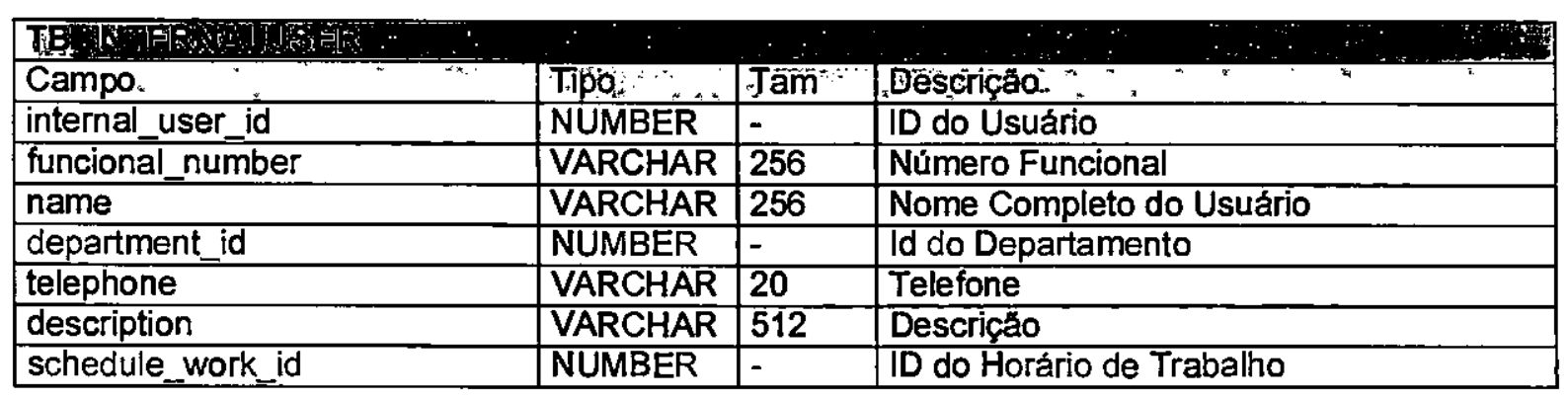


Tabela 15 - Tabela Operacional com as descriçóes do Departamento

\begin{tabular}{|l|l|l|l|}
\hline Campo & \multicolumn{1}{|l|}{} \\
\hline department_d & NUMBER & - & ID do Departamento \\
\hline department_code & VARCHAR & 20 & Codigo do Departamento \\
\hline department_name & VARCHAR & 256 & Nome do Departamento \\
\hline description & VARCHAR & 512 & Descriçăo \\
\hline
\end{tabular}

Tabela 16 - Tabela Operacional com as características do Host Cliente

\begin{tabular}{|c|c|c|c|}
\hline 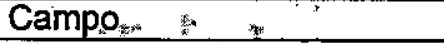 & $T i \beta \delta_{n-1}^{*}$ & Tain & Déscriçá \\
\hline client_host_id & NUMBER & - & ID do Host Cliente \\
\hline host_address & VARCHAR & 15 & Endereço IP do host \\
\hline host_name & VARCHAR & 256 & Nome do host \\
\hline submask & VARCHAR & 15 & Máscara da Rede \\
\hline gateway & VARCHAR & 15 & Gateway \\
\hline location & VARCHAR & 1 & Localizaçăo (Interno/Externo) \\
\hline description & VARCHAR & 512 & Descriçăo \\
\hline operation_system & VARCHAR & 256 & Sistema Operacional \\
\hline amount_of_processors & NUMBER & - & Quantidade de Processadores (Unitário) \\
\hline processor & VARCHAR & 256 & Modelo do Processador \\
\hline clock_of_processor & NUMBER & - & Clock do Processador (MHz) \\
\hline amount_of_memories & NUMBER & - & Quantidade de Memória RAM (Mb) \\
\hline network_adapter & VARCHAR & 256 & Modelo do Adaptador de Rede \\
\hline speed_of_network_adapter & NUMBER & - & Velocidade do Adaptador de Rede (bits/s) \\
\hline department_id & NUMBER & - & ID do departamento \\
\hline
\end{tabular}

Tabela 17 - Tabela Operacional com os Horários de Trabalho do Usuário

\begin{tabular}{|c|c|c|c|}
\hline Campo & Tipo: & Tam & Dêscriçắo \\
\hline schedule_work_id & NUMBER & - & ID do Horário de Trabalho \\
\hline description & VAR $\bar{R}$ HAR & 512 & Descriçăo \\
\hline from_weekday & NUMBER & - & Dia da Semana Inicial(1-7) \\
\hline to_weekday & \begin{tabular}{|l} 
NUMBER \\
\end{tabular} & & Dia da Semana Final (1-7) \\
\hline from_time & NUMBER & - & Hora Inicial \\
\hline to_time & NUMBER & - & Hora Final \\
\hline
\end{tabular}

Tabela 18 - Tabela Operaclonal com as Permissరes de Uso dos Hosts Clientes

\begin{tabular}{|c|c|c|c|}
\hline Campo. & Tipo & Tiân & Déscriçăo \\
\hline Internal_user_id & NUMBER & - & Usuário \\
\hline Client_host_id & NUMBER & |- & Host \\
\hline Description & VARCHAR & 512 & Descrição \\
\hline From_weekday & NUMBER & - & Dia da Semana Inicial(1-7) \\
\hline to_weekday & NUMBER & - & Dia da Semana Final (1-7) \\
\hline From_time & NUMBER & - & Hora Inicial \\
\hline to_time & NUMBER & - & Hora Final \\
\hline
\end{tabular}


Tabela 19 - Tabela Operacional com as características do Firewall

\begin{tabular}{|l|l|l|l|}
\hline Calmpo & \multicolumn{1}{|l|}{} \\
\hline firewall_id & NUMBER & - & DEscre \\
\hline firewall_name & VARCHAR & 256 & Nome do Firewall \\
\hline description & VARCHAR & 512 & Descriçăo \\
\hline operation_system & VARCHAR & 256 & Sistema Operacional \\
\hline processor & VARCHAR & 256 & Modelo do Processador \\
\hline clock_of_processor & NUMBER & - & Clock do Processador (MHz) \\
\hline amount_of_processors & NUMBER & - & Quantidade de Processadores \\
\hline amount_of_memories & NUMBER & - & Quantidade de Memória RAM (Mb) \\
\hline
\end{tabular}

Tabela 20 - Tabela Operacional com as características da Interface do Firewall

\begin{tabular}{|c|c|c|c|}
\hline Campo. & Tipo & Tàm & Descriçăo \\
\hline interface_id & NUMBER & - & ID da Interface \\
\hline firewall id & NUMBER & - & ID do Firewall \\
\hline phisical_device_name & VARCHAR & 20 & Nome do Dispositivo Fisico \\
\hline interface name & VARCHAR & 256 & Nome da Interface \\
\hline Interface_address & VARCHAR & 15 & Endereço IP da Interface \\
\hline submask & VARCHAR & 15 & Máscara de Rede \\
\hline gateway & VARCHAR & 15 & Gateway \\
\hline description & VARCHAR & 512 & Descriçăo \\
\hline speed of interface & NUMBER & - & Velocidade da Interface (bits/s) \\
\hline
\end{tabular}

Tabela 21 - Tabela Operacional com as possiveis tipos de açðes do Firewall

\begin{tabular}{|c|c|c|c|}
\hline \multicolumn{4}{|c|}{ 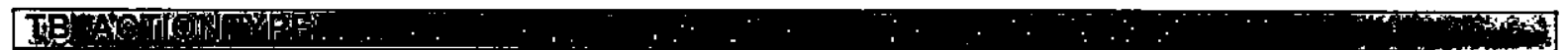 } \\
\hline Campo & Tipo & Tam & Descriçăo: \\
\hline Action type id & NUMBER & - & Tipo da Ação \\
\hline description & VARCHAR & 512 & Descriçăo \\
\hline
\end{tabular}

Tabela 22 - Tabela Operacional com as possiveis açőes realizadas pelo Firewall

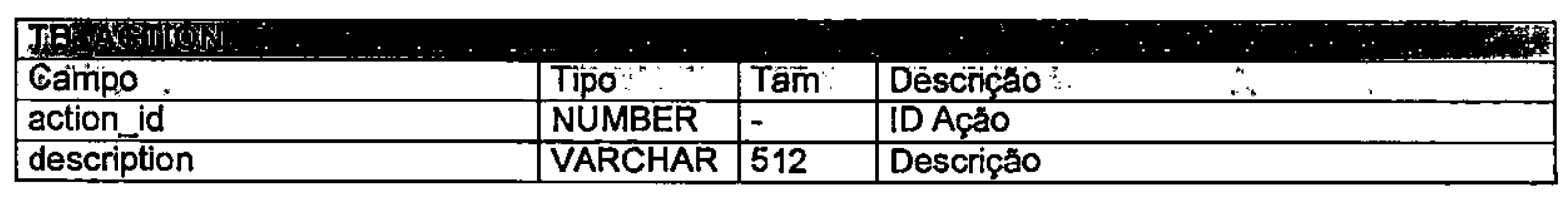

Tabela 23 - Tabela Operacional com os protocolos suportados pelo Firewall

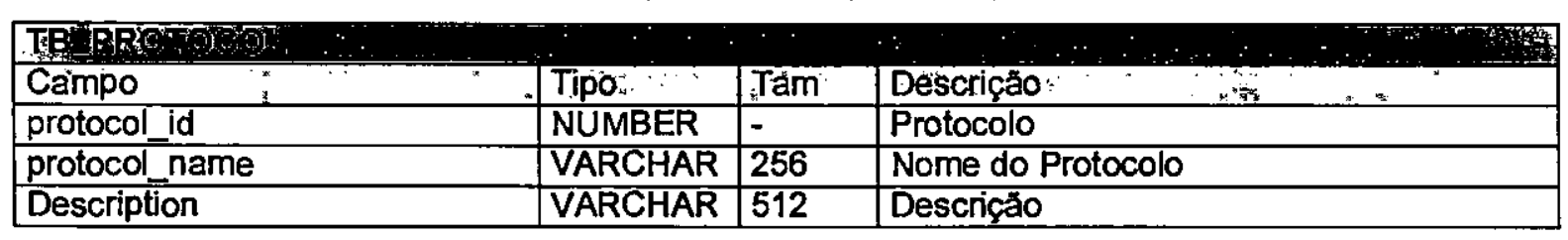


Tabela 24 - Tabela Operacional com os serviços suportados pelo Firewall

\begin{tabular}{|c|c|c|c|}
\hline Campo & TTpo & Tân: & Déscriçáo \\
\hline Service id & NUMBER & - & ID Serviço \\
\hline Description & VARCHAR & 512 & Descriçăo \\
\hline Protocol_id & NUMBER & - & ID Protocolo \\
\hline Main_port & NUMBER & - & Porta principal do Serviço (Listener) \\
\hline Source_port from & NUMBER & - & Porta Iricial \\
\hline Source_port to & NUMBER & - & Porta Final \\
\hline
\end{tabular}

Tabela 25 - Tabela Operacional com os horários de acesso permitido ao Firewall

\begin{tabular}{|c|c|c|c|}
\hline Campo & & & \\
\hline Time permission id & & & \\
\hline & & - & ID do Horario Permitido \\
\hline Time_permission name & VARCHAR & 256 & Nome do Horário \\
\hline Description & VARCHAR & 512 & Descrição \\
\hline From weekday & NUMBER & - & Dia da semana inicial \\
\hline to_weekday & NUMBER & - & Dia da semana final \\
\hline From_time & NUMBER & - & Horário Inicial \\
\hline to_time & NUMBER & - & Horário Final \\
\hline
\end{tabular}

Tabela 26 - Tabela Operacional com as possiveis causas de açōes do Firewall

\begin{tabular}{|c|c|c|c|}
\hline Campo & Tipo: & Täm & Déscrięăón \\
\hline rule_id & NUMBER & - & ID da Regra \\
\hline description & VARCHAR & 512 & Descricăo \\
\hline newtork_client & NUMBER & - & ID da Rede cliente \\
\hline network_server & NUMBER & - & ID da Rede servidora \\
\hline action id & NUMBER & - & ID da Ação \\
\hline time_permission_id & NUMBER & - & ID do horário de permissăo \\
\hline service_id & NUMBER & - & ID do serviço \\
\hline Track & NUMBER & - & \\
\hline
\end{tabular}

Tabela 27 - Tabela Operacional com Grupos de Subredes com acesso ao Firewall

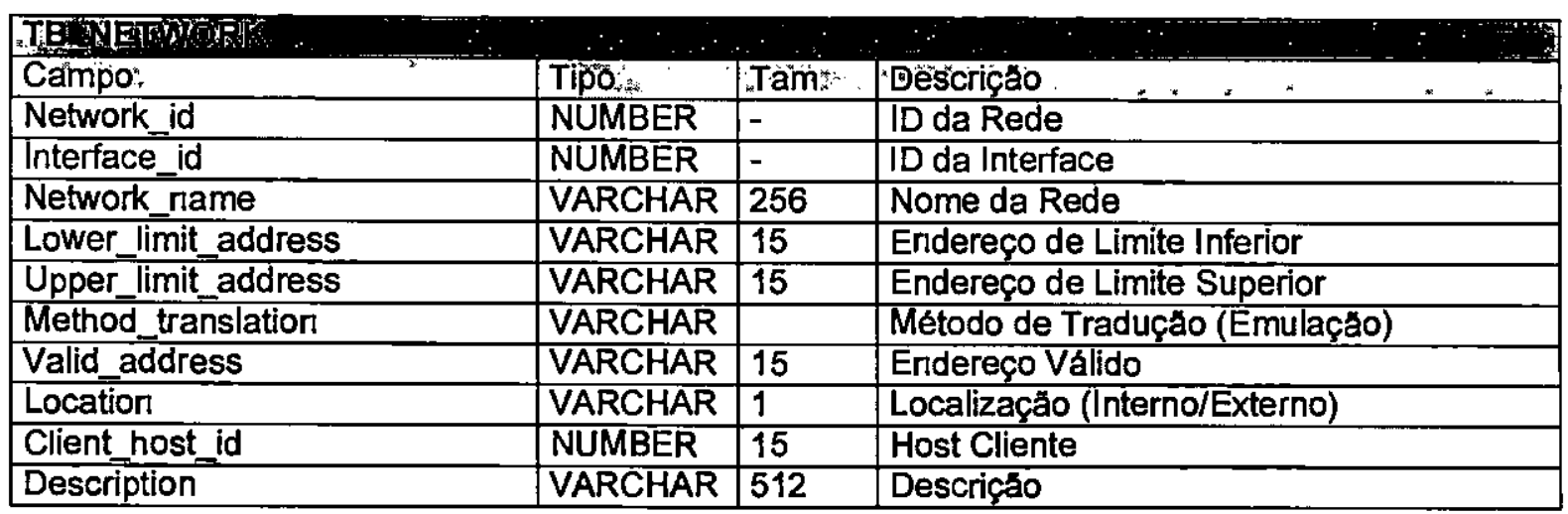


Tabela 28 - Tabela Operacional com as Datas de Acessos

\begin{tabular}{|c|c|c|c|}
\hline Campo & Tipo: & Tran & Descricăo: \\
\hline Date_access_id & NUMBER & - & Data de Acesso \\
\hline description & VARCHAR & 512 & Descriçăo \\
\hline dateaccess & DATE & - & Data \\
\hline year & NUMBER & - & Ano \\
\hline quarter & NUMBER & - & Trimestre \\
\hline month & NUMBER & - & Més \\
\hline weekday & NUMBER & - & Dia da Semana \\
\hline day & \begin{tabular}{|l|} 
NUMBER \\
\end{tabular} & - & Dia do Més \\
\hline hour & \begin{tabular}{|l} 
NUMBER \\
\end{tabular} & - & Hora \\
\hline
\end{tabular}

\section{Ambiente Warehouse}

Neste trabalho, as tabelas de fatos de granulosidade grossa são caracterizadas com o uso do prefixo DMH (Datamart High). Enquanto as tabelas de Fatos de Granulosidade Fina possuem o prefixo DML (Datamart Low). As tabelas dimensionais são representadas somente com o prefixo DM.

\section{Tabelas de Fatos de Granulosidade Grossa}

Tabela 29 - Tabela de Fatos sobre os acessos realizados ao Servidor Web

\begin{tabular}{|c|c|c|c|}
\hline & & & \\
\hline Campo & Tipó & Fämón" & Descriçắn' \\
\hline date_acess_id & NUMBER & - & ID da Data de Acesso \\
\hline server id & NUMBER & - & ID do Servidor \\
\hline visitant_id & NUMBER & - & ID do Visitante \\
\hline internal_user_id & NUMBER & - & ID do Usuário Interno \\
\hline Client region & NUMBER & - & \begin{tabular}{|l} 
Regiăo do Cliente \\
\end{tabular} \\
\hline Total_bytes_sent & NUMBER & - & Total de bytes enviados \\
\hline Total_bytes_received & NUMBER & - & Total de bytes recebidos \\
\hline Total_page_view & NUMBER & - & Total de Páginas Visualizadas \\
\hline Total_Image_view & NUMBER & - & Total de Imagens Visualizadas \\
\hline Total_resource_view & NUMBER & - & Total de Recursos Visualizados \\
\hline Total_client_page_error & NUMBER & - & Total de Páginas com erro no Cliente \\
\hline Total_client_image_error & NUMBER & - & Total de Imagens com erro no Cliente \\
\hline Total_client_resource_error & NUMBER & - & Total de Recursos com erro no Cliente \\
\hline Total_server_page_error & NUMBER & - & Total de Páginas com erro no Servidor \\
\hline Total_server_image_error & NUMBER & - & Total de Imagens com erro no Servidor \\
\hline Total_server_resource_error & NUMBER & - & Total de Recursos com erro no Servidor \\
\hline Total_time_taken & NUMBER & - & Total de Tempo Despendido \\
\hline Total_time_access & NUMBER & - & Total de Tempo de Acesso (UA-PA) \\
\hline Total_ssl_connection & NUMBER & - & Total de Conexס̋es Seguras (SSL) \\
\hline Size_of the_biggest_page & NUMBER & - & Tamanho da major Página \\
\hline Size_of_the_biggest_image & NUMBER & - & Tamanho da maior Imagem \\
\hline Size_of the_biggest_resourc & NUMBER & - - & inho do maior Recurso \\
\hline
\end{tabular}


Tabela 30 - Tabela de Fatos sobre os acessos realizados ao Servidor Proxy

\begin{tabular}{|c|c|c|c|}
\hline Campo & Tipo: & Tain & Déscriçăo: \\
\hline date_access_id & NUMBER & - & ID da Data de Acesso \\
\hline Server_id & NUMBER & - & ID do Servidor \\
\hline Internal_user_id & NUMBER & - & ID do Usuário \\
\hline Department_id & NUMBER & - & ID do Departamento \\
\hline Destination_id & NUMBER & - & ID do Destino \\
\hline total_bytes_sent & NUMBER & - & Total de Bytes enviados \\
\hline total bytes received & NUMBER & - & Total de Bytes recebidos \\
\hline total_time_taken & NUMBER & - & Total do tempo despendido \\
\hline Total time_access & NUMBER & $=$ & Total de tempo de acesso (UA-PA) \\
\hline Total_page_view & NUMBER & - & Páginas vistas \\
\hline Total_Image_view & NUMBER & - & Imagens vistas \\
\hline Total_Resource_view & NUMBER & - & Recursos vistos \\
\hline Total_client_page_error & NUMBER & - & Total de Páginas com erro no Cliente \\
\hline Total_client_image_error & NUMBER & - & Total de Imagens com erro no Cliente \\
\hline Total_client_resource_error & NUMBER & - & Total de Recursos com erro no Cliente \\
\hline Total_server_page_error & NUMBER & - & Total de Páginas com erro no Servidor \\
\hline Total_server_image_error & NUMBER & - & Total de Imagens com erro no Servidor \\
\hline Total_server_resource_error & NUMBER & - & Total de Recursos com erro no Servidor \\
\hline Total_page_cache & NUMBER & - & Total de Páginas acessadas no cache \\
\hline Total_Image_cache & NUMBER & - & Total de Imagens acessadas no cache \\
\hline Total_Resource_cache & NUMBER & - & Total de Recursos acessados no cache \\
\hline size_of the_biggest_page & NUMBER & - & Tamanho da major Página \\
\hline size_of the biggest image & NUMBER & - & Tamanho da maior Imagem \\
\hline size_of the biggest resource & NUMBER & - & Tamanho do maior Recurso \\
\hline
\end{tabular}

Tabela 31 - Tabela de Fatos sobre os acessos realizados ao Firewall

\begin{tabular}{|c|c|c|c|}
\hline \multicolumn{4}{|l|}{ Dif } \\
\hline Campo & Tipos? & Tamin & Descriçáo \\
\hline date_access_id & NUMBER & - & ID da Data de Acesso \\
\hline firewall id & NUMBER & - & ID do Firewall \\
\hline internal_user_id & NUMBER & - & ID do Usuário \\
\hline department_id & NUMBER & - & ID do Departamento \\
\hline source id & NUMBER & - & ID da Origem \\
\hline destination_id & NUMBER & - & ID do Destino \\
\hline service id & NUMBER & - & ID do Serviço \\
\hline Total_bytes_sent & NUMBER & - & Bytes enviados \\
\hline Total_bytes_received & NUMBER & - & Bytes recebidos \\
\hline Total_time_access & NUMBER & - & Total de Tempo de Acesso (UA-PA) \\
\hline Total accept connection & NUMBER & - & Total de Conexões Aceitas \\
\hline Total reject_connection & NUMBER & - & Total de Conexóes Rejeitadas \\
\hline Total_alet_event & NUMBER & - & Total de Eventos de Alerta \\
\hline Total_control_event & NUMBER & - & Total de Eventos de Controle \\
\hline Total_sucessful_authentication & NUMBER & - & Total de Sucessos de Autenticaçáo \\
\hline Total_failed_authentication & NUMBER & - & Total de Falhas de Autenticaçăo \\
\hline
\end{tabular}


Tabelas de Fatos de Granulosidade Fina

Tabela 32 - Tabela de Fatos sobre os acessos realizados ao Servidor Web

\begin{tabular}{|l|l|l|l|}
\hline Gampo & \multicolumn{1}{|l|}{} \\
\hline Date_access_id & NUMBER & - & ID da Data de Acesso \\
\hline Webserver_id & NUMBER & - & ID do Servidor de Web \\
\hline Visitant_id & NUMBER & - & ID do Visitante \\
\hline Client_host_id & NUMBER & - & ID do Host Cliente \\
\hline Internal_user_id & NUMBER & - & ID do Usuário \\
\hline File_id & NUMBER & - & ID do Arquivo \\
\hline User_agent & VARCHAR & 256 & Agente do Usuário \\
\hline Server_port & NUMBER & - & Porta conectada no Servidor Web \\
\hline Method_access & VARCHAR & 256 & Método de Acesso \\
\hline Uri_query & VARCHAR & 512 & URI Query \\
\hline Referrer & VARCHAR & 512 & URI que fez referência ao URI atual \\
\hline Bytes_sent & NUMBER & - & Bytes enviados \\
\hline Tirne_taken & NUMBER & - & Ternpo despendido \\
\hline http_status & NUMBER & - & Status do Protocolo HTTP \\
\hline
\end{tabular}

Tabela 33 - Tabela de Fatos sobre os acessos realizados ao Servidor Proxy

\begin{tabular}{|c|c|c|c|}
\hline Gampo & Tipo & Tami & Deschón: \\
\hline Date_access_id & NUMBER & - & ID da Data de Acesso \\
\hline Proxyserver id & NUMBER & - & ID do Servidor Proxy \\
\hline Internal_user id & NUMBER & - & ID do Usuário \\
\hline Source host & NUMBER & - & ID do Host Origem (Computador Cliente) \\
\hline Destination_host & NUMBER & - & ID do Host Destino (Servidor Web) \\
\hline Object & VARCHAR & 512 & Objeto \\
\hline Object type & VARCHAR & 10 & Tipo do Objeto \\
\hline Object_source & VARCHAR & 10 & Fonte do Objeto (Cache, Internet) \\
\hline User_agent & VARCHAR & 256 & Agente de Usuário \\
\hline Authentication_status & VARCHAR & 256 & Status da Autenticaçăo \\
\hline Proxy_port & NUMBER & - & Porta conectada no Servidor Proxy \\
\hline Method_access & VARCHAR & 256 & Método de Acesso \\
\hline Protocol name & VARCHAR & 256 & Norne do Protocolo \\
\hline Bytes_sent & NUMBER & - & Bytes Enviados \\
\hline Bytes_received & NUMBER & - & Bytes Recebidos \\
\hline Time_taken & NUMBER & - & Ternpo despendido \\
\hline Destination_port & NUMBER & - & Porta conectada no Host Destino \\
\hline
\end{tabular}


Tabela 34 - Tabela de Fatos sobre os acessos realizados ao Firewall

\begin{tabular}{|c|c|c|c|}
\hline Cătripón... & T & Mration, & Deserichob \\
\hline Date_access_id & NUMBER & - & ID da Data de Acesso \\
\hline Firewall_id & NUMBER & - & ID do Firewall \\
\hline Internal user id & NUMBER & - & ID do Usuário \\
\hline Service_id & NUMBER & - & ID do Serviço \\
\hline Source hot & NUMBER & - & ID do Host Origem \\
\hline Destination host & NUMBER & - & ID do Host Destino \\
\hline Server_port & NUMBER & - & Porta conectada no Servidor \\
\hline Bytes_sent & NUMBER & - & Bytes enviados \\
\hline Bytes_received & NUMBER & - & Bytes recebidos \\
\hline Action & VARCHAR & 256 & Açšo Realizada \\
\hline Rule & VARCHAR & 256 & Regra Utilizada \\
\hline Action_type & VARCHAR & 256 & Tipo da Açăo \\
\hline
\end{tabular}

\section{Tabelas Dimensionais}

Tabela 35 - Tabela Dimensional com os horários de acesso

\begin{tabular}{|c|c|c|c|}
\hline Campo & Tipo & Tam & Descriça: \\
\hline Date_access_id & NUMBER & $=$ & ID da Data de Acesso \\
\hline Date_access & DATE & - & Data de Acesso \\
\hline Description & VARCHAR & 512 & Descriçăo da Data de Acesso \\
\hline Year & NUMBER & - & Ano \\
\hline Quarter & NUMBER & - & \begin{tabular}{|l} 
Trimestre \\
\end{tabular} \\
\hline Month & NUMBER & - & Mes \\
\hline Weekday & NUMBER & - & Dia da semana \\
\hline Day & NUMBER & - & Dia \\
\hline hour & NUMBER & - & Hora \\
\hline
\end{tabular}

Tabela 36 - Tabela Dimensional com as caracteristicas dos Hosts

\begin{tabular}{|c|c|c|c|}
\hline Càmpo & Tipó & Tâm & Descriơa \\
\hline Client_host_id & NUMBER & - & ID do Host Cliente \\
\hline Host address & VARCHAR & 15 & Endereco IP do host \\
\hline Host_name & VARCHAR & 256 & Nome do host \\
\hline Submask & VARCHAR & 15 & Máscara da Rede \\
\hline Gateway & VARCHAR & 15 & Gateway \\
\hline Type_host & VARCHAR & 1 & Host Intemo/Host Externo (l/E) \\
\hline location & VARCHAR & 1 & Localizaçăo (Departamento/Site) \\
\hline description & VARCHAR & 512 & Descriçăo \\
\hline operation_system & VARCHAR & 256 & Sistema Operacional \\
\hline amount_of_processors & NUMBER & - & Quantidade de Processadores (Unitário) \\
\hline processor & VARCHAR & 256 & Modelo do Processador \\
\hline clock_of_processor & NUMBER & - & Clock do Processador (MHz) \\
\hline amount_of memories & NUMBER & - & Quantidade de Memória RAM (Mb) \\
\hline network_adapter & VARCHAR & 256 & Modelo do Adaptador de Rede \\
\hline speed_of_network_adapter & NUMBER & - & Velocidade do Adaptador de Rede (bits/s) \\
\hline
\end{tabular}


Tabela 37 - Tabela Dimensional com as caracteristicas dos Firewall

\begin{tabular}{|c|c|c|c|}
\hline Campo & Tipo: : & Tann & Déseriçá: \\
\hline Firewall_id & NUMBER & - & ID do Firewall \\
\hline Firewall_name & VARCHAR & 256 & Nome do Firewall \\
\hline Interface_name & VARCHAR & 256 & Nome da Interface \\
\hline Interface_address & VARCHAR & 15 & Endereço da Interface \\
\hline Interface_submask & VARCHAR & 15 & Máscara de Rede da Interface \\
\hline Phisical_device_name & VARCHAR & 20 & Nome do dispositivo Fisico \\
\hline Gateway & VARCHAR & 15 & Gateway \\
\hline Description & VARCHAR & 512 & Descriçăo \\
\hline Operation system & VARCHAR & 256 & Sistema Operacional \\
\hline Processor & VARCHAR & 256 & Processador \\
\hline Clock_of_processor & NUMBER & - & Clock do Processador (MHz) \\
\hline Amount_of memories & NUMBBER & - & Quantidade de Memórias (Mb) \\
\hline Speed_of_interface & NUMBER & - & Velocidade da Interface (bits/s) \\
\hline
\end{tabular}

Tabela 38 - Tabela Dimensional com os serviços suportados pelo Firewall

\begin{tabular}{|c|c|c|c|}
\hline \multicolumn{4}{|l|}{ G S SEA } \\
\hline Campo & Típo: & Tamin & Déscriçáno \\
\hline Service_id & NUMBER & - & ID do Serviço \\
\hline Description & VARCHAR & 512 & Descrição \\
\hline Protocol_id & NUMBER & - & ID Protocolo \\
\hline Main_port & NUMBER & - & Porta principal do Serviço (Listener) \\
\hline Source_port_from & NUMBER & - & Porta Injicial \\
\hline Source_port_to & NUMBER & - & Porta Final \\
\hline
\end{tabular}

Tabela 39 - Tabela Dimensional com as características do Servldor Web

\begin{tabular}{|c|c|c|c|}
\hline Campo: & Tipo. & Tam & Dêscriçăo \\
\hline Webserver_id & NUMBER & - & ID do Servidor Web \\
\hline Webserver_address & VARCHAR & 15 & Endereço do Servidor $W e b$ \\
\hline Gateway & VARCHAR & 15 & Gateway \\
\hline Submask & VARCHAR & 15 & Máscara da Sub-rede \\
\hline Server name & VARCHAR & 256 & Nome do Servidor \\
\hline Description & VARCHAR & 512 & Descrição \\
\hline Operation_system & VARCHAR & 256 & Sistema Operacional \\
\hline Amount_of_processors & NUMBER & - & Quantidade de Processadores (Unitário) \\
\hline Processor & VARCHAR & 256 & Modelo do Processador \\
\hline clock_of_processor & NUMBER & - & Clock do Processador (MHz) \\
\hline amourtt_of_memories & NUMBER & - & Quantidade de Memória RAM (Mb) \\
\hline network adapter & VARCHAR & 256 & Modelo do Adaptador de Rede \\
\hline speed_of_network_adapter & NUMBER & - & Velocidade do Adaptador de Rede (bits/s) \\
\hline
\end{tabular}

Tabela 40 - Tabela Dimensional com as características dos arquivos armazenados no Servidor Web

\begin{tabular}{|c|c|c|c|}
\hline \multicolumn{4}{|l|}{ BMATEE } \\
\hline Campo & Tipo & Tam & Dẽscriçăo \\
\hline File id & NUMBER & - & ID do Arquivo \\
\hline URI_stem & VARCHAR & 512 & Corpo Principal do URI \\
\hline Directory & VARCHAR & 256 & Diretório onde se localiza o Arquivo \\
\hline File_type & VARCHAR & 10 & Tipo de Arquivo (Imagem, Página, etc.) \\
\hline Size & NUMBER & - & Tamanho do Arquivo (bytes) \\
\hline Modification_date & DATE & - & Data de Modificação \\
\hline
\end{tabular}


Tabela 41 - Tabela Dimensional com as caracteristicas dos Usuário

\begin{tabular}{|c|c|c|c|}
\hline \multicolumn{3}{|c|}{ 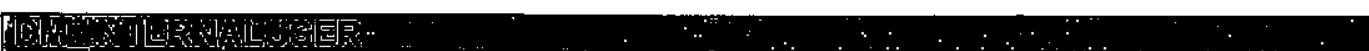 } & Why \\
\hline Internal_user_id & NUMBER & - & ID do usuário \\
\hline Funcional_number & VARCHAR & 256 & Número Funcional do Usuário \\
\hline name & VARCHAR & 256 & Nome do Usuário \\
\hline department & VARCHAR & 256 & Nome do Departamento \\
\hline telephone & VÁR丨́CHAR & 20 & Telefone \\
\hline description & VARCHAR & 512 & Descriçăo do Usuário \\
\hline
\end{tabular}




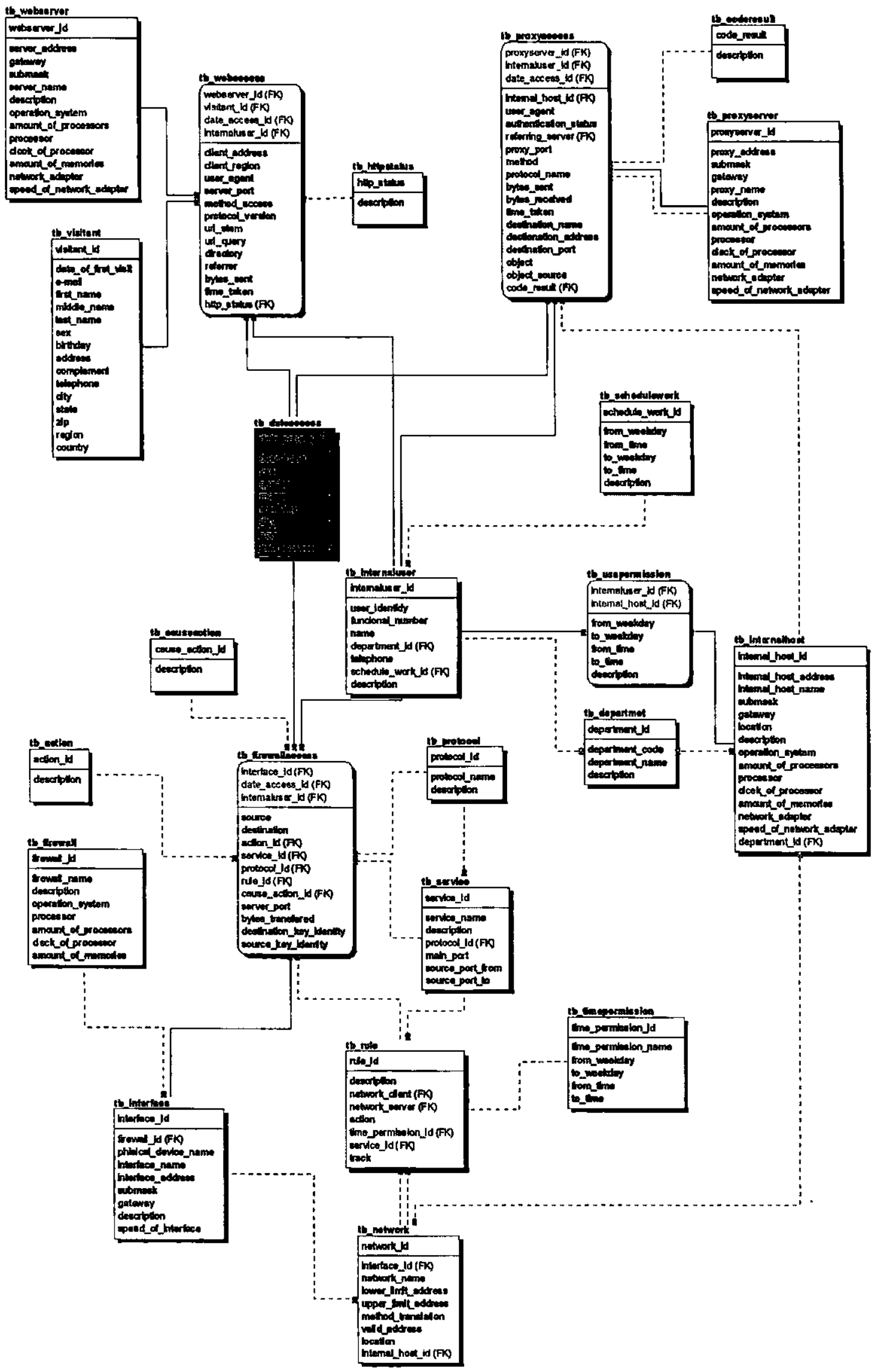

Figura 22 - Projeto fisico do ambiente operacional (OLTP) para monitoramento 


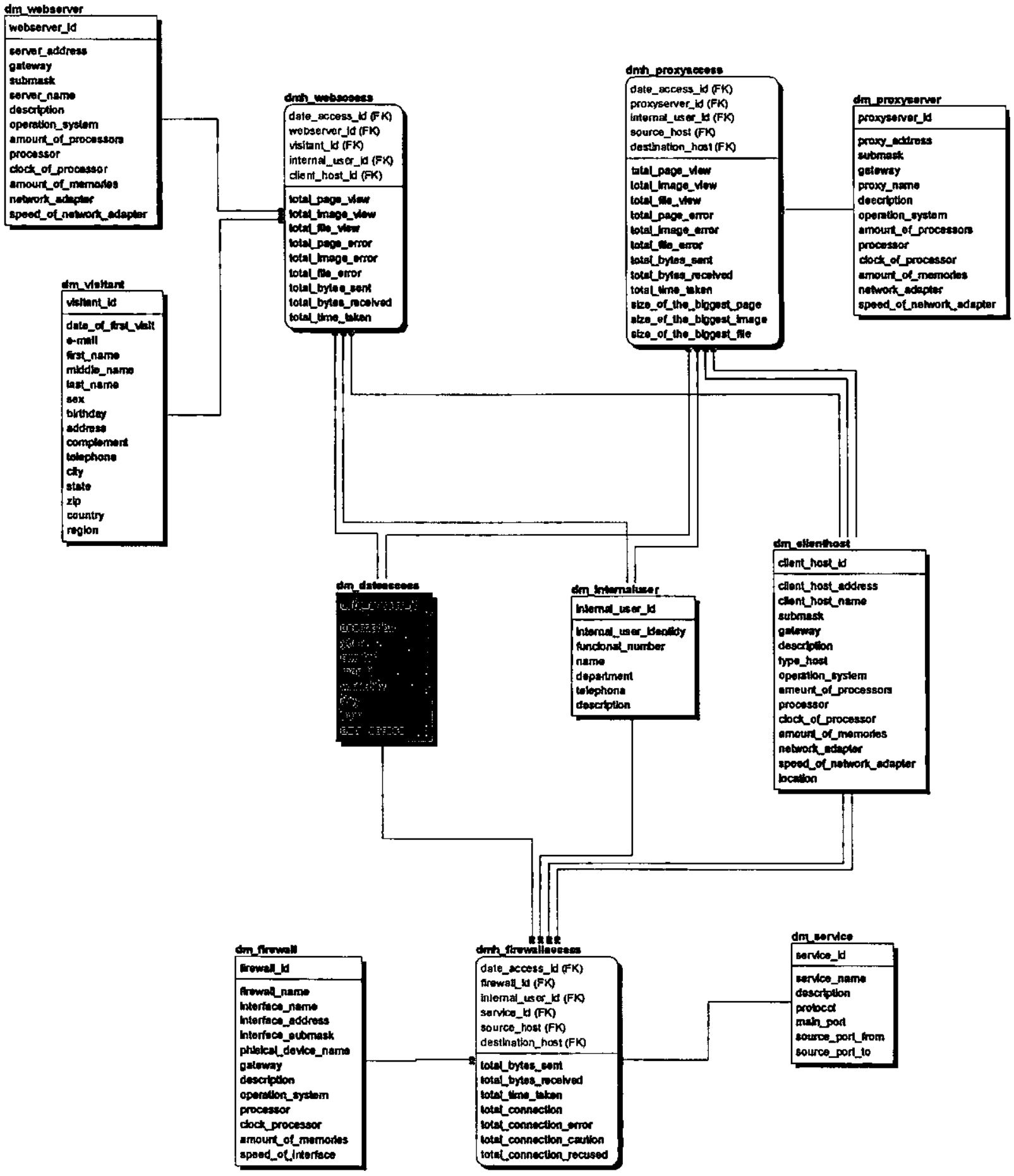

Figura 23 - Projeto fisico do ambiente Warehouse (granulosidade grossa) 


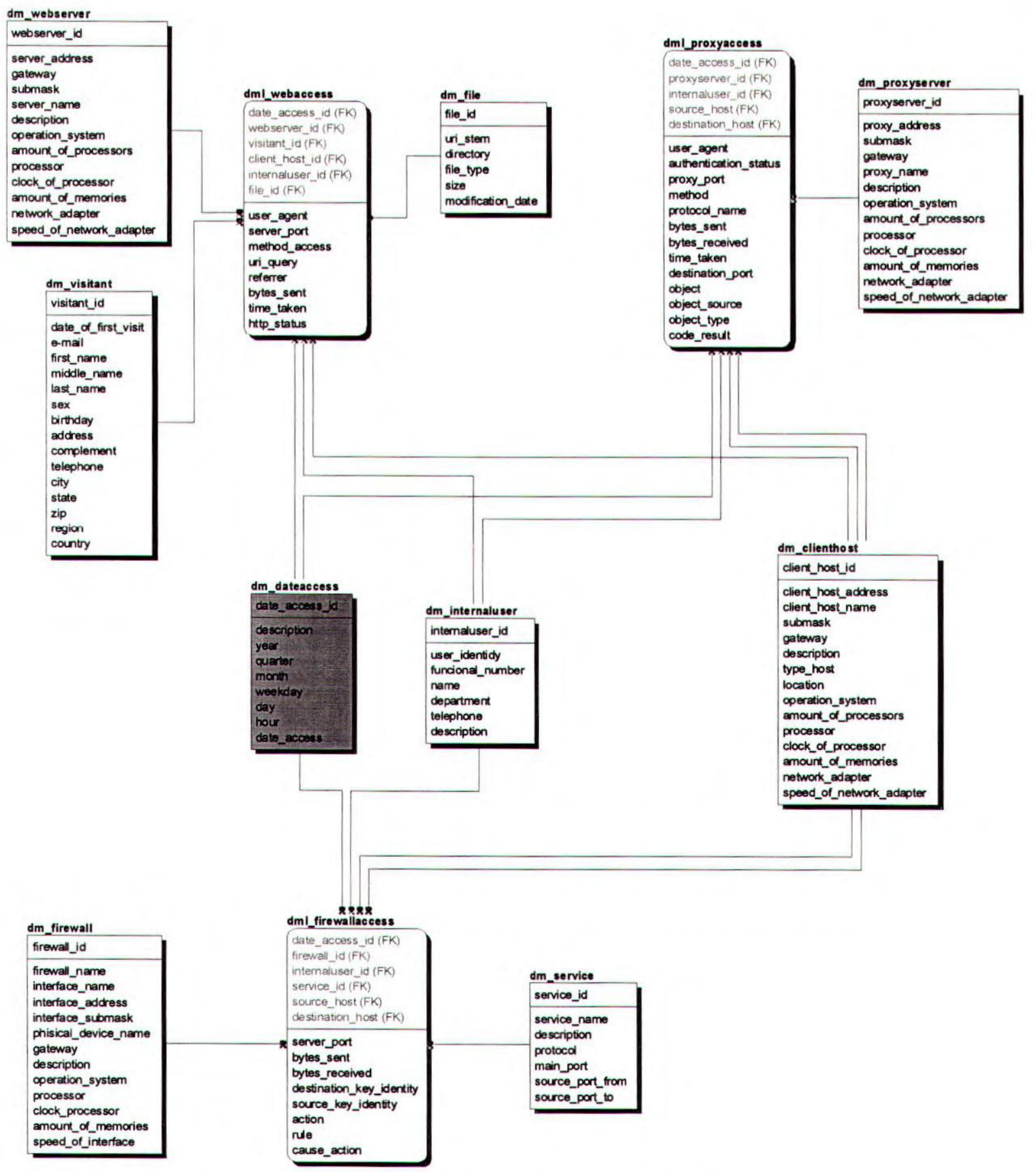

Figura 24 - Projeto físico do ambiente Warehouse (granulosidade fina) 


\section{REFERÊNCIAS BIBLIOGRÁFICAS}

(Bispo, 1998)

(Bowman, 1981)

(Bremmer et al, 1998)

(Campos \& Rocha, 1997)

(Ceri \& Pelagatti, 1984)

(Checkpoint, 1999)

(Copeland \& Hwang, 1998)

(Corey et al, 1998)

(Furlan, 1997)
BISPO, C. A F. Uma Análise da Nova Geração de Sistemas de Apoio à Decisão. Monografia de Qualificação. EESC, 1998

BOWMAN, B. at all. Modeling for MIS. 1981

BREMMER, L. M, IASI, A. F., SERVATI, AI. A Bíblia da Intranet. Makron Books, 1998

CAMPOS, M. L., ROCHA F ${ }^{\circ}$, A. V. Data Warehouse in Jornada de Atualização em Informática, pp. 221-261. XVII Congresso da Sociedade Brasileira de Computação, Brasília -DF, 1-8 de agosto de 1997.

CERI, S., PELAGATTI, G. Distributed Databases: Principles \& Systems. McGraw-Hill, 1984.

Virtual Private Network Security Components. 22 mar. 1999. http://www.checkpoint.com/products/vpn1/vpnwp.html

COPELAND, K. W.; HWANG, C. J. Third-Generation Web Applications, Full-Service Intranets, EDI: The Fully Integrated Business Model for Electronic Commerce. Internet Society. http://www.isoc.org/inet97/proceedings/C5/C5_2.HTM . Novembro/98

COREY, M. J., ABBEY, M.; ABRAMSON, I.; TAUB, B.. Oracle 8 Data Warehousing. Osborne/McGraw Hill, 1998

FURLAN, J.D. Modelagem do Negócio. Makron Books, São Paulo, 1997

HALLAM-BAKER , P. M., BEHLENDORF , B. Extended Log File Format. 1996. Abril 2000. http://www.w3.org/TRMD-logfile.html.

(Hallam-Baker \& Behlendorf 1996)

(Hills, 1997a)

HILLS, M. Intranet business strategies. John Wiley \& Sons. 1997

(Hills, 1997b)

HILLS, M. Intranet as Groupware. John Wiley \& Sons. 1997

(Inmon, 1997)

(Intranet Journal, 1999)

(Kondratiuk, 1998)

(Kugler \& Aragon, 1984)

(Levitt, 1998)
INMON, W. H. Como Construir o Data Warehouse. Editora Campus, Rio de Janeiro, 1997.

Intranet 101 -A guide for Intranet newbies...The Intranet Journal: . Abril 1999. http://www.intranetjournal.com/newbie.html

KONDRATIUK, E. R. Data Warehouse: Detalhes que Fazem a

Diferença. Developer's Magazine, ano 2, n. 18, p. 22, fevereiro de 1998

KUGLER, J. L., ARAGON, A.. Planejamento e controle de sistemas de informação. Livros Técnicos e Científicos Editora S. ${ }^{a}, 1984$

LEVITT, L. Intranets: Internet Technologies Deployed Behind the Firewall for Corporate Productivity. Internet Society. http://www.isoc.org/conferences/inet96/proceedings/b2/b2_3.htm. Novembro/98 
(Módulo, 1999)

(Moreira, 1999)

(O'Reilly, 1998)

(Orr, 1996)

(Rodley, 1997)

(Selker, 1994)

(Soden, 1975)

(Tanler, 1996)

(Tanier, 1997)

(Zimmerman \& Evans, 1996)

(Oracle Corporation, 1999)

(Fonseca et al, 1998)
VPNs e IP Tunneling. 19 mar. 1999.

http://mingus.modulo.com.br/funciona.htm

MOREIRA, E. S., GOULARTE, R.. As Infovlas como Catalisadoras de Negócios. 1999

O'REILLY, T. What the Internet is Telling Us About Itself. Internet Soclety.

http://www.isoc.org/isoc/whatis/conferences/inet/97/proceedings/C2/C 2_2.HTM. Novembro/98

ORR, K. Data Warehouse Technology, The Ken Orr Institute, 1996.

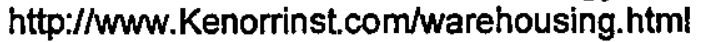

RODLEY, J. Developing Databases for the Web \& Intranets. Coriolis Group Books, 1997

SELKER, T. Coach: A Teaching Agent that Learns. Communications of the ACM, 37(7):92-99. 1994.

SODEN, J. V. Pragmatic guidelines for EDP long range planning. 1975.

TANLER, R. Putting the Data Warehouse on the Intranet. Intemet Systems: May 1996. 08 abr. 1999. http://www.dbmsmag.com/9605i08.htm!

TANLER, R. The Intranet Data Warehouse. John Wiley \& Sons, 1997

ZIMMERMAN, S., EVANS, T. Building na Intranet with Windows NT 4. Sams.Net, 1996

Oracle @ Warehouse Builder: Oracle Warehouse Bullder User's Guide, Release 2.0. Part No. A81064-01. Oracle Corporation, 1999.

FONSECA, E. L. S; MEIRA JR., W.; MURTA, C.D; ALMEIDA, V. A. F. Análise de Desempenho de Hierarquias de Servidores Proxy Cache WWW. XXV Seminário Integrado de Software e Hardware, v. 1, 1998. pp 241-275. 